\title{
LIPASE-CATALYZED ACIDOLYSIS OF FISH LIVER OIL WITH DiHydRoXYPhenYlaceTIC ACID in ORganic SOlVENT Media
}

by

Rosalie Karam

A thesis submitted to the Graduate and Post-Doctoral Studies Office in partial fulfillment of the requirements of the degree of Master of Science

\author{
${ }^{\circledR}$ Rosalie Karam
}

Department of Food Science and Agricultural Chemistry

McGill University

Montreal, Canada

August 2007 


\section{SUGGESTED SHORT TITLE \\ Lipase-Catalyzed Acidolysis of Fish Liver Oil}


This thesis is dedicated to my very loving and strong mother, Marie. 


\section{Abstract \\ M.SC. ROSALIE KARAM}

Commercial lipases, including Lipozyme IM 20 from Rhizomucor meihei and Novozym 435 from Candida antarctica, were investigated to determine their capacity as biocatalysts for the biosynthesis of phenolic lipids, using dihydroxyphenylacetic acid (DHPA) and fish liver oil (FLO) as substrates. Novozym 435 showed a higher bioconversion yield (63\%) as compared to that (18\%) for Lipozyme IM 20. As a result, Novozym 435 was subsequently used for further investigations. The phenolic lipids were recovered and characterized by thin-layer chromatography, high-performance liquid chromatography and gas-liquid chromatography. The structural analyses indicated the synthesis of five major phenolic lipids. In order to optimize the initial enzymatic activity and bioconversion yield, selected parameters, including lipase amount (20 to $60 \mathrm{mg}$ solid enzyme or 200 to $600 \mathrm{U}$ ), organic solvent ratios (hexane:2-butanone; 65:35 to 85:15, $\mathrm{v} / \mathrm{v}$ ), substrate molar ratios (FLO/phenolic acid, $1: 1$ to $8: 1$ ), Silica gel (1.5 to $5.5 \mathrm{mg} / \mathrm{mL}$ ) and molecular sieve $(10 \mathrm{mg} / \mathrm{mL}$, Type 4A; 8-12 mesh), were investigated. The experimental results showed that the use of $50 \mathrm{mg}$ of solid Novozym 435 (500 U) resulted in a maximum bioconversion yield of $83 \%$ of total phenolic lipids, at a molar substrate ratio 4:1. The bioconversion yield of phenolic monoacylglycerols (MAGs) increased from 11 to $70 \%$, when the ratio of the hexane:2-butanone reaction medium was changed from 85:15 to 75:25 (v/v), respectively, whereas that of phenolic diacylglycerols (DAGs) remained relatively unchanged (13 to 16\%). However, the addition of molecular sieve and Silica gel to the reaction medium resulted in a decrease in the bioconversion yield by $34 \%$ and $62 \%$, respectively. Under the optimized conditions, the phenolic lipids showed a significant relative increase in C20:5 n-3 and C22:6n-3 content in the phenolic MAGs and phenolic DAGs as compared to that in the unmodified FLO. The phenolic lipids demonstrated radical scavenging properties of approximately half to that of $\alpha$ tocopherol, but also less than that of DHPA. 


\section{RESUME M.SC. ROSALIE KARAM}

Des lipases commerciales, incluant Lipozyme IM 20 de Rhizomucor meihei et Novozym 435 de Candida antarctica, ont été étudiées afin de déterminer leur efficacité comme biocatalyseur dans la biosynthèse des lipides phénoliques, en utilisant comme substrats, l'acide dihydroxyphényl acétique (ADHP) et l'huile du foie de poisson (HFP). Novozym 435 a montré un rendement de bioconversion élevé (63\%) en comparant (18\%) avec Lipozyme IM 20. Novozym 435 a ainsi été considéré comme un biocatalyseur approprié pour la suite du travail. Les lipides phénoliques ont été récupérés et caractérisés par chromatographie sur couche mince, chromatographie liquide à haute performance et celle liquide en phase gazeuse. Les analyses structurales ont révélé la synthèse de cinq phénoliques lipides majeurs. Afin d'optimiser l'activité enzymatique et le rendement de la bioconversion, des paramètres sélectionnés ont été étudiés, incluant la concentration en enzyme (20 à $60 \mathrm{mg}$ d'enzyme solide ou 200 a $600 \mathrm{U}$ ), le ratio du solvant organique (hexane:2-butanone; 65:35 à 85:15, v/v), le ratio molaire des substrats (HFP/acide phénolique, 1:1 à $8: 1)$, gel du Silice $(1.5$ à $5.5 \mathrm{mg} / \mathrm{mL})$ et le tamis moléculaire (10 $\mathrm{mg} / \mathrm{mL}$, Type 4A; 8-12 mesh). Les résultats expérimentaux ont montré que l'utilisation de Novozym 435 (500 U), sous forme solide, à une concentration de $50 \mathrm{mg}$ permettait d'atteindre un rendement maximal de la bioconversion des lipides phénoliques de $83 \%$ à un ratio molaire des substrats de 4:1. Le rendement de la bioconversion de monoacylglycerols (MAGs) phénoliques a augmenté de 11 à 70\%, lorsque le ratio du mélange réactionnel hexane:2-butanone a été changé de 85:15 à 75:25 (v/v), respectivement. En parallèle, le rendement de la bioconversion des diacylglycerols phénoliques (DAGs) est resté relativement constant (13 to 16\%). Cependant, l'addition du tamis moléculaire ou du gel de silice dans le milieu réactionnel a conduit à une diminution du rendement maximal de la bioconversion par 34 et $62 \%$, respectivement. En utilisant les conditions réactionnelles optimales, les proportions en C20:5 n-3 et C22:6n3 dans les lipides phénoliques synthétisés ont augmenté en comparant avec l'huile non modifiée. Les lipides phénoliques ont démontré des propriétés antioxydantes avec une efficacité correspondante à la moitie du celle de $\alpha$-tocophérol, mais plus faible que celle d'ADHP. 


\section{ACKNOWLEDGEMENTS}

I would like to thank my supervisor, Dr Selim Kermasha for his support, guidance and for giving me the opportunity to study under his supervision.

I would also like to thank Dr. Salwa Karboune who has been a role model and a constant source of motivation throughout the course of this work. Her encouragement and input was very much appreciated. Beyond all, I have learnt the real meaning of patience through her guidance.

I would also like to acknowledge Dr. Richard St-Louis for his collaboration in the structural LC/MS analysis.

My deepest thanks also go out to all my lab colleagues for being such a wonderful support team; you will all be truly missed. A very big thank you to Noha Sorour for always being positive.

Last but definitely not least, my very loving and supportive parents, John and Marie, and my brother Wisam, I couldn't have done this without you, thank you for believing in me. To all my friends back home in Lebanon and in Montreal, thank you for always putting a smile on my face. A special thank you to Nadim and Claudine your humor, love and support got me going. 


\section{TABLE OF CONTENTS}

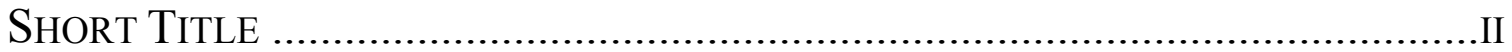

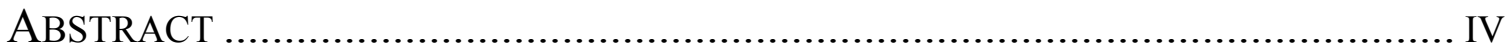

RÉSUMÉ

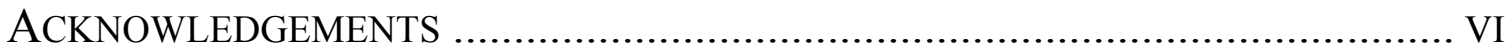

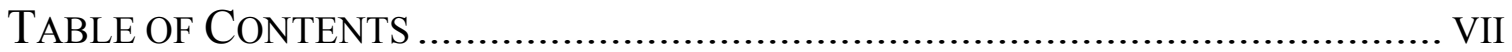

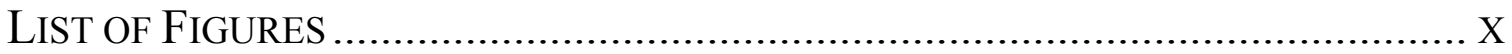

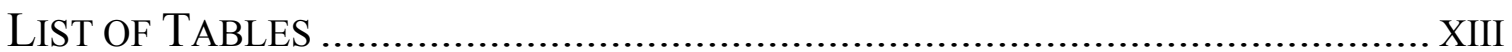

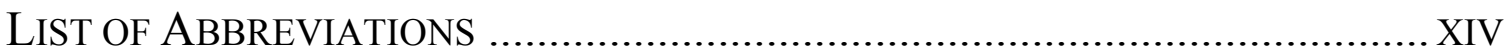

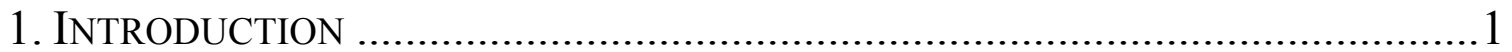

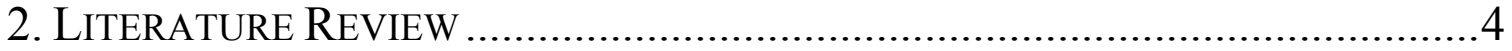

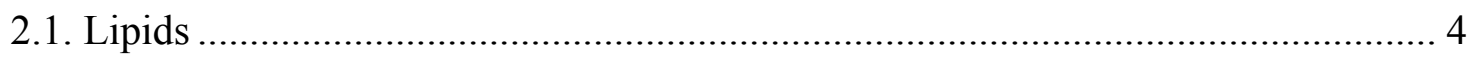

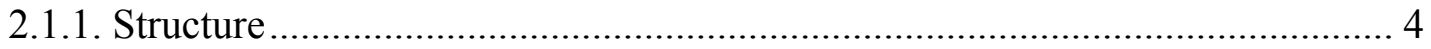

2.1.2. Nutritional and Functional Properties of Structured Lipids............................. 5

2.2. Polyunsaturated Fatty Acids (PUFAs) ……………............................................. 7

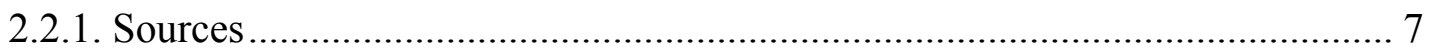

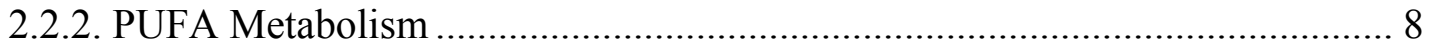

2.2.3. Health Properties of Fish Oil ....................................................................... 9

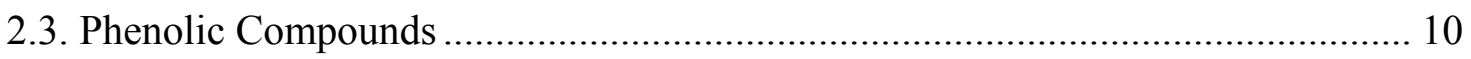

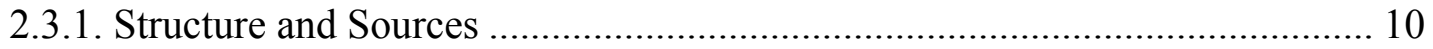

2.3.2. Nutritional and Antioxidant Properties .......................................................... 11

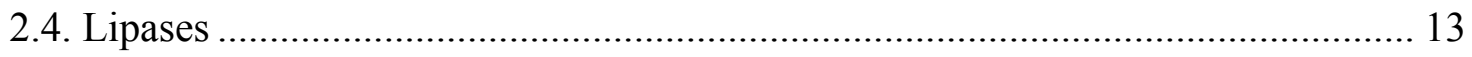

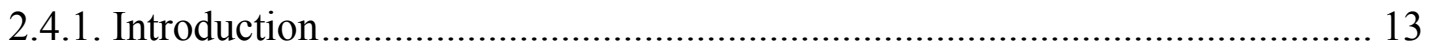

2.4.2. Lipase Catalyzed Reactions ..................................................................... 14

2.4.2.1. Hydrolysis ....................................................................................... 15

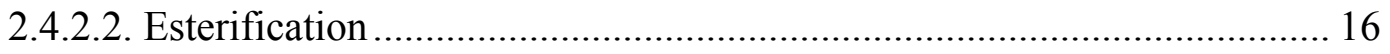

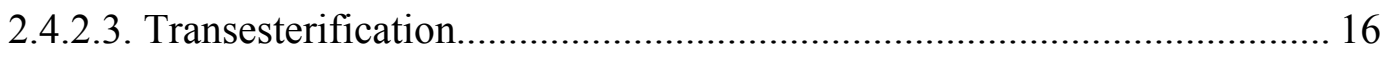

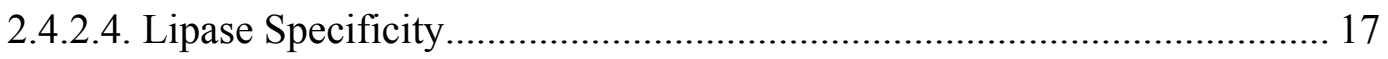

2.5. Biocatalyst in Non-Conventional Media ........................................................... 17

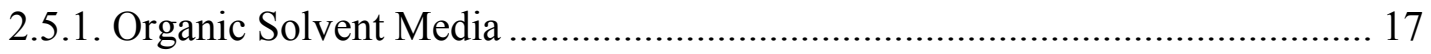

2.5.2. Advantages in Organic Solvent Media ……………..................................... 18

2.5.3. Effect of Water Activity........................................................................... 18

2.5.4. Effect of Reaction Temperature................................................................. 19 
2.6. Biosynthesis of Phenolic Lipids ...................................................................... 20

2.6.1. Parameters that affect the Enzymatic Activity and Product Yield ................. 21

2.6.1.1. Addition of Molecular Sieve.................................................................... 21

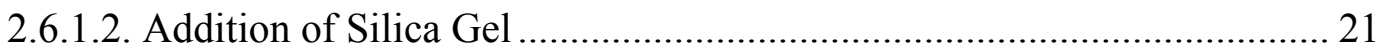

2.6.2. Analysis of Phenolic Lipids ..................................................................... 22

2.6.3. Antioxidant Determination of Phenolic Lipids.............................................. 23

2.7. Fatty Acid Composition After Oil Modification ..................................24

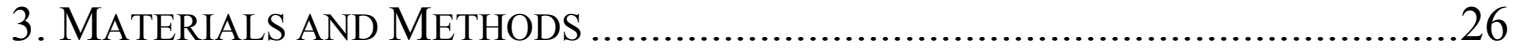

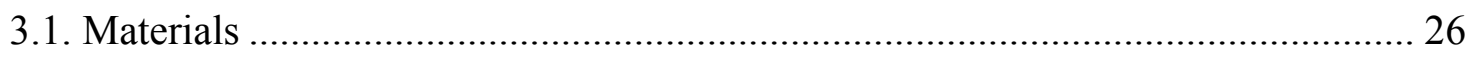

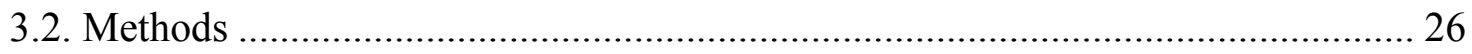

3.2.1. Acidolysis Reaction of Fish Liver Oil with Dihydroxphenylacetic acid ........ 26

3.2.1.1. Acidolysis Reaction ........................................................................... 26

3.2.2. Determination of Bioconversion Yield by HPLC Analysis............................. 27

3.2.3. Characterization of Phenolic Lipid End-Products .......................................... 28

3.2.3.1. Thin-Layer Chromatography (TLC) Analysis of Phenolic Lipids .......... 28

3.2.3.2. High Performance Liquid Chromatography (HPLC) Analysis of Phenolic

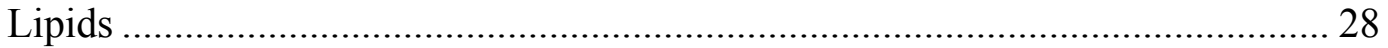

3.2.3.3. Mass Spectrometry (MS) Analysis of Phenolic Lipids............................ 29

3.2.4. Optimization of Lipase-Catalyzed Acidolysis Reaction.................................. 29

3.2.4.1. Selection of Biocatalyst ........................................................................ 29

3.2.4.2. Effect of Lipase Concentration ............................................................ 29

3.2.4.3. Effect of Organic Solvent Mixture Ratio.................................................. 29

3.2.4.4. Effect of Molar Substrate Ratio ……………........................................ 30

3.2.4.5. Effect of Molecular Sieve ................................................................... 30

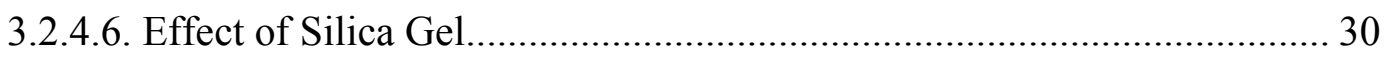

3.2.5. Determination of Fatty Acid Composition .................................................... 30

3.2.6. Determination of Antioxidant Activity of Phenolic Lipids ............................. 31

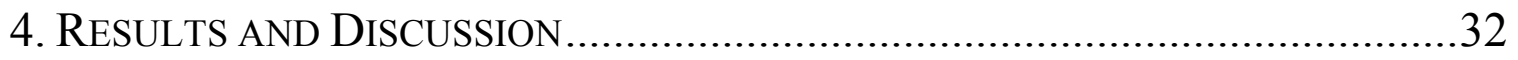

4.1. Acidolysis of Fish Liver Oil with Dihydroxphenylacetic acid .............................. 32

4.2. Characterization of Phenolic Lipid Products .......................................................... 35

4.2.1. TLC Analysis of Reaction Components ........................................................ 35

4.2.2. HPLC/LC-MS Analysis of Reaction Components ......................................... 37 
4.3. Optimization of Lipase-Catalyzed Acidolysis Reaction ................................... 39

4.3.1. Effect of Enzyme Concentration on the Bioconversion Yield....................... 39

4.3.2. Effect of Organic Solvent Mixture on the Bioconversion Yield ................... 44

4.3.3. Effect of Substrate Molar Ratio on the Bioconversion Yield ........................ 48

4.3.4. Effect of Molecular Sieve on the Bioconversion Yield ................................ 52

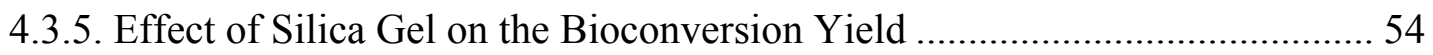

4.4. Determination of the Fatty Acid Composition of Phenolic Lipids ....................... 56

4.5. Determination of the Radical Scavenging Activity of Phenolic Lipids................ 58

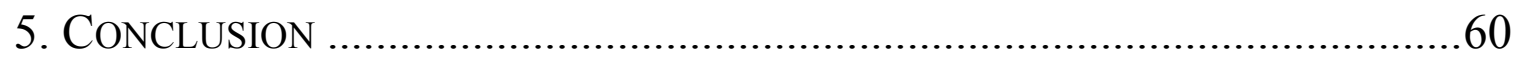

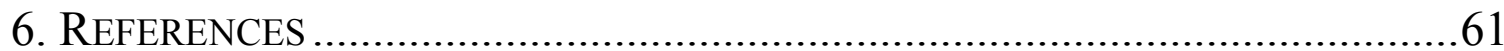




\section{LIST OF FIGURES}

Figure Number

Page

1. Structures of selected phenolic compounds commonly found in foods.

.11

2. Autoxidation reaction, species identification is as follow: lipid $(\mathrm{RH})$, oxygen $\left(\mathrm{O}_{2}\right)$, free radicals, $\left(\mathrm{R}^{\bullet}\right.$ and $\left.\mathrm{H}^{\circ}\right)$, peroxy radical $\left(\mathrm{ROO}^{\circ}\right)$ and non-radical products $(\mathrm{RR}$, ROOR),including hydroperoxides (ROOH) 12

3. Radical scavenging action of phenolic antioxidants, where $\mathrm{PH}$ is the phenolic antioxidant, $\mathrm{P}^{-}$is phenolic radical, $\mathrm{ROO}^{\circ}$ is the peroxide radical and $\mathrm{ROOH}$ hydroxide

4. Chemical structures of (i) caffeic acid, (ii) ferulic acid (iii) coumaric acid

5. Lipase catalyzed reactions 14

6. Enzymatic hydrolysis of triacylglycerol: $\mathrm{R}_{1}, \mathrm{R}_{2}$, and $\mathrm{R}_{3}$ are different acyl groups

7. Reaction scheme of lipase-catalyzed acidolysis reaction of fish liver oil with dihydroxyphenylacetic acid. . . .33

8. Time course for the acidolysis reaction of fish liver oil with dihydroxyphenylacetic acid, catalyzed by Novozym 435 (•) or Lipozyme- IM 20 ( o ) in hexane:2-butanone solvent mixture $(75: 25, \mathrm{v} / \mathrm{v})$ at a substrate molar ratio of $4: 1$. .34 
9. Thin-layer chromatography separation of components of a reaction mixture, blank

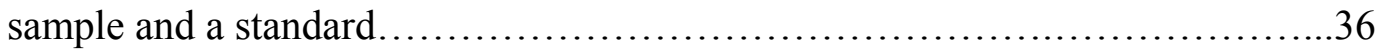

10. HPLC chromatograms of (A and $B$ ) the initial reaction mixture for the acidolysis of fish liver oil and dihydroxyphenylacetic acid and (A' and $\left.\mathrm{B}^{\prime}\right)$ the enzymatic acidolysis reaction mixture monitored at $280 \mathrm{~nm}$ and $215 \mathrm{~nm}$, respectively. Peak numbers were identified as follows: dihydroxyphenylacetic acid \# 1 , fish liver oil \# 7, 8, 9, 10, 11 and 12, phenolic monoacylglycerols \# 2, 3, and 4, phenolic diacylglycerols \# 5 and 6 .

11. Atmospheric Pressure Chemical Ionization-Mass Spectrometry (APCI-MS) analysis of (A) monolinolenyl dihydroxphenyl acetate and (B) dilinolenyl dihydroxphenyl acetate, (A') monolinoleyl dihydroxyphenyl acetate, (B') linoleyl linolenyl dihydroxphenyl acetate and (A") monooleyl dihydroxyphenyl acetate.

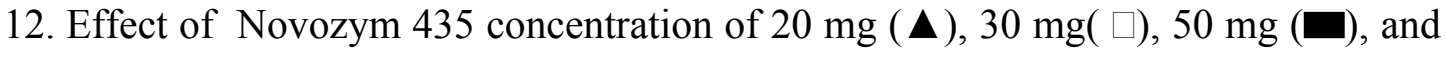
$60 \mathrm{mg}$ (o) on the bioconversion yields of total phenolic lipids (A), phenolic monoacylglycerols (B) and phenolic diacylglycerols (C) using hexane:2butanone solvent mixture of 75:25 (v/v) as reaction medium at fish liver oil to dihydroxyphenylacetic acid molar ratio of $4: 1$

13. Effect of hexane:2-butanone organic solvent mixture ratio of 85:15 ( $\mathbf{\Lambda}), 75: 25$ $(\square)$ and $65: 35(\bullet)$ on the bioconversion yield of total phenolic lipids throughout 10 days of Novozym 435-catalyzed acidolysis reaction of fish liver oil with dihydroxyphenylacetic acid.

14. Time course for the acidolysis reaction of fish liver oil with dihydroxyphenylacetic acid at different substrate molar ratios of 1:1 (•), 2:1 (ם), 4:1 ( $\mathbf{\Delta}), 6: 1(\square)$, and 8:1 $(\bullet)$ .49 
15. Time course for the acidolysis reaction of fish liver oil with dihydroxphenylacetic acid in the presence of molecular sieve [(total phenolic lipids ( $\bullet$, phenolic monoacylglycerols (ם) and phenolic diacylglycerols $(\bullet)]$ and in the absence of molecular sieve [total phenolic lipids $(\diamond)$, phenolic monoacylglycerols $(\square)$ and phenolic diacylglcyerols $(\mathrm{o})]$.

16. Time course for the remaining percentage of diphenylpicrylhydrazl (DPPH) radical after reaction with dihydroxyphenylacetic acid ( $\mathbf{\Delta})$, alpha-tocopherol ( $\square$ ), ester of dihydroxyphenylacetic acid with fish liver oil $(\bullet)$, and with DPPH $(\boldsymbol{\square})$ as a control trial. 


\section{LIST OF TABLES}

TABLE NUMBER

Page

1. Typical fatty acid composition of fatty acids in commercial fish oils............................................................

2. Relative percent of fatty acid composition of menhaden fish oil before and after modification, with and without hexane...........................24

3. Effect of organic solvent mixture on the enzyme activity and the bioconversion yield of Novozym 435-catalyzed acidolysis of fish liver oil with dihydroxyphenylacetic acid.................................46

4. Effect of molar substrate ratio on the enzyme activity and the bioconversion yield of Novozym 435-catalyzed acidolysis of fish liver oil with dihydroxyphenylaceticacid........................................50

5. Effect of Silica gel on the enzyme activity and the bioconversion yield of Novozym 435-catalyzed acidolysis of fish liver oil with dihydroxyphenylacetic acid.......................................55

6. Relative fatty acid composition of fish liver oil before and after its acidolysis with

dihydroxyphenylacetic acid at 4:1 molar substrate ratio in hexane:2-butanone mixture $(75: 25, \mathrm{v} / \mathrm{v})$ 


\title{
List OF ABBREVIATIONS
}

\author{
AA: Arachidonic acid \\ BHA: Butylated hydroxyanisole \\ BHT: Butylated hydroxytoluene \\ BY: Bioconversion yield \\ DAG: Diacylglycerol \\ DGLA: Dihomogamma-linolenic acid \\ DHA: Docosahexaenoic acid \\ DHPA: Dihydroxyphenylacetic acid \\ $\mathrm{DPPH}^{\bullet}$ : Diphenylpicrylhydrazl
}

EPA: Eicosapentaenoic acid

FA: Fatty acid

HPLC: High performance liquid chromatography

LCFA: Long chain polyunsaturated fatty acid

LC-MS: Liquid chromatography-mass spectroscopy

MAG: Monoacylglycerol

MCTAG: Medium chain triacylgycerol

PLU: Propyl laurate units

PUFA: Polyunsaturated fatty acid

R: Acyl group

RH: Lipid

SL: Structured lipid

$\mathrm{H}_{2} \mathrm{SO}_{4}$ : Sulfuric acid

TAG: Triacylglycerol

TLC: Thin layer chromatography

UV: Ultraviolet 


\section{INTRODUCTION}

The importance of polyunsaturated fatty acids (PUFAs) in human nutrition and disease prevention has been and still is one of the major issues for the neutraceutical and pharmaceutical industries (Kris-Etherton et al., 2000). Both $\omega-3$ and $\omega-6$ PUFAs, arachidonic acid (AA) and eicosapentaenoic acid (EPA), respectively, are precursors of eicosaniods which are in turn involved in a wide range of physiological functions and hormonal activities (Haraldsson et al., 2001). The numerous health benefits of $n-3$ PUFAs, such as EPA and DHA, have been scientifically linked to the prevention of diseases, including cardiovascular, cancer and diabetes (Roche, 1999; Halsted; 2003).

On the other hand, phenolic compounds are another important group of compounds that are naturally present in many foods. In addition to many sensory properties, phenolic compounds possess antioxidant, antimicrobial and anticarcinogenic properties (Silva et al., 2000; Holman, 2001). Chemical antioxidants in the past, such as butylated hydroxyanisole (BHA) and butylated hydroxytoluene (BHT), were being used to prevent oxidation and subsequent rancidity and to extend the shelf life of processed foods (Shahidi and Nacsk, 1995a). Nevertheless, evidence has shown that such chemical antioxidants can promote carcinogenesis (Buisman et al., 1998; Stamatis et al., 1999). As a result, the use of chemical antioxidants has led onto a general rejection by consumers, who are now favoring the use of natural antioxidants, such as phenolic compounds (Stamatis et al., 1999). However, the hydrophilic nature of phenolic acids limits their solubility in the hydrophobic medium and consequently reduces their potential use as antioxidants in fats and oils. Altering the physical structure of phenolic compounds by the addition of an aliphatic side-chain group has shown to improve and expand the use of phenolic compounds in emulsion systems (Kontogianni et al., 2001). As a result, the production of such novel biomolecules could have the potential to be used as bioingredients in the food industry imparting both physiological and biological health benefits.

Recently, the literature showed increasing interest in the incorporation of phenolic antioxidants into unsaturated lipids which could result by the production of novel bio- 
molecules, phenolic lipids, that possess both functional and nutritional benefits (Petel et al., 2003; Lue et al., 2005). The biosynthesis of such bio-molecules could be obtained by lipase-catalyzed reaction in non-conventional media. Using lipase as a biocatalyst and substrate models, recent research work in our laboratory (Karboune et al., 2005; Lue et al., 2005; Sabally et al., 2005a,b and 2006a,b; Safari et al., 2006) confirmed the validity of such an approach. In addition, the synthesis of phenolic lipids, using endogenous oils, such as flax seed oil (Sabally et al., 2006b) and fish liver oil (Sabally et al., 2007), was also reported. The advantages of using enzyme-catalyzed reactions, in comparison to chemical processes, offer an increase in the selectivity of side chains, milder reaction conditions and a more natural approach towards the synthesis of end products (Laane et al., 1987). The use of non-conventional media, in particular organic solvent media, favors the synthetic reactions rather than hydrolysis.

Previous preliminary work in our laboratory has shown the validity of the biotechnological approach for the synthesis of phenolic lipids using fish liver and flaxseed oils and dihydrocaffeic acid (Sabally et al., 2006b and 2007). In order to optimize the bioconversion yield and enzymatic activity, a wide range of parameters including the choice of biocatalyst, lipase concentration, organic solvent ratio, molar substrate ratio as well as the presence of molecular sieve and Silica gel were investigated. The present work is part of an on-going research in our laboratory aimed at the biosynthesis of phenolic lipids that could be used as nutraceuticals and natural ingredients of great added value. The optimization of the bioconversion process contributed greatly for the validity of this approach for the development of the production of phenolic lipids, using endogenous fish liver oil and selected phenolic compounds.

The specific objectives of this research were:

1. To investigate the biosynthesis of a lipase-catalyzed acidolysis reaction, using as substrates fish liver oil and the phenolic acid model, dihydroxyphenylacetic acid, as well as biocatalysts Lipozyme IM 20 and Novozym 435. 
2. To recover, to separate and to carry out the structural characterization of phenolic lipids.

3. To optimize the enzymatic system for the biosynthesis of phenolic lipids, using as substrates fish liver oil and dihydroxyphenylacetic acid, with immobilized Novozym 435 lipase from Candida antartica as biocatalyst.

4. To evaluate the antioxidant activity of these novel biomolecules. 


\section{LITERATURE REVIEW}

\subsection{Lipids}

Lipids are a class of hydrocarbon-containing organic compounds. They are categorized by their insolubility in water and their solubility in non-polar solvents, such as ether or chloroform (Christie, 1982). Lipids are generally classified into three groups according to their fatty acid composition, simple, compound, and derived lipids. Those containing esters of fatty acids with acylglycerols including mono, di- and triacylgycerols, are referred as simple lipids. Compound lipids are those which consist of three or more major compounds, such as phospholipids, glycolipids and lipoproteins. Derived lipids are usually described as compounds that contain a fatty acid (FA) and alcohol which are obtained from either simple and/or compound lipids (Krauses, 2004).

Dietary fat is an essential component for digestion, absorption, and transport of fatsoluble vitamins and phytochemicals, such as carotenoids and lycopenes. Dietary fat contributes approximately $34 \%$ of the energy in the human diet. Because fat is a main source of energy ( $9 \mathrm{kcal} / \mathrm{g})$, humans are able to obtain adequate energy with a reasonable daily composition of fat-containing food items food products.

\subsubsection{Structure}

Derived lipids, such as fatty acids or fatty alcohols consist largely of long lipophilic hydrocarbon tails attached to either a carboxylic or alcohol functional group; they exist

primarily as unbranched hydrocarbon chains with an even number of carbons that are saturated with hydrogens. Fatty acids are grouped according to the number of carbons, the number of double bonds and the position of the first double bond in the chain. Generally, fats which are liquid at room temperature have shorter fatty acid chains or more double bonds. Saturated fats, which are solid at room temperature, have longer fatty acid chain length. The chain length and extent of saturation contribute to the melting temperature of a fat.

Saturated fatty acids do not contain any double bonds or other functional groups along the chain. The term "saturated" refers to hydrogen, in that all carbons, apart from the carboxylic acid group, contain as many hydrogens as possible. In general, fatty acids 
containing only one double bond are referred to as monounsaturated fatty acids, while those containing two or more double bonds are referred to as polyunsaturated fatty acids (PUFAs). Unsaturated fatty acids are usually distinguished from one another based on the position of the first double bond from the methyl end of the fatty acid chain. Three distinct groups categorize unsaturated fatty acids, $n-3, n-6$ and $n-9$, which indicate that the first double bond exists between the third and fourth, sixth and seventh, and ninth and tenth, respectively, from the first methyl end of the fatty acid chain. Examples of unsaturated lipids belonging to each group, include the long chain monounsaturated oleic acid $\left(\mathrm{C}_{18: 1}, n-9\right)$, the double bonded polyunsaturated linoleic acid $\left(\mathrm{C}_{18: 2}, n-6\right)$ and linolenic acid containing three double bonds $\left(\mathrm{C}_{18: 2}, n-3\right)$. Two PUFAs of nutritional and biological interest are linoleic and linolenic acids. Both acids are considered as essential fatty acids that cannot be synthesized by precursors in the body yet posses beneficial health properties that can be obtained through the diet. Linoleic acid $\left(\mathrm{C}_{18: 2}, n-6\right)$ has 18 carbons and 2 double bonds starting at double bond number 6 , while $\alpha$-linolenic acid $\left(\mathrm{C}_{18: 3}, n-3\right)$ has a 18 carbon chain with 3 double bonds starting at double bond number 3. $\omega-6$ and $\omega-3$ fatty acids types are present in fats or oils of plant and animal origins (Krauses, 2004).

\subsubsection{Nutritional and Functional Properties of Structured Lipids}

As defined, structured lipids are triacylgylcerols (TAGs) that have been catalyzed chemically or enzymatically changing the fatty acid composition and/or their positional distribution in the glycerol (НØy et al., 2001). Due to such modifications, structured lipids from endogenous natural oils and fats provide specific functional and nutritional properties that can be used for edible and pharmaceutical purposes. Rearrangement of fats is not a new process; the food industry has been doing this for years to configure the properties of fats (Willis et al., 1998). Structured lipids are usually aimed at the improvement of the physical characteristics of fats for food formulation or for nutritional and pharmaceutical uses. A large area has focused on Medium-Chain Triacylgycerols (MCTAGs) which has been the basis for structured lipids. Attaching medium-chain fatty acids onto a glycerine molecule forms MCTAGs. The metabolic pathway of MCTAGs is shorter than that of typical fats and oils. They are metabolized rapidly as glucose, hence resulting in a fat that has $7 \mathrm{kcal} / \mathrm{g}$ compared to the typical $9 \mathrm{kcal} / \mathrm{g}$; this pathway provides 
twice the energy output of carbohydrates, which make the MCTAGs to meet the nutritional needs of hospitalized patients in need of special dietary needs, such as malabsorptive diseases. The advantages of structured lipids are well documented; they have been shown to improve immune function, reduce the risk of blood coagulation and reduce the risk of certain cancers (Willis et al., 1998; Calder et al., 2001).

$\omega-3, \omega-6$ and $\omega-9$ fatty acids are more and more being incorporated into structured lipids aiming at promoting nutritional and functional benefits, this tendency is likely to continue. There has been a great and numerous efforts at developing methods to concentrate PUFAs in marine oil and vegetable oils. The possibilities offered by biotechnologies in the realm of the production and transformation of fats appear to be numerous and attractive (Shahidi, 1998). Thus, degumming, neutralization and bleaching of crude oils can be achieved by enzymatic methods which offer a more gentle approach than conventional technologies. Selective interesterification, biocatalyzed by a 1-3 specific lipase, offers a potential for producing triacylgycerols in which the distribution of fatty acids on the glycerol positions 1,2, and 3 is better controlled thus resulting at the transformation of an more nutritive triacylglycerol. Cerdan et al. (1998) were able to modify and concentrate the fatty acid composition of cod liver oil through the use of a 13, specific lipase from Pseudomonas resulting in an enriched triacylgycerol yield of $84.7 \%$ containing $27.4 \%$ eicosapentaeonic acid (EPA) and $45.1 \%$ docosahexaenoic acid (DHA), respectively. The rearrangement of the position of fatty acids on the glycerol backbone as well as the reductions of the trans fatty acid content has been accomplished by the use of biocatalysts (Gunstone, 1999).

The edible oil industry also depends widely on the rearrangement of lipids to obtain better melting and crystallization properties of oils, which make them suitable for their use in table spreads and shortenings. Additional uses of structured lipids are seen in foodgrade emulsifiers, found as mono- and diacylglycerols (Krog, 1997) as well as the ability to alter organoleptic propertied in food products (Guptam et al., 2003). 


\subsection{Polyunsaturated Fatty Acids (PUFAs)}

In part to broaden the understanding of active beneficial compounds, current focus has been centralized on PUFAs due to their involvement in vital biological properties, such as inflammatory, immune and cancer processes. As such, scientists continue to investigate the sources, structures and corresponding health properties of such fatty acids.

\subsubsection{Sources}

Major sources of PUFAs include fish and marine oils, olive oil and flaxseed oils along with a selected group of micro-organisms. The main sources of $\omega-6$ fatty acids are vegetable oils, such as corn, soy and canola, which contain a high proportion of linoleic acid, 50, 53 and 21\%, respectively (Gurr et al., 1991; Deckere et al., 1998; Willis et al., 1998). $\omega-3$ fatty acids are predominately found in flaxseed oil, marine plankton, and fatty fish. The main component found in fatty fish and fish oil making them of high importance in terms of health and disease is the presence of two essential fatty, EPA $\left(\mathrm{C}_{20: 5} n-3\right)$ and DHA, $\left(\mathrm{C}_{22: 6} n-3\right)$. Recent increase in the publics' awareness and interest of the benefits of these two $\omega-3$ PUFAs has lead the industry to expand and utilize marine oils, specifically fish oil, as a novel bio-ingredient and in the production of nutraceutical products (Shahidi et al., 1998).

Fish oil content usually consists of approximately $95 \%$ triacylglycerols, $1 \%$ phospholipids and the remainder is of unsponified matter such as cholesterol, hydrocarbons, fatty alcohols and fat soluble vitamins. Marine oils differ mainly from oils of plant and animal origin in that their fatty acid chain lengths have up to 20 to 22 carbon atoms; hence, giving such oils the importance of belonging to the $\omega-3$ family. It has been noted that at least 36 fatty acids have been identified in fish oil of menhaden origin. Around 8 to 10 PUFAs make up 85 to $90 \%$ of the total, while the remaining of fatty acids is present at levels of less than $2 \%$. Fish lipids differ between species and according to diet; however they are rich in PUFAs of the $n-3$ family. Specifically, the fatty acid composition of fish oil has been related to the geographical location and season. As such, different fish oils have been categorized into three categories. First being the herring-type oil from the northern hemisphere, which represents mainly the herring, mackerel, capelin and the sand eel type. Secondly, the anchovy type oil originates from the southern 
hemisphere; is represented by the anchovy, horse mackerel and sardine (Opstvedt et al., 1990). Thirdly, the menhaden-type oil located by the Atlantic coast. Table one represent the fatty acid composition of such commercial oils.

Table 1. Typical fatty acid composition of fatty acids in commercial fish oils.

\begin{tabular}{lcccc}
\hline & \multicolumn{4}{c}{${\text { Relative }(\%)^{\mathrm{a}}}$} \\
Fatty acid & Herring-type $^{b}$ & Cod liver $^{b}$ & Menhaden $^{b}$ & Salmon $^{b}$ \\
\hline $\mathrm{C}_{14: 0}$ & 7.4 & 6.7 & 9.0 & \\
$\mathrm{C}_{16: 0}$ & 14.1 & 20.1 & 19.1 & 10.7 \\
$\mathrm{C}_{18: 0}$ & 2.2 & 9.6 & 3.0 & 3.6 \\
$\mathrm{C}_{18: 1} n-9$ & 12.3 & 3.4 & 12.2 & 24.5 \\
$\mathrm{C}_{18: 2} n-6$ & 2.4 & 0.7 & 3.3 & 5.2 \\
$\mathrm{C}_{18: 3} n-3$ & 5.2 & 2.2 & 1.6 & 5.3 \\
$\mathrm{C}_{20: 1} n-9$ & 4.0 & 7.2 & 2.1 & 7.0 \\
$\mathrm{C}_{20: 4} n-6$ & $<1.0$ & $<1.0$ & $<1.0$ & 4.5 \\
$\mathrm{C}_{20: 5} n-3$ & $<1.0$ & 11.5 & $<1.0$ & 17.0 \\
$\mathrm{C}_{22: 6} n-3$ & 8.0 & 20.2 & 7.7 & \\
\hline
\end{tabular}

${ }^{a}$ Relative percent (w/w) of fatty acid $\mathrm{g} / 100 \mathrm{~g}$ sample.

${ }^{b}$ Adapted from Willis et al. (1998).

\subsubsection{PUFA Metabolism}

$\omega-3$ and $\omega-6$ PUFAs are derived from three different 20 -carbon fatty acid chains called eicosanoids, which contain hormone-like activity. Dihomogamma-linolenic acid (DGLA), arachidonic acid (AA), and eicosapentaenoic acid (EPA) are the precursors for eicosanoid series 1, 2, and 3, respectively. AA metabolism begins with linoleic acid (LA), while that of EPA with $\alpha$-linolenic acid (LNA). Since humans cannot insert double bonds before carbon 9 , oleic acid $\left(\mathrm{C}_{18: 2} n-9\right)$ cannot be converted into linoleic acid $\left(\mathrm{C}_{18: 2} n-6\right)$, which make them essential fatty acids. The enzymes $\Delta_{12}$ and $\Delta_{15}$ desaturases are lacking in humans, thus making them necessary to be obtained from the diet (Gurr et al., 1991 
and 2002; Benatti et al., 2004). Desaturases insert double bonds; they catalyze the insertion of more double bonds after elongation to form methylene-interrupted PUFAs (Willis et al., 1998). This process produces $n-3$ PUFAs from $\alpha$-LNA and $n-6$ PUFAs from LA. Plant tissues and fish oils tend to be rich sources of linoleic and $\alpha$-linolenic acids. Once consumed in the diet, linoleic acid is converted to gamma-linolenic $\left(\mathrm{C}_{18: 3} \mathrm{n}\right.$ 6) and DGLA $\left(\mathrm{C}_{20: 3} n-6\right)$ gets converted to arachidonic acid $\left(\mathrm{C}_{20: 4} n-6\right)$. Within the same pathway alpha-linolenic acid can be converted to EPA $\left(\mathrm{C}_{22: 5} n-3\right)$ and DHA $\left(\mathrm{C}_{22: 6} n-3\right)$. EPA and DHA are found in high concentrations in fish oils especially in cold water fish or fish which live in warmer waters such as cod fish (Calder et al., 2001).

\subsubsection{Health Properties of Fish Oil}

Interests in $n-3$ fatty acids have began over the past decades and are now regarded as nutritional essential components of ones diet. Linoleic acid $\left(\mathrm{C}_{18: 2}, n-6\right)$ and $\alpha$-linolenic acid (n-3) are the two main compounds that represent dietary essential fatty acids since they cannot be synthesized by humans. Lack of such essential fatty acids has proved to lead to a wide range of deficiencies such as dermatitis, growth retardation, impaired vision and infertility (Gurr, 1992; Calder et al., 2001). To prevent such deficiencies, linoleic acid $\left(\mathrm{C}_{18: 2}, n-6\right)$ is needed in the diet at levels of 0.5 and $2.0 \%$ of total energy while linolenic acid $\left(\mathrm{C}_{18: 3}, n-3\right)$ is needed at levels around 0.5\% (Willies et al., 1998); however, it should be noted that the optimal health depends on the balance of intake of both the $n-3$ and $n-6$ series acids in the body. Fish consumption has been associated with lower cardiac mortality and sudden cardiac arrest (Deckere, 1998; Calder, 2001; Lee et al., 2003). Along with the benefits on cardiovascular dieases obtained from fish, epidemiological studies discussed by McCann and Ames (2005) have shown the protective effect of fish lipids against inflammatory diseases and the need of DHA in the brain. The nervous system, with the second largest lipid concentration, contains approximately 35\% PUFAs as its lipid content; most of which are long-chained FAs. DHA along with some EPA are believed to be incorporated into membrane phospholipids or vertebrates as phosphatidylcholine and phosphatidyethanolamine. In addition, the consumption of fish oils and its effect on hypertriglyceridemic patients has been reported (Stansby et al., 1990). 
However despite the health benefits associated with n-3 PUFA, a major limitation of PUFAs is that they are highly unsaturated and easily oxidized resulting in the production of off-flavors which on the long term results in the deterioration and decrease of the food quality in terms of shelf life and acceptability. However, upon the use of a natural antioxidant this can be corrected.

\subsection{Phenolic Compounds}

\subsubsection{Structure and Sources}

Due in part to the growing recognition of beneficial bioactive compounds present in food and food products, the need to understand the properties of such naturally occurring phenolic compounds in food has led the industry to expand the research in this area. The term "phenolic" or "polyphenol" is chemically defined as a substance that contains an aromatic ring containing one or more hydroxyl substitute including functional derivatives (Ho et al., 1992; Rice-Evans et al., 2003). In general, phenolic acids are present in a wide variety of food plants as esters or glycosides conjugated with other compounds, such as flavonoids, alcohols, hydroxyl fatty acids, sterols and glucosides. Phenolic compounds found in foods may be categorized accordingly to three groups, simple phenols and phenolic acids, hydroxycinnamic acid derivatives and flavonoids. The simple phenols include the monophenols, such as $p$-cresol found in berry fruits (e.g. raspberry, blackberry) and diphenols, such as hydroquinone found commonly in sesame oil and vanilla. The hydroxycinnamic acid derivatives and their derivatives include $p$-couramic, caffeic and ferulic acid. An important hydroxycinnamic acid derivative would be the substance chlorogenic acid, an ester of caffeic acid; it is primarily found in coffee beans and has been shown to slow the release of glucose in the bloodstream after a meal (Hollman, 2001). Phenolic compounds are responsible for the enzymatic browning in apples and pears. The most commonly known and important group of phenolic compounds are the flavonoids, which include catechins, proanthocyanins, anthocyanidins and flavons, flavonols and their glycosides (Ho et al., 1992). Catechins are widely found in tea leaves, contributes to the antioxidant properties of green tea. Proanthocyanins, or tannins, are widely present in apples, grapes, strawberries, plum and barley. Anthocyanidins are responsible for the bright colors of flower petals and fruits. Flavons, 
flavonols and glycosides are widely distributed in the plant kingdom. Chemical structures of some of the most common phenols found in food are displayed in Figure 1.
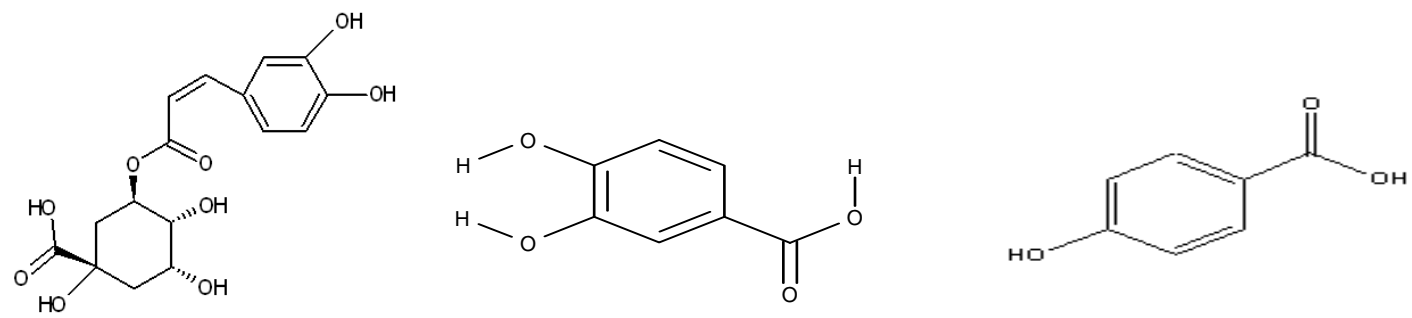

chlorogenic acid

dihydroxybenzoic acid

p-hydroxybenzoic acid

Figure 1. Structures of selected phenolic compounds commonly found in foods.

\subsubsection{Nutritional and Anti-oxidant Properties}

Antioxidants are defined as substances that are present in foods or in the body at low concentrations; these compounds delay or prevent the oxidation of oxidizable substrate (Shahidi and Naczk, 1995a). Antioxidants are enormously used by food manufactures to prevent quality deterioration of food products and to maintain or to increase the nutritional value. Butylated hydroxyanisole (BHA) and butylated hydroxytoluene (BHT) are the two most commonly used synthetic antioxidants used in food systems. These antioxidants have proven effective in a variety of food products in terms of stability and are low in cost (Ho, 1992). However, due to their susceptibility of promoting carcinogenesis, their use in the food industry has been rejected by consumers. Therefore, research is focusing on the development and enhancement of natural antioxidants present in foods. Most natural antioxidants, such as those found in plants, are phenolic in nature and possess varying antioxidant activity. Additional advantages associated with phenolic compounds relate to their antimicrobial, anticarcinogenic and antimutagenic effects as well as their organoleptic attributes (Andlauer et al., 2000; Friedman et al., 2000; Hollman, 2001).

In general, it is well documented that the auto-oxidation mechanism of food lipids occurs in a three step process, (I) initiation (II) propagation and (III) termination. Through initiation, the free radical species are formed which then react with atmospheric oxygen and each other forming a chain reaction. Propagation involves the continuation of the 
chain reaction as there remains an abundance of free radical species. Termination, the final step, involves free radicals reacting with each other forming non-radical species. It should be mentioned that this completes one cycle of lipid autoxidation; however, this usually causes the cycle to repeat itself until the oxidizable substrate is depleted (Cuppett et al., 1997). Figure 2 depicts the following mechanism:

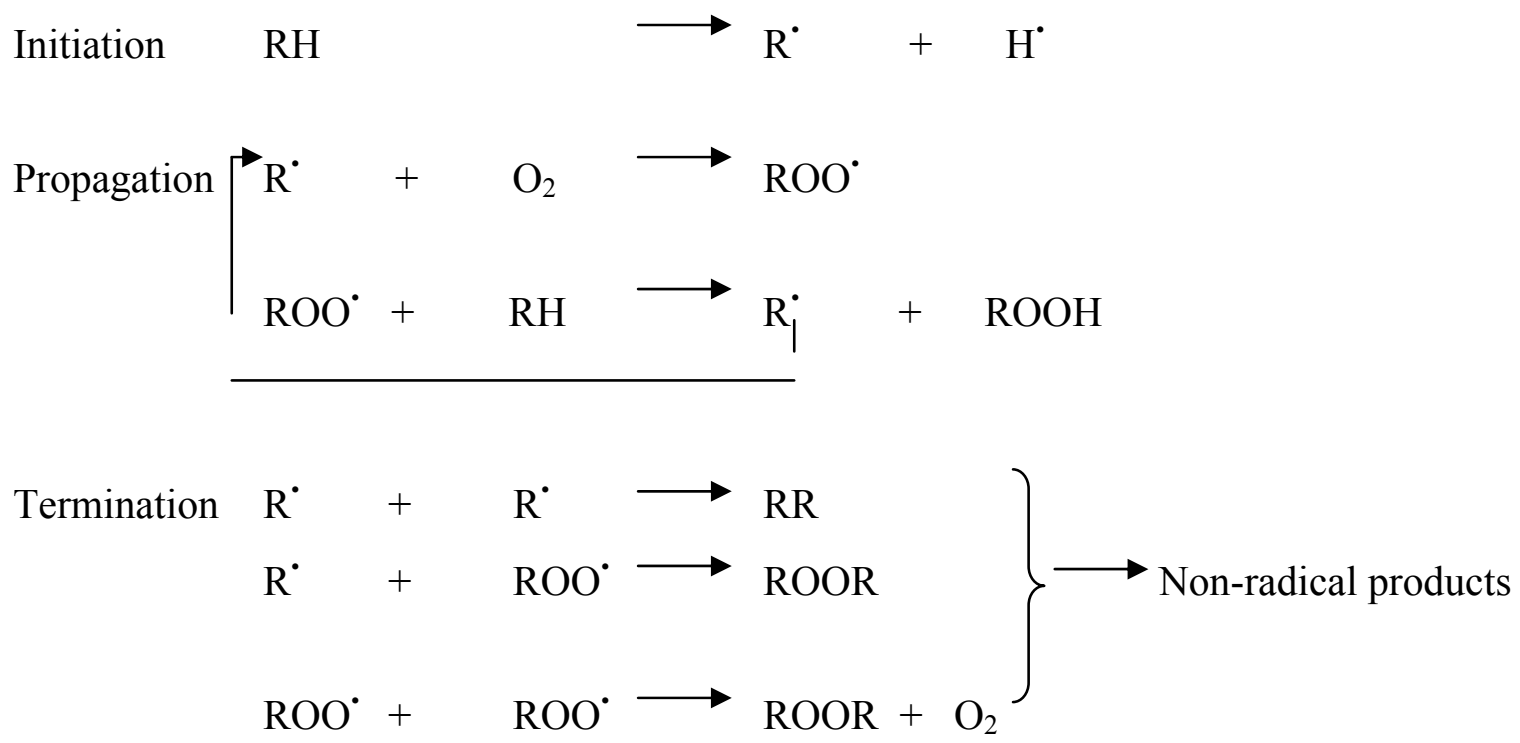

Figure 2. Autoxidation reaction, species identification is as follows: lipid (RH), Oxygen $\left(\mathrm{O}_{2}\right)$, free radicals, $\left(\mathrm{R}^{\circ}\right.$ and $\left.\mathrm{H}^{\circ}\right)$, peroxy radical $\left(\mathrm{ROO}^{\circ}\right)$ and non-radical products (RR, ROOR), including hydroperoxides (ROOH).

Phenolic antioxidants inhibit lipid oxidation by trapping the peroxy radical. This could occur in one of two ways:

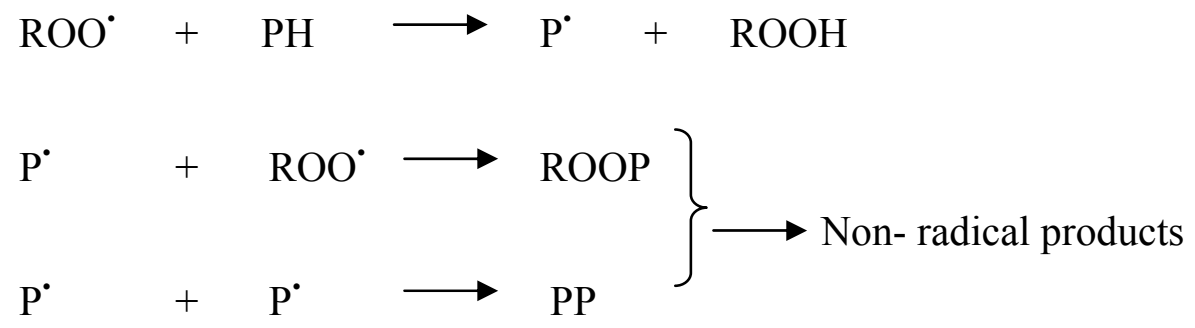

Figure 3. Radical scavenging action of phenolic antioxidants, where $\mathrm{PH}$ is the phenolic antioxidant, $\mathrm{P}^{\bullet}$ is phenolic radical, $\mathrm{ROO}^{\circ}$ is the peroxide radical and $\mathrm{ROOH}$ hydroperoxide. 
Among naturally found phenolic compounds, phenolic acids and flavonoids are of high interest due to their potential biological properties. Many phenolic acids are known to be potent antioxidants through their radical scavenging activity and to their molecular structure. Due to their chemical structure, the reactivity of phenolic acids increases as the number of hydroxyl $(\mathrm{OH})$ and methoxyl groups increases (Silva et al., 2000), hence, for caffeic acid is more active than ferulic acid, which in turn is more active than coumaric acid (Cuppett et al., 1996). Selected dietary phenolic acids are shown in Figure 4:

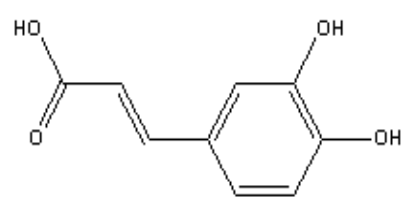

(i)

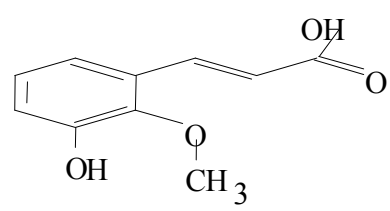

(ii)

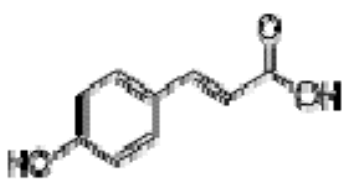

(iii)

Figure 4. Chemical structures of (i) caffeic acid, (ii) ferulic acid (iii) coumaric acid.

\subsection{Lipases}

\subsubsection{Introduction}

Lipases, or triacylglycerol acyl hydrolases, are defined as enzymes which hydrolyze triacylglycerols into mono-, di- and triglycerides (Whitaker, 1996). Lipases are found in a vast number of microorganisms, mammals, plants and microorganisms (Verger et al., 1990). Most commonly known lipases are human pancreatic lipase, pig pancreatic lipase and pregastric lipase. Lipases have been employed in the production of pharmaceuticals, cosmetics, leather, detergents, foods, medical diagnostics and other organic synthetic materials (Indlekofer et al., 1995). This is largely due to their ready availability, high enzyme selectivity, low cost of production and enormous utility in organic synthesis. In addition, a main advantage associated with the use of lipases is the ability of obtaining natural products as opposed to those produced chemically. Such advantages have made the use of lipases as biocatalysts highly desirable as compared to that of chemical methods. 
There is a steady increase in the use of lipases in the food industry; lipases have enabled for the modifications in food products such as the production of esters, biodegradable polyesters and fatty acids. For instance, in the chocolate industry, the free fatty acids in the flavor of milk chocolate, caramels and toffee is obtained by the use of cultured lipases (Gandhi et al., 1997 and 2000). The extensive use of lipases has been on fat modification. The food industry also widely employs the use of lipases to improve the fatty acid composition of certain oils, e.g. palm oil, by incorporating essential fatty acids (Dossat et al., 2002). In addition lipases are being utilized for the development in the purification of PUFAs from fish oil sources. Biosynthesis of modified lipids as such has been the focus of usage throughout the food sector.

\subsubsection{Lipase Catalyzed Reactions}

Lipases catalyze the hydrolysis of triacylgycerols into fatty acids and glycerol, as well as the reactions that involve synthesis. The two main categories in which lipase-catalyzed reactions may occur are as follows (Fig. 5).

(i) Hydrolysis

$$
\mathrm{RCOOR}^{\prime}+\mathrm{R}^{\prime} \mathrm{OH} \longrightarrow \mathrm{RCOOH}+\mathrm{R}^{\prime} \mathrm{OH}
$$

(ii) Synthesis

(a) Esterification

$$
\mathrm{RCOOH}+\mathrm{R}^{\prime} \mathrm{OH} \longrightarrow \mathrm{RCOOR}^{\prime}+\mathrm{H}_{2} \mathrm{O}
$$

(b) Interesterification

$$
\mathrm{RCOOR} \text { ' + R',COOR } \longleftrightarrow \text { RCOOR + R',COOR' }
$$

(c) Alcoholysis

$$
\mathrm{RCOOR}{ }^{\prime}+\mathrm{R} \text { ' } \mathrm{OH} \rightleftarrows \mathrm{RCOOR} \text { ' + R'OH }
$$

(d) Acidolysis

$$
\mathrm{RCOOR}{ }^{\prime}+\mathrm{R} \text { ' } \mathrm{COOH} \rightleftarrows \mathrm{R} \text { ' } \mathrm{COOR}+\mathrm{RCOOH}
$$

Figure 5. Lipase catalyzed reactions.

*Adapted from Ghandi. (1997) 


\subsubsection{Hydrolysis}

Lipid hydrolysis refers to the reaction of an ester in the presence of water producing an acid and an alcohol. Furthermore, the presence of water is essential, since it is required to break the covalent bonds present in the substrate as well as the subsequent incorporation of their elements into these bonds to form the reaction products (Whitaker, 1996). Thus, a high water activity, usually, promotes the hydrolysis of triacylglycerols (Osorio et al., 2001). The hydrolysis reaction takes place in the presence of water with the FAs on the glycerol backbone being replaced with hydroxyl group. Figure 6 shows a triacylgycerol hydrolysis process.

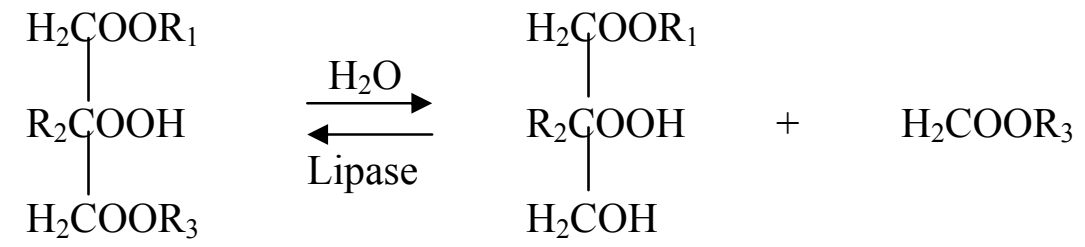

Triacylglycerol

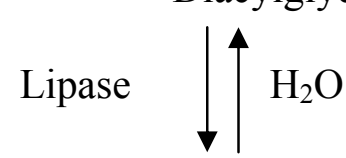

$\mathrm{HCOOR}_{2}$<smiles>[R]O[R]([R])=O</smiles>

Diacylglycerol

Fatty acid

Fatty acid Glycerol Monoacylglycerol Fatty acid

Through the use of hydrolysis, the removal of fatty acids from unstable oils, including conjugated or highly unsaturated fatty acids, owing to conditions which effectively reduce unwanted oxidation reactions (Gandhi, 1997). Several procedures for enzymatic enhancement of $n-3$ PUFAs have been reported in fish oils. Fish oils have been subjected to hydrolysis and are partially esterified through the use of a lipase from Candida rugosa enabling the concentration of PUFAs (Gunstone et al., 1999). Opstvedt et al. (1997) also noted the use of lipase-catalyzed hydrolysis reactions to produce concentrates of PUFAs in natural fish oils. 


\subsubsection{Esterification}

Esterification is generally a chemical reaction in which two compounds as well as a molecule of water, typically an alcohol and an acid, form an ester as the reaction product. The ester synthesis is the reversal of the hydrolysis reaction, and such a reaction is catalyzed by lipases in the presence of water. The water content in a reaction is strongly correlated and affects the activity of the lipase to undergo either esterification or hydrolysis reactions. Low water content and low water activity usually shifts the equilibrium of the reversed reactions to favor the synthesis of lipids. For this reason, the reactions are usually carried out in organic solvents (Osorio et al., 2001). Applications of lipase-catalyzed esterification are widely seen in the food industry. Cerdan et al. (1998) studied the esterification of glycerol and $n-3$ PUFA from cod liver oil using three commercially available lipases; Lipozyme IM from Mucor miehei, Novozym 435 from Candida antarcica and lipase PS from Pseudomonas. Maximum synthesis was obtained with lipase Novozym 435 which showed to be highly effective converting more than $95 \%$ of DHA to TAGs by esterification.

\subsubsection{Transesterification}

Transesterification is the process of exchanging the alkoxy group of an ester compound between two molecules. No water activity is involved in the transesterification reaction, but some may be present in the reaction medium to maintain the lipase activity. Transesterification reactions are divided into three classes that combine both processes of hydrolysis and esterification, interesterification, alcoholysis and acidolysis. Interesterification involves an exchange of acyl among triacylgycerols. Acyl groups may exchange positions within a TAG or among TAG molecules. Alcoholysis involves the exchange between an ester and alcohol, while acidolysis involves the exchange between an ester and an acid. Applications of acidolysis reactions are used in the manufacturing of shortenings. Margarine, obtained by transesterification of hydrogenated fish oil with oils, containing unsaturated fatty acids, such as high oleic sunflower oil, has given better texture (Gandhi et al., 1997). 


\subsubsection{Lipase Specificity}

Lipase specificity is a key aspect of lipase applications. It refers to an enzyme's ability to distinguish between several substrates competing for its active site. Specificity also provides a means of classifying lipases (Persson et al., 2002). Three groups are defined; (i) Non-specific lipases, (ii) acyl group specific, (iii) positional specific lipases. Nonspecific lipases catalyze fatty acids randomly from any position on the glycerol molecule. Acyl group specific lipases catalyze the release of particular types of fatty acids from triacylgylcerols. Positional specific lipases attack "sn-1,3" lipases, those acting only on the sn-1 and sn-3 positions (Quinlan et al., 1993; Whitaker et al., 1996). Much research has been reported regarding the incorporation of medium chain fatty acids and polyunsaturated fatty acids such as capric acid and fish oil through the use of positional specific lipases. In the work of Jennings et al. (1999) the fatty acid composition of menhaden fish oil was modified to contain capric acid by using an immobilized IM 60 specific sn-2 lipase as biocatalyst resulting with an average of $31.1 \%$ incorporation of $\mathrm{C}_{10: 0}$ into fish oil.

\subsection{Biocatalyst in Non-Conventional Media}

\subsubsection{Organic Solvent Media}

Enzymes are biocatalysts that are well known for their high substrate specificity and their use under mild conditions. Such factors have enabled them to catalyze selective transformations. The use of enzymes in organic media has played an exciting area in enzyme technology by providing an increasing number of applications. Several enzymatic activities have been reported in organic solvents and the role of several parameters, such as type of organic media, water content and effect of temperature, have been determined. However, it has been determined that water around the biocatalyst is essentially needed to preserve the protein conformation preventing it from denaturation or inactivation (Ma et al., 2002). In addition, to the importance of water content, another essential parameter is that of solvent hydrophobicity. Enzyme activity in nonaqueous media is correlated with the partition coefficient, $\log P . \log P$ is a quantitative measure of solvent polarity. Solvents with a $\log P$ value of less than 2 are not appropriate for enzymatic reaction systems, whereas those with a $\log P$ value of 2 to 4 are generally unpredictable; however solvents with a $\log P$ greater than 4 can maintain the activity of 
the biocatalysts (Laane et al., 1987; Gupta et al., 2004). For instance, lipases which have higher $\log P$ values are stabilized in aqueous solutions by a series of weak interactions by which van der Waals' interactions, enable them to exhibit strong stabilizing force (Lehninger et al., 1993). Negishe et al. (2003) also reported that lipases, which possess stronger binding forces to water, exert a higher catalytic activity. The literature has reported that the hydrophobic solvents are more appropriate for enzymatic biocatalysts. Hence, proper choice of solvent can greatly affect the reaction.

\subsubsection{Advantages in Organic Solvent Media}

Potential advantages of organic solvent media have been the primary reason for the extensive use in biocatalytic reactions. Such advantages include increased solubility of nonpolar substrates, shifting of thermodynamic equilibrium to favor the synthesis over hydrolysis (e.g., synthesis of esters, peptides, etc), possibility to diminish undesirable side reactions in organic media, as well as substrate and product inhibition, ease of recovery from low boiling solvents, reduction in water-dependent side reactions such as hydrolysis of acid anhydrides or polymerization of quinines, and the relative solubility of many compounds in organic solvents is high (Laane et al., 1987; Dordick, 1989). Another that can be cited is that the use of organic solvent media enables the reduction of waterdependent side enzymatic a reaction leading to more of a synthetic reaction, hence, the selection of an appropriate solvent media is a critical factor for an enzymatic process.

\subsubsection{Effect of Water Activity}

It is now well recognized that enzymes cannot function under total anhydrous conditions; the hydration level of the enzyme molecule is paramount, it has been suggested that approximately 1000 molecules of water per enzyme molecule are sufficient enough for optimum catalytic activity (Halling, 1994; Wehtje et al., 1997). Too little water in the system results in decreased catalytic activity due to inadequate hydration of the protein molecules while too much water may cause agglomeration of particles and unwanted side reactions. Protein hydration was first investigated through the work of Zaks et al. (1988); their work focused on determining the adsorption isotherm of water on the enzyme in different solvents using alcohol dehydrogenase. Zaks et al., (1988) observed that the water content on the enzyme correlated positively with the reaction rates in different 
solvents; the higher the water content of the enzyme, the higher was the reaction rate of unwanted side reactions with the agglomeration of particles leading to a decrease in catalytic activity.

The variation in the activity of a biocatalyst can also be correlated with the thermodynamic water activity $\left(a_{w}\right)$. Thermodynamic $a_{w}$ can be measured via the vapor phase above the reaction mixture and can be expressed as the partial pressure of the solution over the partial pressure of pure water measured through the vapor phase (Pomeranz and Meloan, 1994; Halling, 2002). At equilibrium, $a_{w}$ values are the same for all phases, regardless of the critical water contents of individual phases. Chamouleau et al. (2001) further noted that most lipases can catalyze reactions in very low $\mathrm{a}_{w}(<0.07)$.

\subsubsection{Effect of Reaction Temperature}

The effect of temperature on enzyme activity can be two fold: an increase of temperature leads to an increase in the conversion yield yet the heat denatures the lipase protein structure (Stamatis et al., 1999 and 2001; Biselli et al., 2002). Arcos et al. (1998) reported that the enzymatic production of acylglycerols from linoleic acid and glycerol by lipase in a solvent-free media increased with the increase in temperature in the range of 30 to $70^{\circ} \mathrm{C}$. However, when the temperature was set at $70^{\circ} \mathrm{C}$, greater proportions of the fatty acid and mono-ester was obtained, 13 and $34 \%$ as compared to 5 and 25\%, respectively (Arcos et al., 1998). Almeida et al. (1998) concluded that the conversion yield was increased with the addition of a catalyst as well with the increase in temperature. Generally, it is preferable to use enzymes at high temperatures as such in order to increase the rate of reaction; however they are protein molecules and undergo denaturation at temperatures above those to which they are ordinarily exposed to in their natural environment. Although the conversion yield increases by increasing temperatures, the maximum activity of enzymes ranges between 50 to $60^{\circ} \mathrm{C}$ (Köse, 2001). Previous research has shown that the optimal temperature for Novozym 435 lipase activity for the biosynthesis of phenolic lipids was in the range of 45 to $60^{\circ} \mathrm{C}$ (Guyot et al., 1997; Buisman et al., 1998). Lue et al. (2005) reported that the maximum temperature of $55^{\circ} \mathrm{C}$ for the Novozym 435-esterification reaction of cinnamic acid with oleyl alcohol falls within the same range as reported in the literature. 


\subsection{Biosynthesis of Phenolic Lipids}

Enzymatic synthesis of fats and oils is receiving more attention as a promising alternative for their modification because of the high selectivity of biocatalysts (Gunstone, 1999). Furthermore, lipase-catalyzed reactions occur under mild processing conditions and the resulting end products would be viewed as a more "natural" product than those chemically modified ones (Torres et al., 2005). The enzymatic processes can be used in the production of fats and oils containing beneficial fatty acids and or/phenolic compounds (Lue et al., 2005; Karboune et al., 2005; Sabally et al., 2006a,b and 2007).

The enzymatic synthesis of phenolic lipids have been reported in the literature (Humeau et al., 1995; Guyot et al., 1997; Stamatis et al., 1999; Lue et al., 2005, Karboune et al., 2005; Sabally et al., 2005a,b, 2006a,b and 2007). Works reported by Stamatis et al. (1999) revealed the esterification of cinnamic or p-hydroxypheneylacetic acid with short or medium chain FA using lipase from Candida antarctica, resulted in high yields of 82 and $97 \%$ after 12 days of reaction. Esterification of phenolic acids using long chain alcohols aiming at the synthesis of phenolic lipids has also been conducted in organic media. In agreement to Stamatis et al. (1999) recent work in our laboratory resulted in a successful $100 \%$ esterification yield of cinnamic acid and oleyl alcohol using different solvent mixtures and substrate molar ratios (Lue et al., 2005). In addition to recent work in our laboratory, Karboune et al. (2005) conducted work on the transesterification of cinnamic acid with triolein in organic solvent media. A combined yield of monoleyl-1(3)cinnamate and dioleyl-2-cinnamate of $19 \%$ was obtained in an equal ratio of cinnamic and triolein ratio; however using a 4.5 fold excess triolein, the yield increased to $42 \%$ of combined monoleyl-1(3)-cinnamate and dioleyl-2-cinnamate. The synthesis of ascorbyl palmitate using Novozym 435 on ascorbic acid with palmitic acid methyl ester or palmitic acid produced 68\% and 56\% yields respectively (Humeau et al., 1995).

The structuring of TAG molecules with phenolic acids to produce phenolic lipids has shown to have great utility in unsaturated oils such as flaxseed and fish liver oils, since these products can have the potential nutritional and health benefits of both the lipid and phenolic acid. As a result, recently further studies were performed in our laboratory on 
the biosynthesis of phenolic lipids using flaxseed and fish liver oil as substrates using different substrate molar ratios and organic solvent mixtures. Sabally et al. (2006b) conducted work on the enzymatic biosynthesis of phenolic lipids using dihydrocaffeic acid and flaxseed oil as substrates in an organic solvent medium. A combined yield of $67.4 \%$ was obtained in a 1:4 ratio of flaxseed oil to dihydrocaffeic acid; however using an excess of flaxseed oil in a 1:8 ratio, the yield increased to $79.3 \%$ using a $85: 15(\mathrm{v} / \mathrm{v})$ hexane:2-butanone mixture. In addition, more recently Sabally et al. (2007) obtained maximum bioconversion yields of dihydrocaffeoylated fish liver oil of 55.8 and $65.4 \%$ using a hexane:2-butanone mixture of 75:25 and 85:15 (v/v), respectively.

\subsubsection{Parameters Affecting the Enzyme Activity and Product Yield}

\subsubsection{Addition of Molecular Sieve}

In order to promote the biosynthesis by shifting the thermodynamic reaction towards synthesis rather than hydrolysis, a reduction of water content in the reaction mixture can be accomplished through the addition of molecular sieve pellets as dehydrating agents. Zaks and Kilbanov (1988) reported that the addition of molecular sieves increased the rate and bioconversion level; this is due to the effect of the molecular sieves to sequester the water layer from the enzyme molecule which is essential for the water-enzyme interaction (Halling, 2000). However, Karboune et al. (2005) observed a 28 and 35\% decrease in the maximum bioconversion yield upon the addition of $10 \mathrm{mg} / \mathrm{mL}$ of molecular sieves to the lipase-catalyzed biosynthesis of cinnamoylated lipids.

\subsubsection{Addition of Silica Gel}

Silica gel, an amorphous form of silicon dioxide, functions as a dessicator. The advantage of using Silica gel as an adsorbent is the physical adsorption of bounded water into its internal pores (Castillo et al., 1997). No chemical side-reactions take place, which make Silica gel appealing. In general, Silica gel is used as an adsorbent for the glycerol during enzymatic reactions in the biosynthesis of phenolic lipids. Karboune et al. (2005) investigated the addition of Silica gel as an adsorbent for the glycerol in the biosynthesis of cinnamoylated lipids; an increase in the maximum bioconversion yield of $17 \%$, was obtained with the addition of $2.2 \mathrm{mg} . \mathrm{mL}^{-1}$ of Silica gel to the reaction mixture. Halling 
(2000) indicated that Silica gel added to a reaction medium result in an improvement in lipase-catalyzed esterification reactions.

\subsubsection{Analysis of Phenolic Lipids}

The structural analyses of phenolic lipids have been carried out using a wide range of various techniques. These mainly include, thin-layer chromatography (TLC; Buisman et al., 1998; Lee et al., 2004; Sabally et al., 2005a,b,c), high-performance liquid chromatography (HPLC; Guyot et al., 1997; Stamatis et al., 1999; Lue et al., 2005), gasliquid chromatography (GLC; Buisman et al., 1998), liquid -chromatography mass spectrometry (LC-MS; Christophoridou et al., 2005; Compton et al., 2000; Karboune et al., 2005; Sabally et al., 2005b,c).

Thin-layer chromatography has been used for initial quantitative analyses of substrates by employing a wide range of organic solvent mixtures. Products from the esterification of PUFAs with glycerol were characterized and analyzed by TLC using silica gel G-25 plates (Cerdan et al., 1998). The elution solvent used was chloroform/acetone/methanol mixture (95:4.5:0.5, v/v/v) and the plates were visualized by developing the plate with iodine vapor in a nitrogen stream. Visualization of TLC plates is accomplished by either ultraviolet absorbance (Stamatis et al., 1999) or by using chromogenic reagents (Guyot et al., 2001; Kontogianne et al., 2001).

High-performance liquid chromatography (HPLC) has often been used over other instrumentation and has shown scientifically to be the overall preferred method of choice for quantification and separation of phenolic lipids following biosynthesis reactions (Moreno et al., 2003). Phenolic lipids were separated on C18 reverse phase column using a gradient elution of methanol/water mixture with UV detection at 280nm (Guyot et al., 1997). Using a similar elution solvent mixture of methanol/water and a C18 Nucleosil column, Stamatis et al. $(1999,2001)$ analyzed phenolic lipid products with $280 \mathrm{~nm}$ detection. Guyot et al. (1997) determined the amounts of mono-, di- and tricaprin produced by using reversed-phase HPLC and employing a C18 column in conjunction with an organic mobile medium analyzing the end-products with ultraviolet (UV) detection at $280 \mathrm{~nm}$. UV detection was also combined with a C18 column using an 
isocratic column for the determination of phenolic lipids as previously reported (Karboune et al., 2005; Lue et al., 2005; Sabally et al., 2006a,b and 2007).

Gas-liquid chromatography (GLC) analysis has been conducted for the quantification of lipase-catalyzed structured lipids determining their fatty acid composition (Willis et al., 1999). Buisman et al. (1998) has reported on the GC analysis of phenolic lipid esters through the use of a CP Sil CB-MS column linked to an FID detector.

Recent research on phenolic lipids has also made use of atmospheric pressure chemical ionization-mass spectroscopy (APCI-MS) as well as electrospray ionization (ESI) techniques in combination with liquid chromatography-mass spectrometry (LC-MS) (Compton et al., 2000; Kontogianni et al., 2001; Sabally et al., 2006a). LC-MS is considered to be one of the most powerful techniques used for the characterization of biomolecules due to its high sensitivity and specificity. Generally its application is oriented towards the specific detection and potential identification of chemicals in the presence of other chemicals (in a complex mixture). LC-MS has been used for the structural characterization of lipids and phenolic lipids (Kontogianni et al., 2001; Andrikopoulos, 1991 and 2002).

\subsubsection{Antioxidant Determination of Phenolic Lipids}

Increasing research and development on naturally occurring phenolic compounds has promoted critical interest in their biological properties. As a result, the measurement of antioxidant activity has become a focal point by both the food industry and by health professionals (Shahidi and Naczk, 1995a,b,c; Shahidi and Wanasundara, 1998).

Most phenolic compounds have antioxidant properties through their radical scavenging ability. The antioxidant properties of such can be measured either directly, spectrophotometrically, using a free radical method using the DPPH radical method (Gan and Seib et al., 1998) or by using indirect methods such as using thiobarbituric acid reactive substance and $p-\mathrm{AnV}$, which measure secondary oxidative products (Handelman et al., 1999). 
The flavonoids constitute a large class of compounds which contains a number of phenolic hydroxyl groups attached to ring structure conferring the antioxidant activity (Rice-Evans et al., 1996). Cinammic acid, dihydrocaffeic acid and their ethyl esters showed to have radical scavenging activity towards the free radical DPPH; however, their phenolic lipid ester demonstrated to have a lower scavenging activity than that with the phenolic acid component (Karboune et al., 2005; Sabally et al., 2006b,c). Similarly, Silva et al. (2000) reported on the scavenging activity of caffeic and dihydrocaffeic acid towards the free radical $\mathrm{DPPH}^{\circ}$ as a result of the H-donating ability of the hydroxyl benzoate.

\subsection{Fatty Acid Composition After Oil Modification}

Further studies on the enzymatic synthesis of unsaturated lipids has also been conducted by Jennings et al. (2001); the esterification yield of menhaden fish oil with a medium chained FA, using a lipase from Rhizomucor miehei, resulted in a 36.7\% yield in solventfree and $50.7 \%$ in hexane. As a result, the lipase-catalyzed acidolysis of menhaden fish oil with capric acid $\left(\mathrm{C}_{10: 0}\right)$ was modified to contain $\mathrm{C}_{10: 0}, \mathrm{C}_{20: 5}$ and $\mathrm{C}_{22: 6}$ as major fatty acids present followed by $\mathrm{C}_{16: 0}, \mathrm{C}_{16: 1}, \mathrm{C}_{18: 0}$ and $\mathrm{C}_{18: 1}$. Results of some relative fatty acids values before and after modification are presented in Table 2 (Jennings et al., 2001):

Table 2. Relative percent of fatty acid composition of menhaden fish oil before and after modification, with and without hexane.

\begin{tabular}{|l|c|c|c|}
\hline & & \multicolumn{2}{|c|}{ Reaction Medium } \\
Fatty acid & Before Modification & Hexane & $28.8 \pm 4.7$ \\
\hline C10:0 & $0.0 \pm 0.0$ & $31.1 \pm 4.6$ & $15.1 \pm 2.0$ \\
\hline C16:0 & $2.5 \pm 0.9$ & $13.6 \pm 1.0$ & $9.4 \pm 2.2$ \\
\hline C16:1 n-7 & $2.7 \pm 0.1$ & $11.2 \pm 0.6$ & $6.3 \pm 1.4$ \\
\hline C18:1 n-9 & $9.9 \pm 1.7$ & $6.7 \pm 3.1$ & $16.1 \pm 5.7$ \\
\hline C20:5 n-3 & $34.7 \pm 3.0$ & $12.6 \pm 3.1$ & $13.5 \pm 3.0$ \\
\hline C22:6 $n-3$ & $34.4 \pm 3.1$ & $13.7 \pm 4.4$ & \\
\hline
\end{tabular}

*Obtained from Jennings et al. (2001). 
Table 2 indicates that after incubation in hexane, an average of $31.1 \%$ incorporation of $\mathrm{C}_{10: 0}$ into fish oil was obtained while the fatty acids $\mathrm{C}_{20: 5}$ and $\mathrm{C}_{22: 6}$ declined to 12.6 and $13.7 \%$, respectively. The solvent-free reaction reported an increase of $28.8 \%$ in the fatty acid composition of $\mathrm{C}_{10: 0}$ as compared to the unmodified fish oil, however the fatty acids $\mathrm{C}_{20: 5}$ and $\mathrm{C}_{22: 6}$ decreased to 16.1 and $13.5 \%$, respectively. Similarly to Jennings et al. (2001), Sabally et al. (2007) reported that the lipase-catalyzed reaction increased the level of $\mathrm{C}_{10: 0}, \mathrm{C}_{20: 5}$ and $\mathrm{C}_{22: 6}$ fatty acids in the phenolic lipids as compared to that of the unmodified fish liver oil. 


\section{MATERials AND MethodS}

\subsection{Materials}

Commercially immobilized lipases from Rhizomucor miehei (Lipozyme IM-20, with an activity of $100 \mathrm{U} / \mathrm{g}$ solid enzyme, $1 \mathrm{U}$ corresponds to the amount of enzyme that catalyze the liberation of $1 \mu \mathrm{mol}$ stearic acid per min), and Candida antarctica (Novozym 435, with an activity of 10,000 propyl laurate units/g solid enzyme) were purchased from Novo Nordisk (Copenhagen, Denmark). Dihydroxyphenylacetic acid (DPHA), sodium methoxide as well as 2,2-diphenyl-1-picrylhydrazyl radical (DPPH') was purchased from Sigma Chemical Co. (St-Louis, MO). Fish liver oil was generously donated by Arista Industries, (Wilton, CT). Thin-layer chromatography (TLC) plates (Whatman), acetic acid glacial certified ACS and sulfuric acid $(18 \mathrm{M})$ were obtained from Fisher Scientific (Fair Lawn, NJ). All organic solvents were HPLC grade or higher and were purchased from Fisher Scientific. Standards for gas-liquid chromatography (GLC) and thin layerchromatography (TLC) were purchased from Nu-Check Prep (Elysian, MN).

\subsection{Methods}

\subsubsection{Acidolysis Reaction of Fish Liver Oil with Dihydroxyphenylacetic Acid}

\subsubsection{Acidolysis Reaction}

Lipase-catalyzed acidolysis of the triacylgycerols of fish liver oil and DHPA were carried out according to the method of Sabally et al. (2007) in $50 \mathrm{~mL}$ Erlenmeyer flasks during a reaction time period of 10 days. The enzymatic reaction was initiated by the addition of $30 \mathrm{mg}$ solid Novozym 435 lipase (300 U) in a mixture of hexane:2-butanone $(75: 25, \mathrm{v} / \mathrm{v})$. A typical reaction mixture contained $20 \mathrm{mM}(4 \mathrm{~g})$ fish liver oil based on DHA $\left(\mathrm{C}_{22: 6}, n-3\right)$ and $5 \mathrm{mM}$ DHPA in a $9 \mathrm{~mL}$ organic solvent mixture of hexane and 2-butanone. Prior to each enzymatic reaction, a stock solution of DHPA (1.872 g) was freshly prepared in 2butanone while that of fish liver oil $(26.6 \mathrm{mM} ; 5.32 \mathrm{~g})$ was prepared in hexane.

Control trials, without enzyme component, were carried out in tandem with the enzymatic reactions. All flasks were vacuum sealed and incubated at $55^{\circ} \mathrm{C}$, with continuous shaking at $150 \mathrm{rpm}$ in an orbital incubator shaker (New Brunswick Scientific Co., Inc; Edison, N.J). The enzymatic bioconversion was followed-up by the removal of $350 \mu \mathrm{L}$ aliquot 
from each reaction mixture every second day of the reaction. The samples were dried down under vacuum, using an Automatic Environmental Speed Vac system (Savant Instruments Inc, Holbrook, NY). Samples were then flushed with a gentle stream of nitrogen and stored at $-80^{\circ} \mathrm{C}$ until the TLC and HPLC analyses.

\subsubsection{Determination of Bioconversion Yield by HPLC Analysis}

In order to quantify the substrates and end products, the enzymatic and blank reactions were subjected to HPLC analysis, according to a modification of the procedure described by Sabally et al. (2007). However, before being subjected to HPLC analysis, the dried samples were solubilized in a mixture composed of $154 \mu \mathrm{L}$ of isopropanol and $56 \mu \mathrm{L}$ of acetonitrile.

HPLC analysis was carried out using a Zorbax SB-C18 reversed-phase column (5 $\mu \mathrm{m}$, $250 \times 4.6 \mathrm{~mm}$, Agilent Technologies, Wilimington, DE) and a Beckman HPLC system (Model 126, Instruments Inc, San Ramon, CA) equipped with an ultraviolet diode-array (UV-DAD) detector (Model 168) with computerized data handling and integration analysis (System Gold software, version 8.0, Beckman). Samples were manually injected using a glass syringe $(50 \mu \mathrm{L})$ with an injection volume of $20 \mu \mathrm{L}$. The gradient mobile phase was consisted of two solvents, solvent A (acetonitrile/methanol; 7:5, v/v) and solvent B (isopropanol), with a flow rate of $1 \mathrm{~mL} / \mathrm{min}$ for a total run time of $55 \mathrm{~min}$. The elution was initiated by an isocratic flow of $100 \%$ solvent A for $10 \mathrm{~min}$, followed by a 10 min linear gradient of $40 \%$ of solvent A and $60 \%$ solvent B; a $100 \%$ concentration of solvent $\mathrm{B}$ was reached in further elution of $10 \mathrm{~min}$, which was maintained for an additional period of $10 \mathrm{~min}$. The column was calibrated for the next run by eluting $100 \%$ solvent A for $10 \mathrm{~min}$ period. The detection was carried out at 215 and $280 \mathrm{~nm}$. The eluted samples were also subjected to a spectrophotometric scanning at the region of 190 to 400 $\mathrm{nm}$, at 1 -sec intervals.

The maximal bioconversion yield was defined as the sum of total peak areas of phenolic lipids divided by the peak area of the phenolic acid in the blank, determined at $280 \mathrm{~nm}$, multiplied by 100 . The enzymatic activity was calculated from the slope of the linear portion of the plot of the bioconversion yield versus the reaction time and it was 
expressed as $\mu \mathrm{mol}$ of consumed phenolic acid per g solid enzyme per min of reaction. The bioconversion yield of phenolic monoacylglycerols was defined by the peak area of the phenolic lipids, eluted between 4 and $7 \mathrm{~min}$ at $280 \mathrm{~nm}$, divided by the peak area of the phenolic acid in the blank. However, the bioconversion yield of phenolic diacylglycerols was defined by the peak area of the phenolic lipids, eluted between 7 and 20 min at 280 $\mathrm{nm}$, divided by the peak area of the phenolic acid in the blank.

\subsubsection{Characterization of Phenolic Lipid End-Products}

\subsubsection{Thin-Layer Chromatography (TLC) Analysis of Phenolic Lipids}

Phenolic lipids were also analyzed by TLC analysis on Silica gel 60 plates with fluorescent indicator (Whatman, Fisher Scientific). TLC was carried out in a glass development chamber containing a saturated solvent mixture of hexane/diethyl ether/acetic acid (70:30:1, v/v/v) as indicated by Lee et al. (2004). Prior to the TLC analysis, the phenolic lipids were solubilized in $150 \mu \mathrm{L}$ chloroform. With $10 \mu \mathrm{L}$ disposable micropipettes, the solutions were spotted on the TLC plate and placed in the glass development chambers. The migration was carried out for approximately $90 \mathrm{~min}$. The TLC plates was then dried and sprayed with a $20 \%$ sulfuric acid solution for the characterization of separated compounds, or directly visualized under UV (235 nm) for preparative purposes in a fluorescence analysis cabinet (Spectroline, Model CX20). In order to characterize each separated product, the $\mathrm{R}_{f}$ of the different compounds, subjected to TLC analysis, were determined. The bands corresponding to phenolic mono- and diacylglycerols on the preparative TLC plates were recovered by scraping the Silica gel and its suspension in isopropanol. The homogenate suspension was filtered, using fritted glass filter, and the recovered separated products were concentrated and subjected to HPLC and GLC analyses.

\subsubsection{High Performance Liquid Chromatography (HPLC) Analysis of Phenolic Lipids}

In order to determine and to characterize the phenolic lipid fragments, the phenolic mono- and diacylglycerols were subjected to HPLC analysis, according to a modification of the procedure of Sabally et al. (2007) as described above. 


\subsubsection{Mass Spectrometry (MS) Analysis of Phenolic Lipids}

The reaction components of the lipase-catalyzed acidolysis of fish liver oil with DHPA were analyzed by HPLC interfaced to atmospheric pressure chemical ionization-mass spectrometry (APCI-MS) using the same column and mobile phase as described above. The APCI-MS system (Thermo-Finnigan, San Jose, CA) was equipped with a reversephase column (Zorbax SB-C18), a Surveyor liquid chromatography pump, an autosampler and a Xcalibur@ system control software (Version 1.3) for data acquisition and processing. The mass spectrometer was operated in positive ion mode with a collision energy source of $15 \mathrm{~V}$. The ion spray and capillary voltage were set at $4.0 \mathrm{kV}$ and $15.6 \mathrm{~V}$, respectively.

\subsubsection{Optimization of Lipase-Catalyzed Acidolysis Reaction}

\subsubsection{Selection of Biocatalyst}

The selection of the biocatalyst for the acidolysis reaction was investigated, using two different lipases, Lipozyme IM 20 and Novozym 435. Aliquots of reaction medium were withdrawn over a 10 day period of incubation. The selection of the biocatalyst was determined using well-defined conditions including a solvent mixture of hexane:2butanone, 75:25; $\mathrm{v} / \mathrm{v}$, reaction volume $(9 \mathrm{~mL})$, enzyme amount (30 mg solid enzyme, 300 $\mathrm{U})$, substrate molar ratio (4:1), agitation speed $(150 \mathrm{rpm})$ and reaction temperature $\left(55^{\circ} \mathrm{C}\right)$,

\subsubsection{Effect of Lipase Concentration}

The effect of the amount of the biocatalyst, Novozym 435, was investigated by varying its concentrations from 20 to $60 \mathrm{mg}$ of solid enzyme (200 to $600 \mathrm{U}$ ) in $9 \mathrm{~mL}$ of hexane:2butanone mixture $(75: 25, \mathrm{v} / \mathrm{v})$. The enzymatic reactions were carried out and monitored at defined time intervals during a 10-day incubation period as described above.

\subsubsection{Effect of Organic Solvent Mixture Ratio}

A wide range of solvent mixtures, containing hexane:2-butanone, at different ratios $(65: 35,75: 25,85: 15 ; \mathrm{v} / \mathrm{v})$, were evaluated for the effect of the medium polarity on the bioconversion yield and reaction specificity. The selection of organic solvents was based 
on their degree of hydrophobicity (Laane et al., 1987). Using the optimized conditions of Novozym 435 (50 mg solid enzyme/9 mL) and the reaction conditions described above, samples were recovered at regular time intervals for their analyses.

\subsubsection{Effect of Molar Substrate Ratio}

The effect of the substrate molar ratio was investigated by varying the concentration of fish liver oil from 5 to $40 \mathrm{mM}$, at a constant concentration $(5 \mathrm{mM})$ of DHPA. The resulted substrate molar ratio of fish liver oil and DHPA was ranged from 1:1 to 8:1, respectively. The enzymatic reaction was carried out over a 10 day period, using the optimal assay conditions of Novozym 435 concentration (50 mg solid enzyme $/ 9 \mathrm{~mL}$ ) and the solvent mixture of hexane:2-butanone $(75: 25, \mathrm{v} / \mathrm{v})$.

\subsubsection{Effect of Molecular Sieve}

In order to favor the biosynthesis of phenolic lipids, the addition of the molecular sieve (Type 4A; 8-12 mesh) on the acidolysis reaction was investigated. Under the optimized conditions, using Novozym $435(50 \mathrm{mg} / 9 \mathrm{~mL})$, a hexane:2-butanone mixture of $75: 25(\mathrm{v} / \mathrm{v})$ and a $4: 1$ molar substrate ratio, the enzymatic reaction was investigated in the presence of the molecular sieve at a concentration of $10 \mathrm{mg} / \mathrm{mL}$.

\subsubsection{Effect of Silica Gel}

Under the optimized reaction conditions as previously described over a 10 day time period, the acidolysis reaction was conducted in the presence of Silica gel (60-200 mesh), at a concentration of $1.5,2.5$ and $5.5 \mathrm{mg} / \mathrm{mL}$ of reaction mixture.

\subsubsection{Determination of Fatty Acid Composition}

Fatty acids composition of the fish liver oil and of the phenolic mono- and diacylglycerols, recovered by the preparative TLC, was investigated using GLC. Prior to the GLC analysis, the recovered phenolic mono- and diacylglycerols fractions, $95 \mathrm{mg}$ and $103 \mathrm{mg}$ respectively, were diluted with $6 \mathrm{~mL}$ of hexane and methylated, using $60 \mu \mathrm{L}$ methanolic solution of $2 \mathrm{M}$ sodium methoxide (De Jong et al., 1986). The fatty acid methyl esters were subjected to GLC analysis, using the Agilent 6890 chromatography system (Agilent Technologies, Wilimington, DE), equipped with a FID detector and a 
splitless injector. The separation was carried out with the use of Supelco Omega Wax 24152 fused capillary column $(30 \mathrm{~m} \times 0.32 \mathrm{~mm}$ I.D. $\times 0.25 \mu \mathrm{m}$ film thickness $)$, purchased from J.W. Scientific (Folson, CA), and a FID detector as well as splitless injector. The injector and detector temperatures were set at $250^{\circ} \mathrm{C}$. The initial column temperature was $100^{\circ} \mathrm{C}$ and maintained for $3 \mathrm{~min}$ before its increase to $200^{\circ} \mathrm{C}\left(10^{\circ} \mathrm{C} / \mathrm{min}\right)$, which was held for $15 \mathrm{~min}$ followed by an additional increase to $250^{\circ} \mathrm{C} / \mathrm{min}$ over a period of $5 \mathrm{~min}$. The helium was used as the carrier gas, with a flow rate of $1 \mathrm{~mL} / \mathrm{min}$ with a pressure of 9.8 psi.

\subsubsection{Determination of the Antioxidant Activity of Phenolic Lipids}

The free radical scavenging activity of phenolic lipids was determined according to a modification of the method of Silva et al. (2000), using $\mathrm{DPPH}^{\circ}$ as the stable free radical compound. The samples were composed of only phenolic lipid products and were recovered by preparative HPLC according to the method described previously. Prior to the analysis, in a $1 \mathrm{~mL}$ spectrophotometric cuvette, the sample $(100 \mathrm{mM})$ as well as

references were solubilized with $10^{-4} \mathrm{M}$ ethanolic DPPH $(0.24 \mathrm{mM})$ solution. The decrease in $\mathrm{DPPH}^{\circ}$ concentration was followed spectrophotometrically (Beckman spectrophotometer, Model 650, Inc., Fullerton, CA) at $517 \mathrm{~nm}$ over a period of $15 \mathrm{~min}$, using a blank assay without $\mathrm{DPPH}^{\circ}$. In addition, a control reaction containing only $\mathrm{DPPH}^{\circ}$ free radical was carried out in tandem with the scavenging reaction trial. The percentage of the residual $\mathrm{DPPH}^{*}$ was calculated as the absorbance of the reaction mixture at 517 $\mathrm{nm}$, at a defined time, divided by the initial absorbance of $\mathrm{DPPH}^{*}$ control, multiplied by 100 .

The antioxidant activity of the phenolic acid or phenolic lipid was defined by the percentage of $\mathrm{DPPH}^{*}$ scavenging, using the following formula:

$$
\begin{aligned}
& \text { Residual } \mathrm{DPPH}^{*}(\%)=\mathrm{A}_{\max (\text { phenolic product })} \times \mathrm{Ai}_{\left(\mathrm{DPPH}^{\bullet}\right)} / 100 \\
& \text { Scavenging } \mathrm{DPPH}^{\bullet}(\%)=100-\% \text { residual } \mathrm{DPPH}^{\bullet}
\end{aligned}
$$

Where, $\mathrm{A}_{\max }$ is the maximal absorbance of the phenolic products mixture, and $\mathrm{A} i$ is the initial absorbance of the $\mathrm{DPPH}{ }^{*}$ control solution. 


\section{RESULTS AND DISCUSSION}

\subsection{Acidolysis of Fish Oil with Dihydroxyphenylacetic Acid}

The enzymatic acidolysis of fish liver oil with dihydroxyphenylacetic acid (DHPA) was investigated as a model system for the synthesis of phenolic lipids (Figure 7). In order to determine the appropriate of biocatalyst, two different lipases, including Lipozyme IM-20 from Mucor miehei and Novozym 435 from Candida antarctica, were investigated. Both lipases, having a large substrate specificity, are widely used in the preparation of structured lipids (Cerdan et al., 1998; Diks, 2003); however, they differ in their positional regioselectivity. Lipozyme IM-20, which is a 1,3-specific lipase, preferentially rearranges fatty acids at the sn-1 and sn-3 positions on the glycerol backbone of triacylgycerols (TAGs), while the sn-2 position is partly preserved (Gunstone et al., 1999). On the other hand, Novozym 435, is a non-specific lipase, and it randomly rearranges fatty acids at both the sn-1,3 and sn-2 positions (Jensen et al., 1983; Gandhi et al., 1997).

Figure 8 shows the time course of the acidolysis of fish liver oil with DHPA catalyzed by either Novozym 435 or Lipozyme IM-20, in a hexane:2-butanone organic medium $(75: 25, \mathrm{v} / \mathrm{v})$, over a 10 -day period reaction. Using Novozym 435 as biocatalyst, a large increase in the bioconversion yield of phenolic lipids was obtained within the first 4 days of reaction to $53.5 \%$, with an enzymatic activity of $0.804 \mu \mathrm{mol}$ esterified phenolic acid/ $\mathrm{g}$ solid enzyme/min; thereafter, the bioconversion yield increased to a lower extent up to a maximum of $64.8 \%$ after 8 days of reaction, which was followed by a slow decrease to $58.1 \%$ after an additional two days of reaction. On the other hand, the Lipozymecatalyzed acidolysis reaction showed a different trend of bioconversion yield with a lower extent whereby a steady increase was obtained up to a maximum of $14.1 \%$ after 10 days of reaction, with an enzyme activity of $0.015 \mu \mathrm{mol}$ esterified phenolic acid/g solid enzyme/min. The difference in the catalytic efficiency between the two biocatalysts could be due to the differences in their affinity and regioselectivity towards the TAGs of fish liver oil and DHPA (Stamatis et al., 1999). Similarly, Kim et al. (2006) have reported that the use of Novozym 435 as biocatalyst resulted in a higher degree of incorporation of 


$$
\begin{gathered}
\mathrm{H}_{2} \mathrm{C}-\mathrm{O}-\mathrm{CO}-\mathrm{R} \\
\quad \stackrel{ }{\mid}-\mathrm{O}-\mathrm{CO}-\mathrm{R} \\
\mathrm{H} \mathrm{C} \\
\stackrel{\mid}{\mathrm{H}_{2} \mathrm{C}}-\mathrm{O}-\mathrm{CO}-\mathrm{R}
\end{gathered}
$$

Triacylglycerols (TAGs)
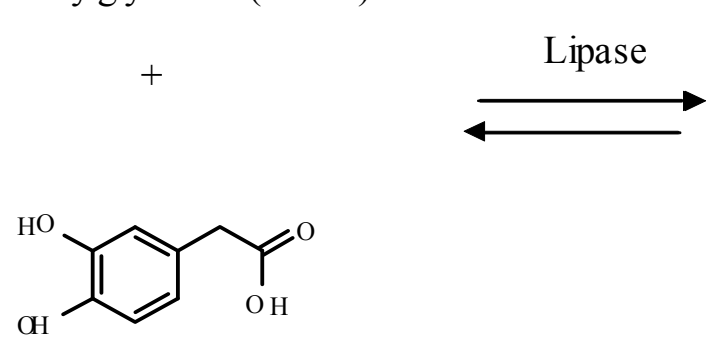

Dihydroxyphenylacetic acid

$$
\begin{aligned}
& \mathrm{H}_{2} \mathrm{C}-\mathrm{O}-\mathrm{CO}-\mathrm{R} \\
& \quad \stackrel{ }{\quad}-\mathrm{O} \\
& \mathrm{H} \mathrm{C}-\mathrm{OH} \\
& \quad \\
& \mathrm{H}_{2} \mathrm{C}-\mathrm{O}-\mathrm{CO}-\mathrm{R}
\end{aligned}
$$

Diacylglycerols

$\mathrm{H}_{2} \mathrm{C}-\mathrm{O}-\mathrm{CO}-\mathrm{R}$

$\mathrm{H} \mathrm{C}-\mathrm{OH}$

$\mathrm{H}_{2} \mathrm{C}-\mathrm{OH}$

Monoacylglycerols

$$
\begin{aligned}
& \mathrm{H}_{2} \mathrm{C}-\mathrm{O}-\mathrm{CO}-\mathrm{R} \\
& +\mathrm{HC}-\mathrm{O}-\mathrm{CO}-\mathrm{R}_{1}+\mathrm{HO}-\mathrm{CO}-\mathrm{R} \\
& \mathrm{H}_{2} \mathrm{C}-\mathrm{O}-\mathrm{CO}-\mathrm{R}
\end{aligned}
$$

Phenolic diacylglycerols $\quad$ Free fatty acids (FFAs)

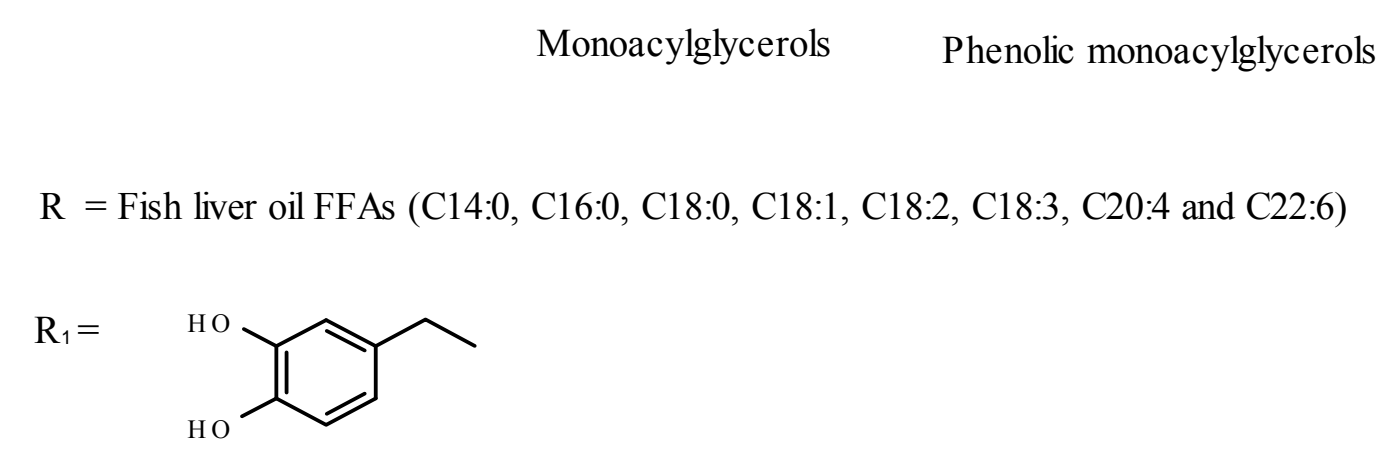

Figure 7. Reaction scheme of lipase-catalyzed acidolysis reaction of fish liver oil with dihydroxyphenylacetic acid. 


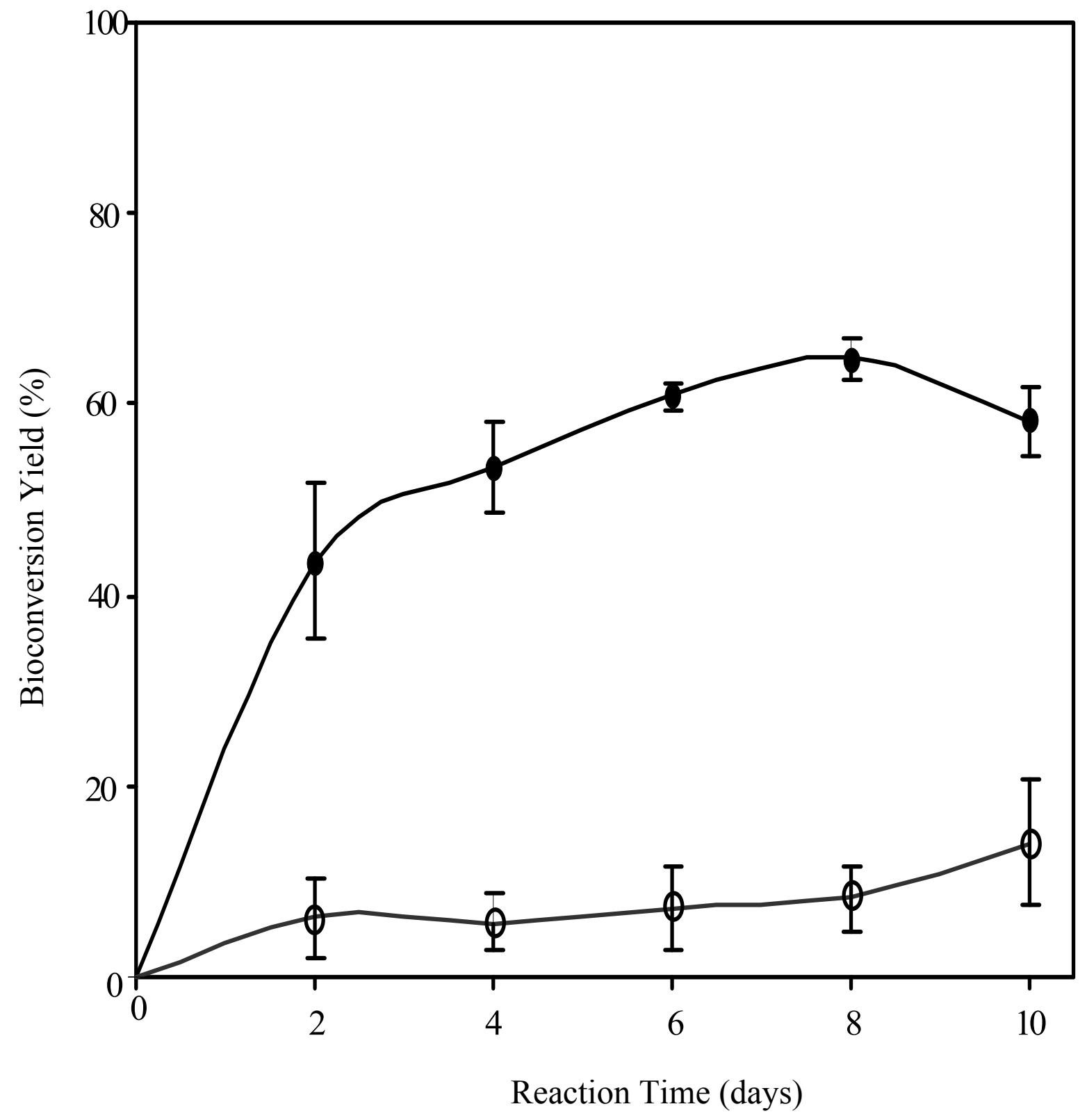

Figure 8. Time course for the acidolysis reaction of fish liver oil with dihydroxyphenylacetic acid, catalyzed by Novozym $435(\bullet)$ or Lipozyme IM-20 (०) in hexane/2-butanone solvent mixture $(75: 25, \mathrm{v} / \mathrm{v})$ at a substrate molar ratio of 4:1. 
pinolenic acid into menhaden oil (19.2 \%) as compared to that obtained with Lipozyme IM-20 (13.6 \%). Likewise, Sabally et al. (2005b) showed that Lipozyme IM-20 catalyzed the esterification reaction of dihydrocaffeic acid with linoleyl alcohol resulted by a low enzymatic activity $(0.34 \mu \mathrm{mol}$ esterified linoleyl alcohol/g solid enzyme/min and maximum esterification yield (40\%), whereas with Novozym 435 as a biocatalyst, an enzyme activity of $0.70 \mu \mathrm{mol}$ esterified linoleyl alcohol $/ \mathrm{g}$ solid enzyme $/ \mathrm{min}$ and a maximum esterification yield of $83 \%$ were obtained after 5 days of reaction. In addition, Cerdan et al. (1998) reported a higher esterification yield (82.4\%) of eicosapentaenoic acid (EPA) and docosahexaenoic acid (DHA) from cod liver oil with glycerol by using Novozym 435 as biocatalyst in comparison to that (61.2\%) obtained with Lipozyme IM20.

The overall experimental findings showed that Novozym 435 was most efficient biocatalyst for the acidolysis of fish liver oil and DHPA as compared to Lipozyme IM-20 and consequently used for further investigation throughout this study.

\subsection{Characterization of Phenolic Lipid Products}

The separation of substrates and phenolic lipid end products, following the lipasecatalyzed acidolysis reaction of fish liver oil and DHPA, was carried out by high performance liquid chromatography (HPLC) and thin-layer chromatography (TLC) analysis. Structural characterization of phenolic lipids were investigated by liquid chromatography-mass Spectrometry (LC-MS) analysis.

\subsubsection{TLC Analysis of Reaction Components}

The acidolysis reaction mixture of fish liver oil and DHPA were analyzed by TLC (Fig. 9). A standard mixture of mono, di- and trilinolenin was used as reference to characterize the bands corresponding to the acylglycerol components of the reaction medium. In contrast to the hydrolysis products, the bands corresponding to the phenolic acid and phenolic lipids were detected under both UV light $(265 \mathrm{~nm})$ as well as visible light, after being sprayed with $0.2 \%$ sulfuric acid. As expected, the monoacylglycerols migrated with the least $\mathrm{R}_{f}$ value while the TAGs migrated with the highest $\mathrm{R}_{f}$ value. The difference in 


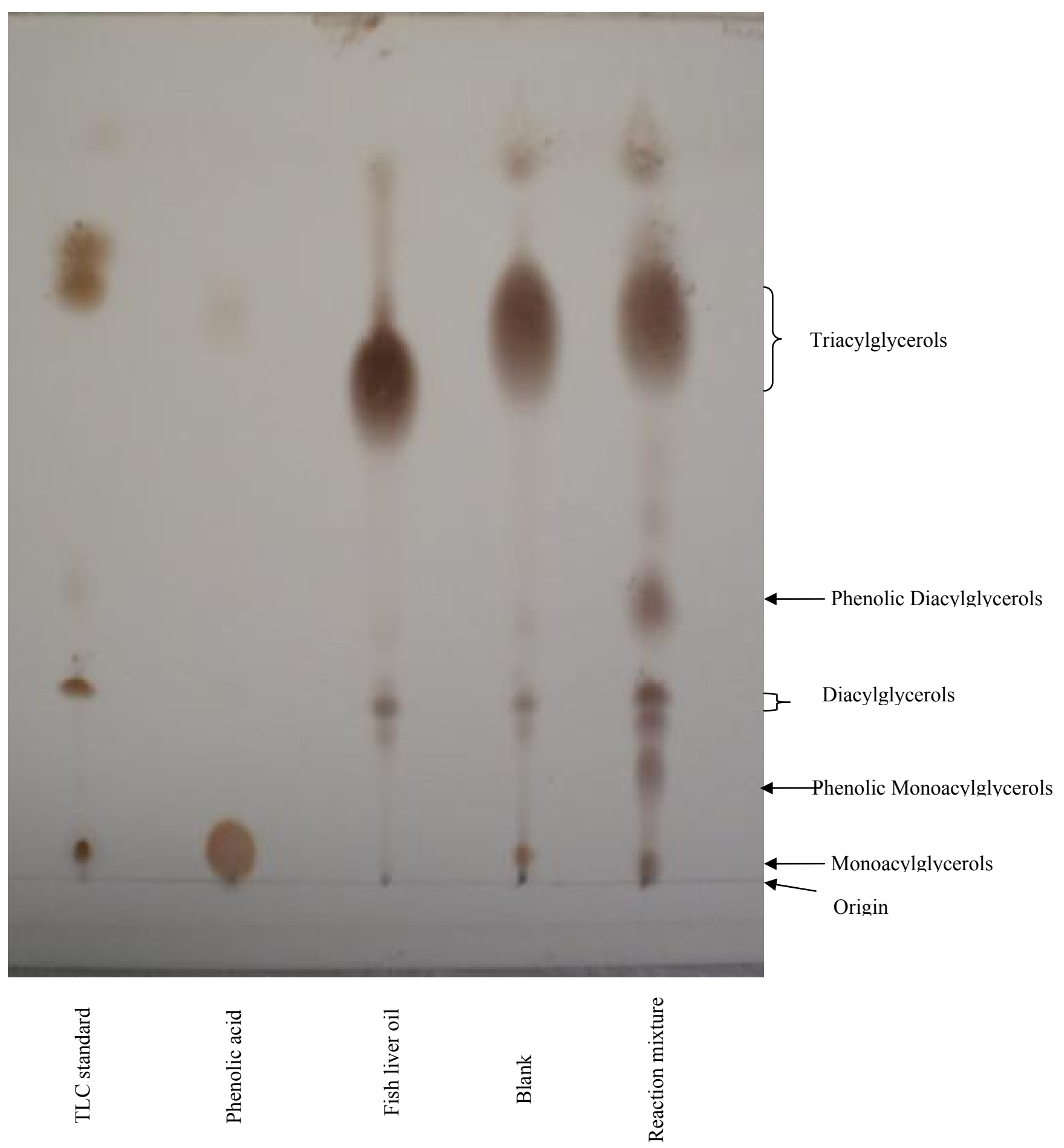

Figure 9. Thin-layer chromatography separation of components of a reaction mixture, blank sample and a standard. 
the migrating rates $\left(\mathrm{R}_{f}\right)$ is depending on the solubility of the migrated components in the mobile phase and on their affinity towards the stationary phase (Dobson, 2002). Figure 9 shows that the mono- and diacylglycerols migrated slower than their corresponding phenolic acylglycerols. In contrary, Sabally et al. (2006b) have reported that the phenolic mono- and diacylglycerols migrated slower than their corresponding acylglycerols. The difference between the experimental finding (Fig. 9) and those reported in the literature (Sabally et al., 2005a,b) may be due to the difference in the polarity of the used mobile phase. Fractions corresponding to each phenolic lipids were scraped from the plates for further analysis using LC-MS.

\subsubsection{HPLC/LC-MS Analysis of Reaction Components}

Acidolysis reaction mixture of fish liver oil with DHPA was analyzed by HPLC and LC/MS. Figure 10 shows a typical HPLC chromatogram of the reaction components of the lipase-catalyzed acidolysis reactions of fish liver oil with DHPA, monitored at 215 and $280 \mathrm{~nm}$. Chromatograms of a blank reaction mixture are shown in Figures 10A and 10B. DHPA was characterized as peak \#1, with reference to the standard, whereas peaks \# 7, 8, 9, 10, 11 and 12 (Fig. 10B), which absorb only at $215 \mathrm{~nm}$, corresponding to TAGs of fish liver oil. Figures 10A' and 10B' represent the chromatograms from the acidolysis reaction mixture of fish liver oil and DHPA; the elution profiles indicated that peak \# 2 , $3,4,5$ and 6 were characterized as the main phenolic lipid products, since they have shown a UV-spectral scanning profile comparable to that of DHPA. Based on the retention time, the potential characterize the peaks of phenolic monoacylglycerols (peaks \# 2, 3 and 4) and diacylglycerols (peaks \# 5 and 6), were identified.

In order to characterize the structures of the potential phenolic lipids, APCI-MS analysis was carried out. The fragmentation patterns of the main phenolic lipids, characterized in the elution HPLC profiles, monitored at 215 and $280 \mathrm{~nm}$, are shown in Figure 11. However due to the complexity of the investigated products, the peaks are a representation of the potential phenolic lipid end products and are based on bioconversion yields that could be an overestimation. 


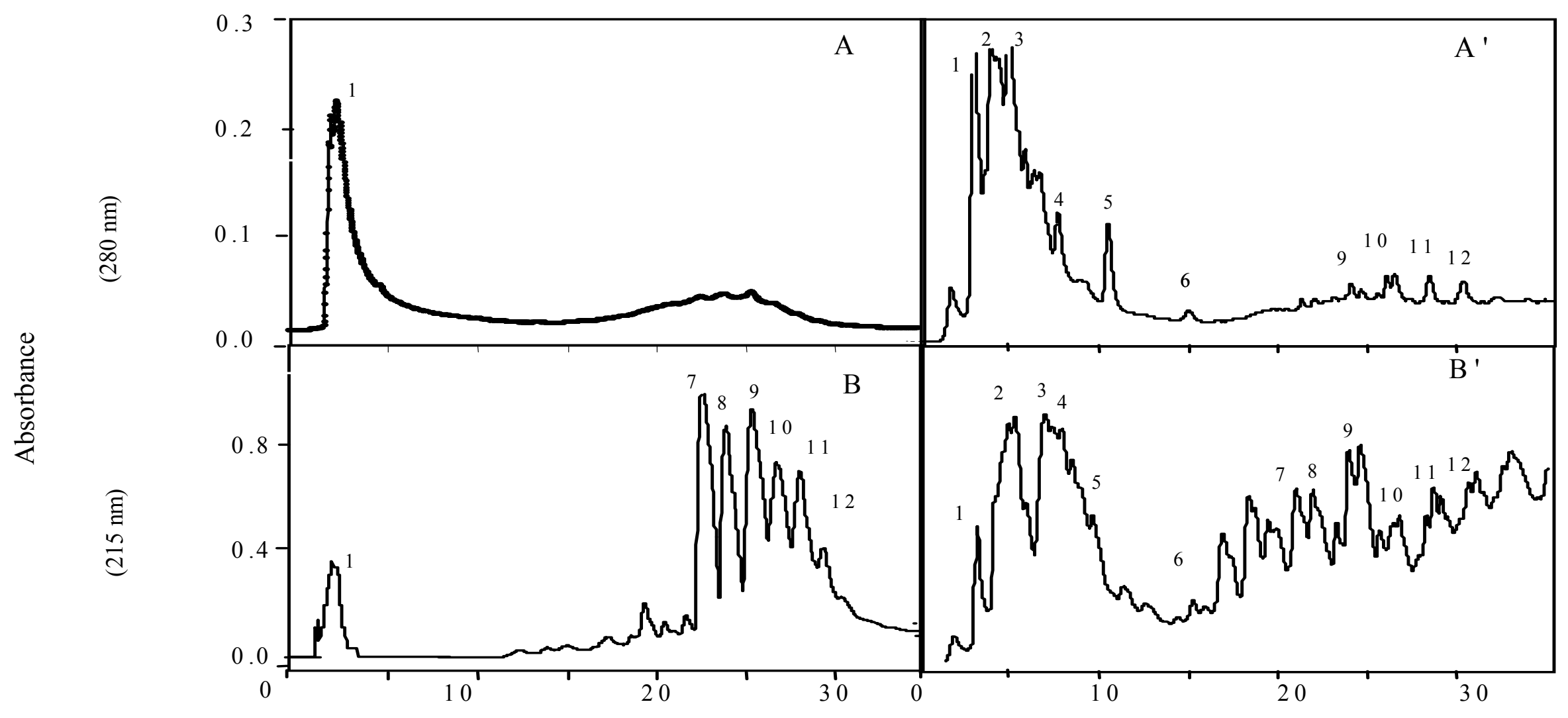

Figure 10. HPLC chromatograms of (A and B) the initial reaction mixture for the acidolysis of fish liver oil dihydroxyphenylacetic acid, ( $A^{\prime}$ and $B^{\prime}$ ) and the enzymatic acidolysis reaction mixture monitored at $280 \mathrm{~nm}$ and $215 \mathrm{~nm}$, respectively. Peak numbers were identified as follows: dihydroxyphenylacetic acid \# 1, fish liver oil \# 7,8,9,10,11 and 12, phenolic monoacylglycerols \# 2 , 3 and 4 and phenolic diacylglycerols \# 5 and 6. 
The fragmentation of peak \#2 (Fig. 11A) resulted in a major molecular ion $\left[\mathrm{M}+\mathrm{H}-\mathrm{H}_{2} \mathrm{O}\right]^{+}$ at $\mathrm{m} / \mathrm{z} 485.5$ corresponding to monolinolenyl 3,4-dihydroxyphenyl acetate, with a fragment ion $[\mathrm{M}]^{+}$at $\mathrm{m} / \mathrm{z} 351.6$ representing the monolinolenin. Peak \#3 (Fig. 11A') was identified as monolinoleyl 3,4-dihydroxyphenyl acetate, with an abundant molecular ion $\left[\mathrm{M}+\mathrm{H}-\mathrm{H}_{2} \mathrm{O}\right]^{+}$at $\mathrm{m} / \mathrm{z} 487.4$ and a fragment ion $\left[\mathrm{M}+\mathrm{H}-\mathrm{H}_{2} 0\right]^{+}$at $\mathrm{m} / \mathrm{z} 337.5$ representing monolinolein. The fragmentation of Peak\# 4 (Fig. 11A") is the characteristic pattern of monooleyl dihydroxyphenyl acetate, with an abundant molecular ion $\left[\mathrm{M}+\mathrm{H}-\mathrm{H}_{2} \mathrm{O}\right]^{+}$at $\mathrm{m} / \mathrm{z}$ 489.5 and a monoolein fragment ion $\left[\mathrm{M}+\mathrm{H}-\mathrm{H}_{2} \mathrm{O}\right]^{+}$at $\mathrm{m} / \mathrm{z}$ 339.6. An abundant molecular ion $[\mathrm{M}]^{+}$at $m / z 763.5$ corresponding to dilinolenyl 3,4-dihydroxyphenyl acetate, together with a dilinolenin fragment ion $\left[\mathrm{M}+\mathrm{H}-\mathrm{H}_{2} \mathrm{O}\right]^{+}$at $\mathrm{m} / \mathrm{z}$ 595.5, was obtained from the fragmentation of peak \#5 (Figure 11B). Fragmentation of peak \# 6 (Fig. 11B') produced a mixed phenolic mono- and diacylglycerol molecular ion $[\mathrm{M}]^{+}$at $\mathrm{m} / \mathrm{z} 765.5$ being linoleyl linolenyl 3,4-dihydroxyphenyl acetate, with fragment ions at $\mathrm{m} / \mathrm{z} 613.6$ and 337.4 corresponding to dilinolenin and monolinolein, respectively. Overall, the HPLC/LC-MS analyses confirmed the formation of three phenolic monoacylglycerols and two phenolic diacylglycerols by the Novozym-catalyzed acidolysis of fish liver oil with DHPA.

\subsection{Optimization of Lipase-Catalyzed Acidolysis Reaction}

The synthesis of phenolic lipids by the lipase-catalyzed acidolysis of fish liver oil with DHPA was optimized in terms of enzyme concentration, substrate molar ratio, organic solvent mixture ratio as well as the addition of molecular sieves and Silica gel.

\subsubsection{Effect of Enzyme Concentration on the Bioconversion Yield}

In order to maximize the bioconversion yield and reduce the reaction time, the lipasecatalyzed acidolysis reaction was carried out using a wide range of enzyme concentrations varying from 20 to $60 \mathrm{mg}$ solid Novozym 435 in a $9 \mathrm{~mL}$ mixture of hexane:2-butanone $(75: 25, \mathrm{v} / \mathrm{v})$. The effects of the enzyme concentrations on both the enzymatic activity and the bioconversion yield of phenolic lipids were investigated. 


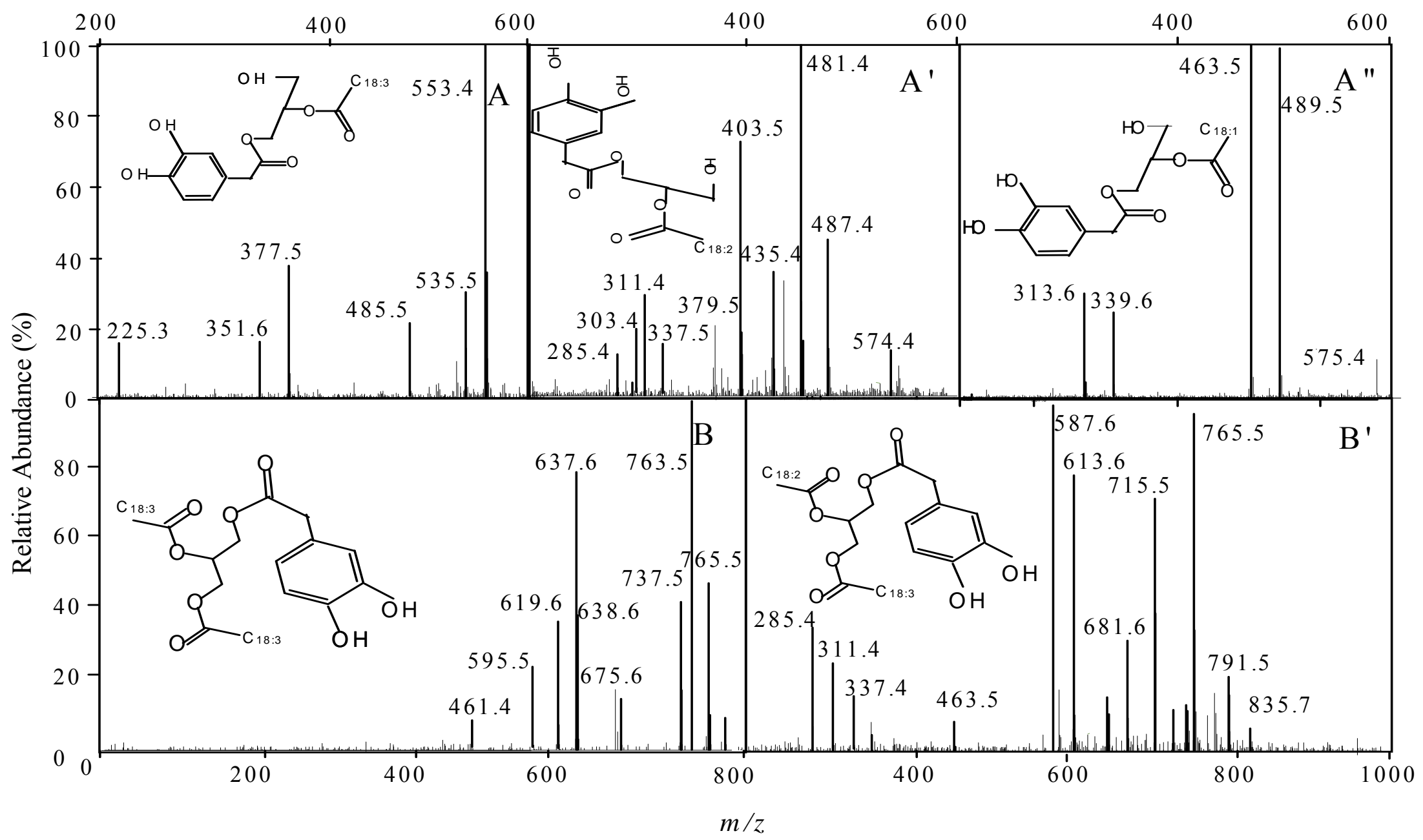

Figure 11. Atmospheric Pressure Chemical Ionization-Mass Spectrometry (APCI-MS) analysis of (A) monolinolenyl dihydroxphenyl acetate and (B) dilinolenyl dihydroxphenyl acetate, (A') monolinoleyl dihydroxyphenyl acetate, (B') linoleyl linolenyl dihydroxphenyl acetate and (A") monooleyl dihydroxyphenyl acetate. 


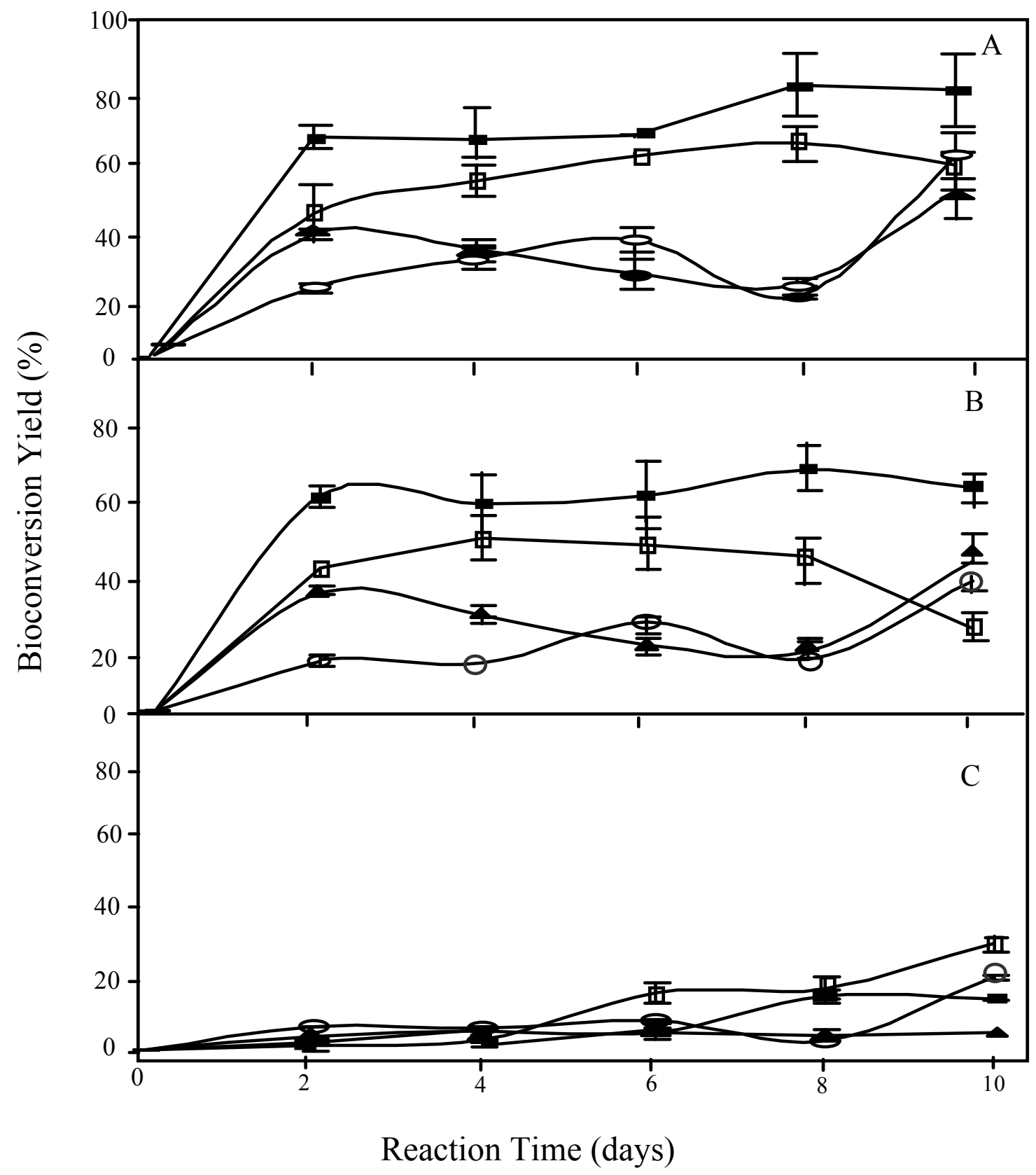

Figure 12. Effect of Novozym 435 concentration of $20 \mathrm{mg}(\mathbf{\Delta}), 30 \mathrm{mg}(\square), 50 \mathrm{mg}(\mathbf{\bullet})$, and $60 \mathrm{mg} \mathrm{(O)}$ on the bioconversion yields of total phenolic lipids (A), phenolic monoacylglycerols (B) and phenolic diacylglycerols (C) using hexane/2-butanone solvent mixture of $75: 25(\mathrm{v} / \mathrm{v})$ as reaction medium at fish liver oil to dihydroxyphenylacetic acid molar ratio of 4:1. 
The results (data not shown) indicated that the initial reaction rate increased linearly $\left(\mathrm{R}^{2}\right.$ $=0.972$ ) from 0.085 to $0.142 \mu \mathrm{mol}$ esterified phenolic acid $/ \mathrm{g}$ solid enzyme $/ \mathrm{min}$, when the lipase concentration was raised from 20 to $50 \mathrm{mg}$ of solid enzyme. Because of the enzymatic activity of lipase was remained relatively constant, with an average of 0.142 $\mu \mathrm{mol}$ esterified phenolic acid/g solid enzyme/min; these results suggest that the acidolysis reaction was kinetically controlled by the lipase within the range of 20 to 50 mg solid enzyme. However, using a higher concentration of $60 \mathrm{mg}$ solid enzyme, the enzymatic activity of lipase decreased significantly to $0.022 \mu \mathrm{mol}$ esterified phenolic $\mathrm{acid} / \mathrm{g}$ solid enzyme/min, these results may be due to the mass transfer limitation at a high enzyme concentration, which could have affected the diffusion of the substrate to the enzyme active site and hence its availability for the reaction (Palmer et al., 1995). The presence of high protein-support interactions as a result of an excess of the enzyme could have altered its active conformation and hence its catalytic efficiency (Colombie et al., 1998; Yadav and Lathi, 2003). Steric hindrance of the enzyme active site may have also contributed to a decrease in the enzymatic activity at high enzyme concentrations (Hadzir et al., 2001).

The time course of the bioconversion yield of the acidolysis reaction of fish liver oil with DHPA at different lipase concentrations is shown in Figure 12. Using $50 \mathrm{mg}$ of solid Novozym 435, the acidolysis of fish liver oil was rapidly achieved within the first 2 days of the reaction, reaching a bioconversion yield of total phenolic lipids of $67.4 \%$, which was increased with a slower extent to 83.0 and $81.7 \%$ after 8 and 10 days, respectively. Using $30 \mathrm{mg}$ of solid Novozym 435, the biosynthesis of total phenolic lipids increased rapidly within the first 2 days of reaction to $43.5 \%$ and thereafter with a lower extent, reaching its maximum of $64.8 \%$ after 8 days of reaction; however, after an additional two days, the maximum bioconversion yield was decreased to $58.1 \%$. The limited increase in the bioconversion yield after 2 days of reaction may be due to the increase in the concentrations of glycerol and or/free fatty acid as by-products as a result of the hydrolysis of TAGs. Indeed, the accumulation of glycerol molecules on the enzyme micro-environment may have led to the formation of the hydrophilic hindrance layer, limiting the substrate diffusion and hence the bioconversion yield of phenolic lipids 
(Stevenson et al., 1994; Castillo et al., 1997; Dossat et al., 2002). Similarly, Karboune et al. (2005) reported that the formation of a hydrophilic hindrance layer of glycerol around the enzyme molecule could be a valid explanation for the limited increase in the bioconversion yield. In addition, Awang et al. (2005) showed that an excess of Novozym 435 ( $>0.2 \mathrm{~g})$ did not increase the esterification yield of oleic acid with oleyl alcohol; these authors attributed such results to the saturation point, at which all the substrates are bounded to the enzyme and any excess of the enzyme will lack the required amount of substrate needed for the formation of enzyme-substrate complex. The increase in enzyme concentration without the presence of adequate amount of substrate resulted by a decrease in the esterification yield (Hoq et al., 1985; Gandhi et al., 2000; Hari et al., 2002). Senanayake and Shahidi (2002) indicated that the extent of DHA incorporation was increased by increasing the amount of the enzyme in the mixture; however a significant increase was not obtained when the amount of enzyme was greater than 100 units.

The results (Fig. 12) also show that the extent of the bioconversion yield of phenolic monoacylglycerols over the reaction course was higher than that of phenolic diacylglycerols. The highest bioconversion yield of phenolic monoacylglycerols and diacylglycerols was achieved using 50 and $30 \mathrm{mg}$ of solid Novozym 435, respectively. Using $50 \mathrm{mg}$ solid Novozym 435, the acidolysis of fish liver oil was rapidly achieved within the first 2 days of the reaction, reaching a bioconversion yield of phenolic monoacylglycerols of $62.5 \%$, which was increased with a lower extent to 70.0 and $64.9 \%$ after 8 and 10 days, respectively. However, using $30 \mathrm{mg}$ of solid Novozym 435, the bioconversion yield of phenolic diacylglycerols increased steadily reaching its maximum of $34.2 \%$, after 10 days. The effect of enzyme concentration on the reaction selectivity may be due to the mass action effect and/or the reaction equilibrium (Compton et al., 2000; Wei et al., 2003; Karboune et al., 2005).

On the basis of these findings, $50 \mathrm{mg}$ of solid Novozym 435 was found to be the most effective biocatalyst amount for the incorporation of DHPA into fish liver oil and consequently used for further investigation throughout this study. 


\subsubsection{Effect of Organic Solvent Mixture Ratio on the Bioconversion Yield}

The effect of varying the ratio of hexane:2-butanone solvent mixture from 65:35 to 85:15 $(\mathrm{v} / \mathrm{v})$ on the bioconversion yield of phenolic lipids was investigated (Fig. 13, Table 3). Yan et al. (2002) have reported that 2-butanone and hexane are appropriate solvents for their use in the production of edible food due to their low solvent toxicity. In addition, such binary solvent mixtures have resulted in higher bioconversion yields and enzymatic activities (Lue et al., 2005; Sabally et al., 2005a,b). Laane et al. (1987) has indicated that the most effective organic solvents are those with relatively high $\log \mathrm{P}$ values, higher than 2.5.

The results (Table 3) show that lipase-catalyzed acidolysis reaction in the hexane:2butanone reaction mixture of $65: 35$ and 85:15 (v/v) resulted in relatively low enzymatic activity of 0.018 and $0.001 \mu \mathrm{mol}$ esterified phenolic acid/g solid enzyme/min, respectively, and low maximum bioconversion yield of phenolic lipids of 34.1 and $26.9 \%$, respectively. In contrast, much higher enzymatic activity of $0.142 \mu$ mol esterified phenolic acid/g solid enzyme/min and maximum bioconversion yield of $83.0 \%$, were obtained when the organic solvent mixture ratio of 75:25 (v/v) was used (Fig. 13); in addition, the organic solvent mixture at a ratio of 75:25 (v/v) favored the production of the phenolic monoacylglycerols (70.3\%) rather than the phenolic diacylglycerols $(13.0 \%)$. While at a ratio of $85: 15(\mathrm{v} / \mathrm{v})$, the maximum bioconversion yield of phenolic monoacylglycerols $(11.0 \%)$ was comparable to that of the phenolic diacylglycerols (15.8\%). On the other hand, the time course (Fig. 13) indicates that using solvent ratio of 75:25 (v/v), the equilibrium reaction was reached after 2 days, whereas at ratios of 65:35 and 85:15 (v/v), the reaction equilibrium was not achieved.

The decreases in enzyme activity and bioconversion yield (Fig. 13, Table 3) at a higher 2butanone proportion could be attributed to the solvents stripping effect on the water layer surrounding the enzyme molecule, which is essential for its activity (Carrea et al., 2000; Sabally et al., 2005a). In addition, the changes in the enzyme microenvironment induced by the nature of the organic solvents could explain the low bioconversion yield in the polar medium (Halling, 2002). Furthermore, the variation in the bioconversion yield and enzyme activity with the organic solvent ratio may be due to the substrate-solvent 


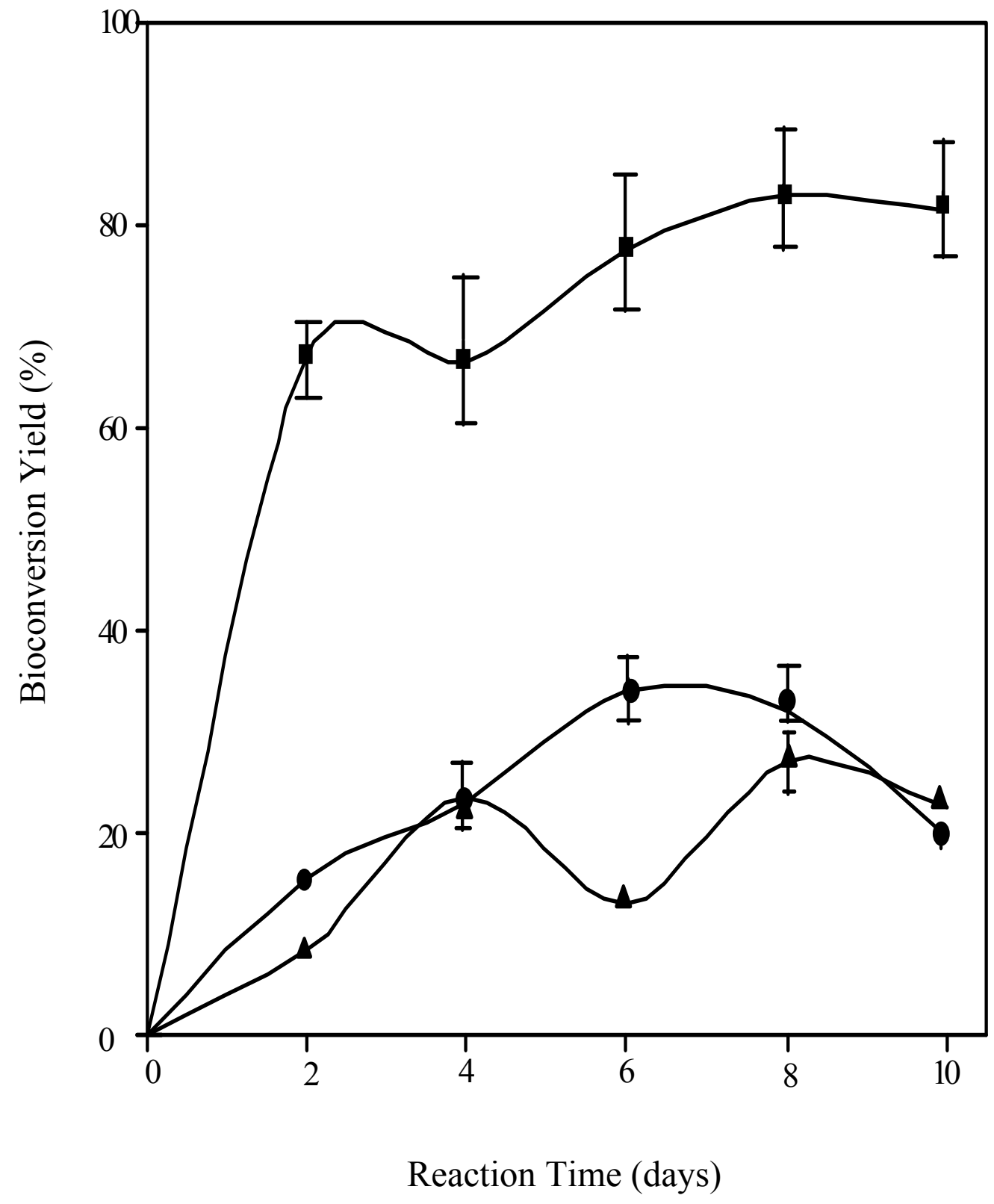

Figure 13. Effect of hexane:2-butanone organic solvent mixture ratio of 85:15 ( $\mathbf{\Lambda})$, 75:25(•) and 65:35 (•) on the bioconversion yield of total phenolic lipids throughout 10 days of Novozym 435-catalyzed acidolysis reaction of fish liver oil with dihydroxyphenylacetic acid. 
Table 3. Effect of organic solvent mixture on the enzyme activity and the bioconversion yield of Novozym 435-catalyzed acidolysis of fish liver oil with dihydroxyphenylacetic acid.

\section{Maximum Bioconversion Yield ${ }^{\mathrm{a}}$}

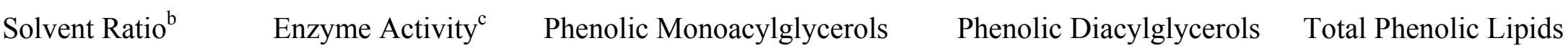

\begin{tabular}{llccc}
\hline $65: 35(\mathrm{v} / \mathrm{v})^{\mathrm{d}}$ & 0.018 & $27.4(4.0)^{\mathrm{e}}$ & $6.6(0.2)^{\mathrm{e}}$ & $34.1(5.3)^{\mathrm{e}}$ \\
$75: 15(\mathrm{v} / \mathrm{v})^{\mathrm{f}}$ & 0.142 & $70.0(13.2)^{\mathrm{e}}$ & $13.0(1.9)^{\mathrm{e}}$ & $83.0(9.9)^{\mathrm{e}}$ \\
$85: 15(\mathrm{v} / \mathrm{v})^{\mathrm{f}}$ & 0.001 & $11.0(0.4)^{\mathrm{e}}$ & $15.8(0.9)^{\mathrm{e}}$ & $26.9(2.6)^{\mathrm{e}}$ \\
\hline
\end{tabular}

${ }^{\mathrm{a}}$ The maximum bioconversion yield in percent was calculated as the total peak area of the phenolic lipids, monitored at $280 \mathrm{~nm}$, at defined reaction time divided by the area of the phenolic acid of the blank multiplied by 100 .

${ }^{\mathrm{b}}$ Acidolysis reaction was carried out in hexane and 2-butanone solvent mixture at different ratios using fish liver oil to dihydroxyphenylacetic acid molar ratio of 4:1.

${ }^{c}$ Enzymatic activity was defined as the concentration of consumed phenolic acid in $\mu$ mol per $g$ of solid enzyme per min of reaction.

d Maximum bioconversion yield was reached after 6-day reaction period.

${ }^{\mathrm{e}}$ Relative standard deviation (RSTD) was calculated from the standard deviation of triplicate samples divided by their mean multiplied by 100 .

${ }^{\mathrm{f}}$ Maximum bioconversion yield was reached after 8-day reaction period. 
interactions, which could affect the partition coefficients of substrates as well as products and subsequently the overall activity of the enzyme-catalyzed reaction (Wehtje and Aldercreutz, 1997). On the other hand, the polarity of the reaction medium, which affects the substrate and product partition, has a great affect on the selectivity of the acidolysis reaction medium (Halling, 2002; Sabally et al., 2006a). Since diacylglycerols and phenolic diacylglycerols are less polar than monoacylglycerols and phenolic monoacylglycerols; they are more soluble in the non-polar medium. Hence, increasing the ratio of hexane in the mixture would favor shifting the thermodynamic equilibrium towards the synthesis of phenolic diacylglycerols. Table 3 indicates that using a hexane:2-butanone mixture of 85:15 (v/v), the reaction was favored for the synthesis of phenolic diacylglycerols $(15.8 \%)$ rather than the phenolic monoacylglycerols $(11.0 \%)$. Increasing the amount of hexane in the reaction medium has shown (Table 3) a trend which resulted in an increase in the conversion of phenolic diacylglcyerols rather than phenolic monoacylglycerols, this is probably due to an increase in the concentration of the diacylglycerol precursors in the enzyme microenvironment (Sabally et al., 2007). Such a trend is usually achieved by the effects of solvent polarity on the acylglycerols composition of the products and the degree of transesterification reactions through the availability of substrates (Yang et al., 2003). The experimental results (Table 3) are in agreement with those reported by Karboune et al. (2005) and Sabally et al. (2006b). Sabally et al. (2006b) indicated that by increasing the amounts of the more polar solvent, 2-butanone in the reaction mixture, from $65: 35$ to $85: 15(\mathrm{v} / \mathrm{v})$, resulted by a decrease in the synthesis of phenolic monoacylglycerols from 34 to $31.8 \%$ and an increase in the production of phenolic diacylglycerols, from 25.1 to $55.8 \%$, in the transesterification of dihydrocaffeic acid with flaxseed oil. These authors concluded that the best organic solvent mixture for the production of phenolic monoacylglycerols (40.3\%) was a mixture of 75:25 (v/v) of hexane:2-butanone, whereas a mixture of 85:15 (v/v) favored the biosynthesis of phenolic diacylglycerols (36.8\%).

The overall results indicated that, under the experimental conditions, hexane:2-butanone $(75: 15, \mathrm{v} / \mathrm{v})$ was the most appropriate solvent mixture for the biosynthesis of phenolic 
lipids and consequently used as the reaction medium for further investigations throughout this study.

\subsubsection{Effect of Substrate Molar Ratio on the Bioconversion Yield}

In order to maximize the bioconversion yield of the Novozym 435-catalyzed acidolysis reaction, the effect of substrate molar ratio was investigated using a wide range of fish liver oil and DHPA ratios, including 1:1, 2:1, 4:1, 6:1 and 8:1.

Figure 14 illustrates the profile of the bioconversion yield of total phenolic lipids over the course of a 10-day reaction period. Using substrate molar ratios of $4: 1,6: 1$, and $8: 1$, the total bioconversion yield of phenolic lipids was increased significantly within the first 4 days of reaction, and thereafter to a lower extent reaching a maximum value of 83.0, 40.8 and $52.1 \%$, respectively, after 8-days; above this reaction time, the bioconversion yield was decreased to $81.3,31.3$ and $44.3 \%$, respectively. In contrast, with the substrate molar ratios of $1: 1$ and $2: 1$, the bioconversion yield was steadily increased over the 10-day reaction time, with a maximum total bioconversion yield of 38.1 and $60.9 \%$, respectively. The increase in the bioconversion yield of phenolic lipids in the presence of an excess of fish liver oil could be explained by the effects of the polarity and viscosity of the reaction medium on the availability of substrate to the enzyme (Wei et al., 2003; Karboune et al., 2005). Furthermore, the decrease in the bioconversion yield, obtained at the ratios of 6:1

and $8: 1$, could be due to a shift in the thermodynamic equilibrium reaction, which may be promoted by an increase in the concentrations of glycerol and/or free fatty acid resulted from the hydrolysis of the triacylgycerols of fish liver oil (Dossat et al., 1999).

In addition as the substrate molar ratio increased from $1: 1$ to $4: 1$, an increase in the enzymatic activity from 0.013 to $0.142 \mu \mathrm{mol}$ esterified phenolic acid $/ \mathrm{g}$ solid enzyme $/ \mathrm{min}$ was obtained along with a decrease afterwards to $0.030 \mu \mathrm{mol}$ esterified phenolic acid/g solid enzyme/min at a substrate molar ratio of 8:1 (Table 4). These findings indicate that an excess of fish liver oil may have had an inhibitory effect on the enzyme itself or by affecting the substrate partition (Compton et al., 2000; Karboune et al., 2005). Similarly, Köse et al. (2002) also reported on the Novozym 435-catalyzed alcoholysis of cotton 


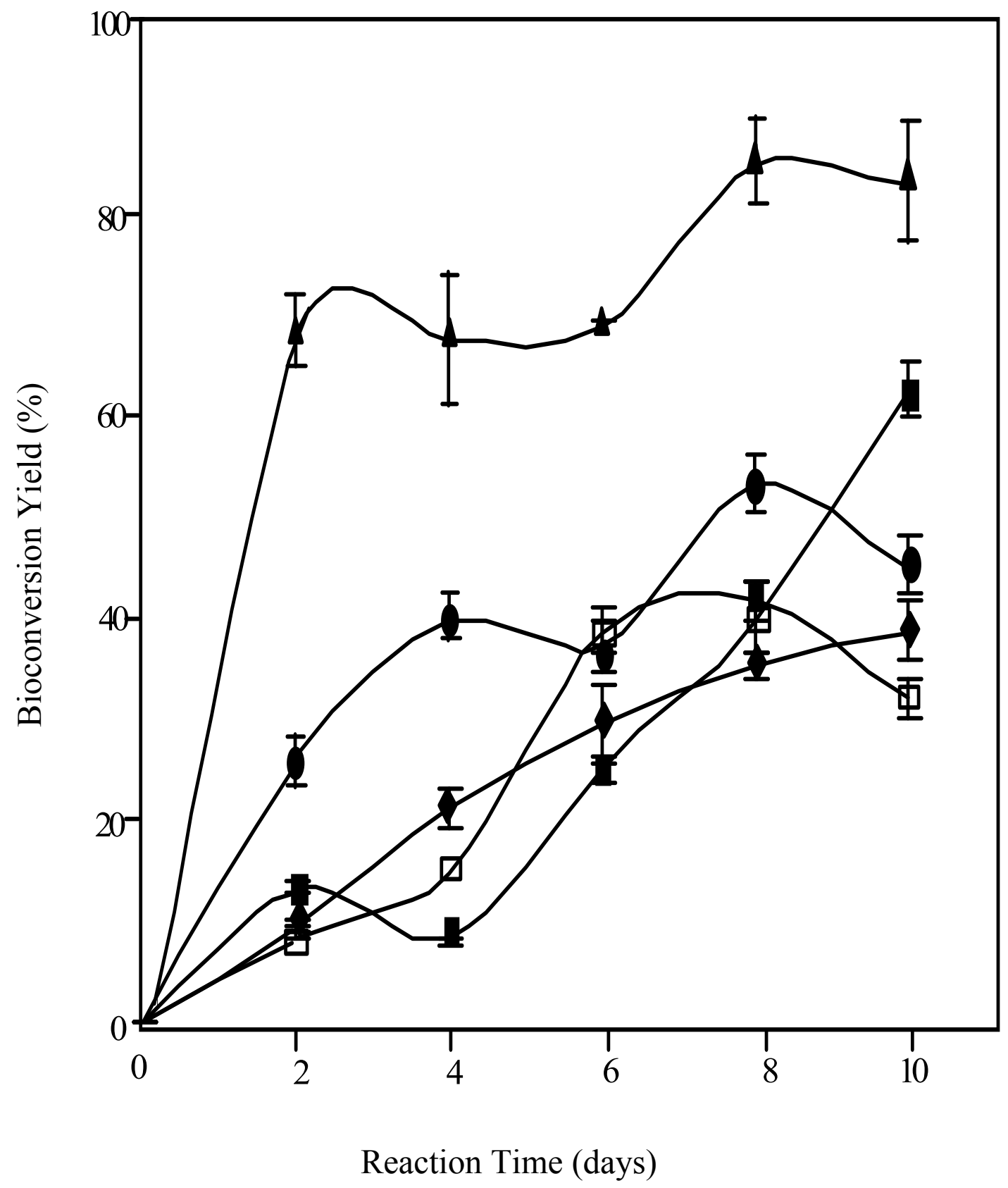

Figure 14. Time course for the acidolysis reaction of fish liver oil with dihydroxyphenyl-

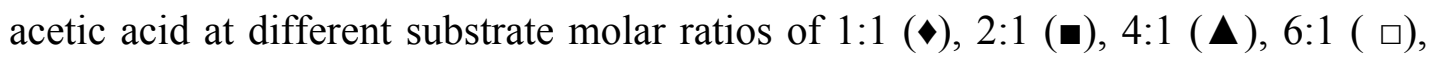
and $8: 1(\bullet)$. 
Table 4. Effect of molar substrate ratio on the enzyme activity and the bioconversion yield of Novozym 435-catalyzed acidolysis of fish liver oil with dihydroxyphenylacetic acid.

\section{Maximum Bioconversion Yield}

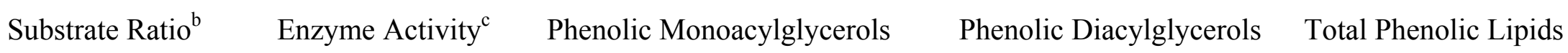

\begin{tabular}{llccc}
\hline $1: 1^{\mathrm{d}}$ & 0.013 & $35.3(3.4)^{\mathrm{e}}$ & $2.3(0.1)^{\mathrm{e}}$ & $38.2(3.0)^{\mathrm{e}}$ \\
$2: 1^{\mathrm{d}}$ & 0.083 & $49.3(5.9)^{\mathrm{e}}$ & $11.6(0.4)^{\mathrm{e}}$ & $60.9(5.4)^{\mathrm{e}}$ \\
$4: 1^{\mathrm{d}}$ & 0.142 & $70.0(13.2)^{\mathrm{e}}$ & $13.0(1.9)^{\mathrm{e}}$ & $83.0(9.9)^{\mathrm{e}}$ \\
$6: 1^{\mathrm{f}}$ & 0.008 & $34.8(2.9)^{\mathrm{e}}$ & $5.9(2.4)^{\mathrm{e}}$ & $40.8(2.5)^{\mathrm{e}}$ \\
$8: 1^{\mathrm{f}}$ & 0.030 & $46.3(9.4)^{\mathrm{e}}$ & $5.8(0.2)^{\mathrm{e}}$ & $52.1(9.1)^{\mathrm{e}}$ \\
\hline
\end{tabular}

\footnotetext{
${ }^{\mathrm{a}}$ The maximum bioconversion yield in percent was calculated as the total peak area of the phenolic lipids, monitored at $280 \mathrm{~nm}$, at defined reaction time divided by the area of the phenolic acid of the blank multiplied by 100 .

${ }^{\mathrm{b}}$ Acidolysis reaction was carried out in hexane:2-butanone solvent mixture (75:25, v/v) at different fish liver oil to dihydroxyphenylacetic acid molar ratios.

${ }^{c}$ Enzymatic activity was defined as the concentration of consumed phenolic acid in $\mu$ mol per $g$ of solid enzyme per min of reaction.

$\mathrm{d}$ Maximum bioconversion yield was reached after 10-day reaction period.

${ }^{e}$ Relative standard deviation (RSTD) was calculated from the standard deviation of triplicate samples divided by their mean multiplied by 100.

f Maximum bioconversion yield was reached after 8-day reaction period.
} 
seed oil with methanol; these authors indicated that the highest methyl esters yield $(84.7 \%)$ was obtained at a 1:4 oil/alcohol molar ratio, whereas the decrease in activity and yield was obtained at higher concentrations of methanol distorted the essential water layer and decreasing hence the enzymatic activity. The effect of the substrate molar ratio on the selectivity of the formation of mono- and diacylglycerols is shown in Table 4. The results indicate that the bioconversion yield of mono- and diacylglycerols increased significantly from 35.3 to $70.0 \%$ and 2.3 to $10.0 \%$, respectively, when the fish liver oil and DHPA ratio was increased from 1:1 to 4:1. However, a decrease in the formation of diacylglycerols was relatively constant thereafter, $5.8-5.9 \%$, with the use of fish liver oil and DHPA at the ratio of $6: 1$ and $8: 1$, respectively. These results suggest that the nonpolar fish liver oil seemed to have favored the synthesis of the phenolic monoacylglycerols. These experimental findings are in agreement with those obtained previously in our laboratory (Karboune et al., 2005; Sabally et al., 2007b). Similarly Karboune et al. (2005) reported on the reaction selectivity of the formation of cinnamoylated monolein and diolein in the transesterification of triolein with cinnamic acid. These authors indicated that the production of cinnamoylated monolein increased significantly from 15 to $27 \%$ when the cinnamic acid to triolein molar ratio was changed from 1:1 to $1: 4.5$, whereas the production of cinnamoylated diolein increased from 4 to $21 \%$ when the substrate molar ratio was decreased from 1:1 to 1:6. In addition, Sabally et al. (2006b) reported that a dihydrocafffeic acid and flaxseed oil ratio of 1:4 resulted in the production of both phenolic mono and diacylglycerols, with transesterification yield of 39.6 and $27.8 \%$ respectively; however, when a 1:8 ratio was used, the transesterification yield of phenolic diacylglycerols $(46.0 \%)$ was higher than that of the phenolic monoacylglycerols (33.3\%). Because of the complexity of the investigated lipasecatalyzed reaction and the involvement of hydrolysis, esterification and acidolysis reactions, it would be difficult to draw a simple reaction scheme (Karboune et al., 2005). Nevertheless, the overall effect of substrate ratio on the reaction selectivity may be attributed to the effect of oil on the polarity of the enzyme micro-environment, which may have affected the availability of the substrates to the enzyme (Dossat et al., 2002). 
The overall results indicated that under the experimental conditions, a molar substrate ratio of 4:1 of fish liver oil and DHPA was found to be the most appropriate one for the biosynthesis of phenolic lipids, and consequently it was used for further investigations throughout this study.

\subsubsection{Effect of Molecular Sieve on the Bioconversion Yield}

In order to maximize the bioconversion yield, by shifting the thermodynamic reaction towards synthesis rather than hydrolysis, a reduction of water content in the reaction mixture was attempted by the addition of molecular sieve pellets as dehydrating agents.

Using a 4:1 molar substrate ratio of fish liver oil and DHPA in the hexane:2-butanone $(75: 25 \mathrm{v} / \mathrm{v})$ reaction mixture, the addition of $10 \mathrm{mg} / \mathrm{mL}$ of molecular sieves resulted in 49.4 and $57.3 \%$ decrease in the maximum bioconversion yield of total phenolic lipids and phenolic monoacylglycerols, respectively (Fig. 15). These experimental findings may be due to the fact that the substrates, fish liver oil and DHPA, were adsorbed in the molecular sieve, hence limiting their availability to the enzyme (Halling, 2002). The results (Fig. 15) could also be attributed to the ability of the molecular sieve to strip off the essential water layer from the enzyme surface, hence distorting the water-enzyme interactions. In contrast to the phenolic monoacylglycerols, a slight increase of $8.3 \%$ in the bioconversion yield of phenolic diacylglycerols was obtained upon the addition of the molecular sieve (Fig. 15). Cerdan et al. (1998) have reported a decrease in the esterification yield of cod liver oil and glycerol by increasing the amount of molecular sieves from 1 to $4 \mathrm{~g} / 9 \mathrm{~mL}$. Similarly, Karboune et al. (2005) has shown that the addition of $10 \mathrm{mg} / \mathrm{mL}$ of molecular sieves to the reaction mixture resulted in a 28 and $35 \%$ decrease in the maximum bioconversion yield of cinnamoylated lipids. The literature has also indicated that the time of addition of the molecular sieves could affect the reaction activity (Zu Yi et al., 1993; Cerdan et al., 1998). The tendency of the triacylgycerol synthesis to increase when the molecular sieves are added at a later stage in the lipasecatalyzed reaction may be due to the removal of water during the initial enzymatic bioconversion (Medina et al., 1999). In addition, Martinez, et al. (2004) have suggested that the addition of molecular sieves should have been preceded in the later stages of the 


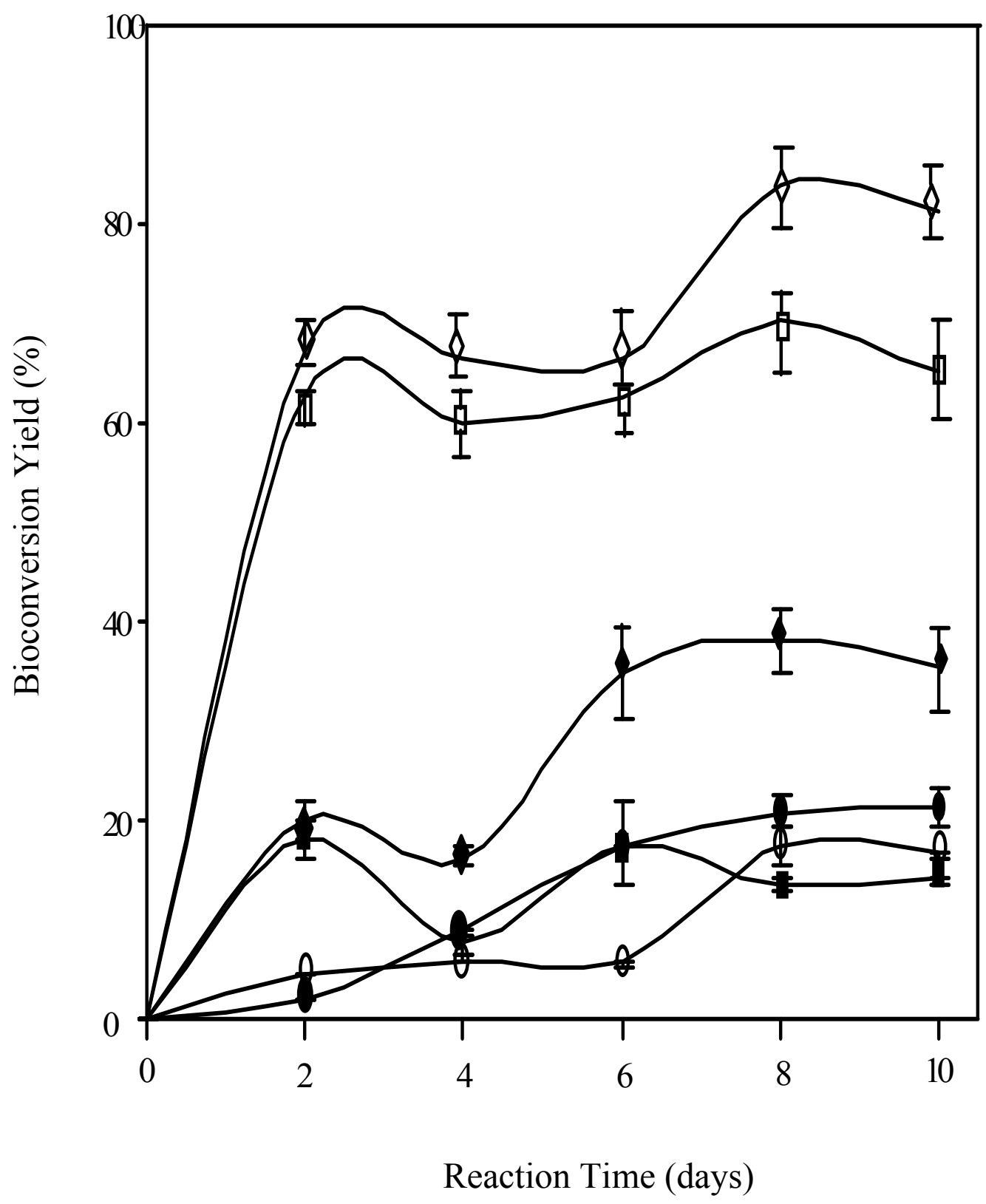

Figure 15. Time course for the acidolysis reaction of fish liver oil with dihydroxphenylacetic acid in the presence of molecular sieve [(total phenolic lipids ( $\$$ ) phenolic monoacylglycerols (๘) and phenolic diacylglycerols (•)] and in the absence of molecular sieve [total phenolic lipids $(\diamond)$, phenolic monoacylglycerols (๑) and phenolic diacylglcyerols $(0)$ ]. 
reaction, involving both hydrolysis and synthesis. Hence, any excess water content would decrease the TAGs yield because since water is a product of the esterification reaction the equilibrium is therefore displaced towards the hydrolysis (Medina et al., 1999).

\subsubsection{Effect of Silica Gel on the Bioconversion Yield}

In order to limit the formation of the glycerol hydrophilic hindrance layer in the enzyme microenvironment, the addition of Silica gel in the reaction mixture was investigated. Using a 4:1 molar substrate ratio of fish liver oil and DHPA in a 75:25 (v/v) hexane:2butanone solvent mixture, the biosynthesis of phenolic lipids was investigated upon the addition of Silica gel at a concentration of $1.5,2.5$ and $5.5 \mathrm{mg} / \mathrm{mL}$. Table 5 summarizes the experimental findings on the maximum bioconversion yields of phenolic mono-, diacylglycerol and total lipids in the presence of different concentrations of Silica gel. The results show that the increase in the concentration of Silica gel from 1.5 to 2.5 $\mathrm{mg} / \mathrm{mL}$ resulted in a limited increase in the bioconversion yield of total phenolic lipids, from 21.0 to $22.5 \%$; however, the addition of Silica gel at a concentration of $5.5 \mathrm{mg} / \mathrm{mL}$ resulted in a more dramatic increase in the bioconversion yield to $41.4 \%$. On the other hand, upon increasing the concentration of Silica gel from 1.5 to $5.5 \mathrm{mg} / \mathrm{mL}$, the enzymatic activity decreased from 0.027 to $0.015 \mu \mathrm{mol}$ esterified phenolic acid/g solid enzyme/min. However, in the absence of Silica gel, the acidolysis reaction resulted in higher bioconversion yield and enzymatic activity of $83.0 \%$ and $0.142 \mu \mathrm{mol}$ esterified phenolic acid/g solid enzyme/min, respectively. These findings could be explained by the dehydrating effect of Silica gel on the enzyme, which may have resulted to its inactivation (Castillo et al., 1997). Similarly, Karboune et al. (2005) also reported an increase in the maximum bioconversion yield of cinnamoylated lipids, from 42 to $55 \%$ upon the addition of Silica gel to the reaction mixture; however, the bioconversion yield significantly declined upon an increase in its concentration, concluding hence that the amount of Silica gel must be well determined before its use. On the basis of the experimental findings (Table 5), it was concluded that the acidolysis reaction was shown to be more effective in the absence of Silica gel. 
Table 5. Effect of Silica gel on the enzyme activity and the bioconversion yield of Novozym 435-catalyzed acidolysis of fish liver oil with dihydroxylphenylacetic acid.

\section{Maximum Bioconversion Yield}

\begin{tabular}{|c|c|c|c|}
\hline Concentration $^{\mathrm{b}}$ & Enzyme Activity $^{\mathrm{c}}$ & Phenolic Monoacylglycerols & Phenolic Diacylglycerols \\
\hline
\end{tabular}

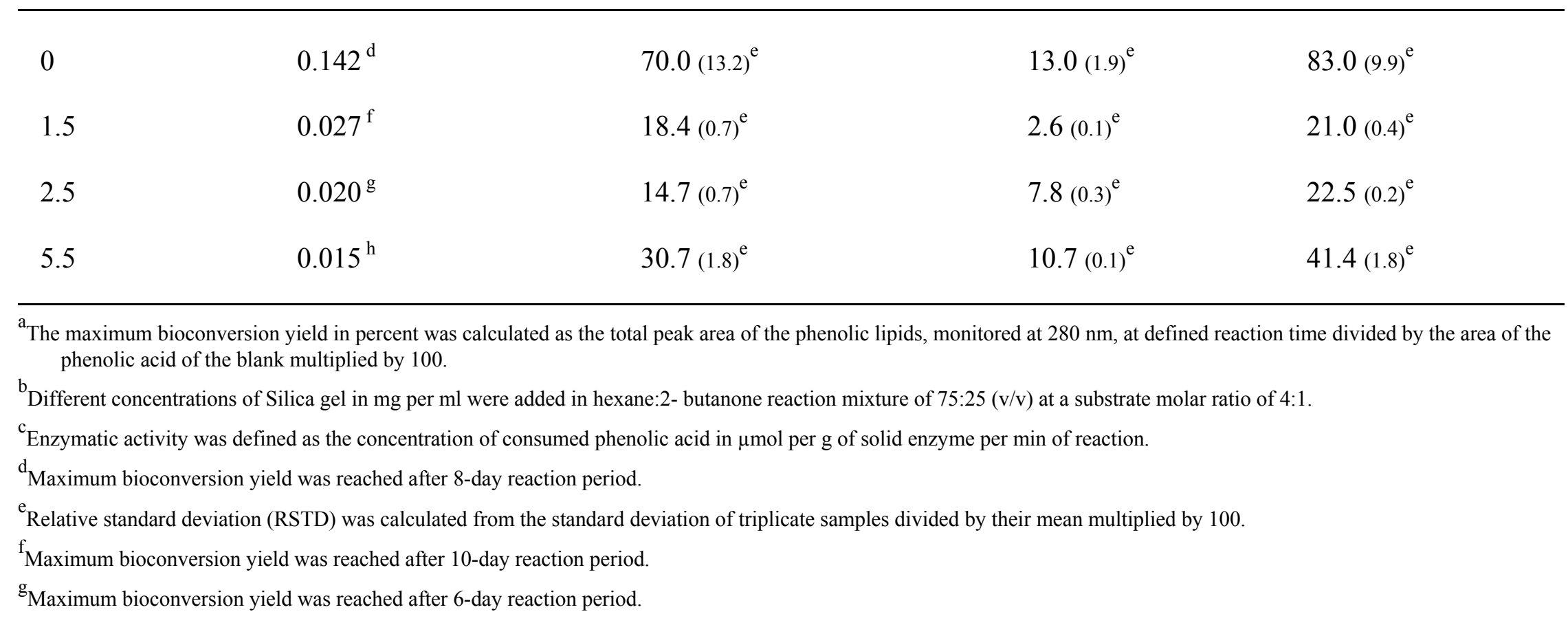




\subsubsection{Determination of the Fatty Acid Composition of Phenolic Lipids}

In order to determine and quantify the relative fatty acid composition of the end products the residual fish liver oil and the phenolic mono- and diacylglycerols fractions, recovered by preparative TLC, were subjected to gas-liquid chromatography (GLC). Fish liver oil contains approximately 29 different fatty acids (data not shown); however, the 9 major fatty acids were identified to be $\mathrm{C}_{14: 0} \mathrm{C}_{16: 0}, \mathrm{C}_{18: 0}, \mathrm{C}_{18: 1}, \mathrm{C}_{18: 2}, \mathrm{C}_{18: 3}, \mathrm{C}_{20: 4}, \mathrm{C}_{20: 5}$, and $\mathrm{C}_{22: 6}$ (Table 6). The most abundant fatty acids include $\mathrm{C}_{16: 0}(20.1 \%), \mathrm{C}_{18: 2}(16.8 \%), \mathrm{C}_{20: 5} n-3$ (11.5\%), and $\mathrm{C}_{22: 6} n-3(20.2 \%)$. The GLC analysis (Table 6) indicated that the acidolysiscatalyzed reaction resulted by a significant increase in the proportions of the two highly desirable essential fatty acids, $\mathrm{C}_{20: 5} n-3$ (EPA) and $\mathrm{C}_{22: 6} n-3$ (DHA). In addition, the results show that the bioconversion process resulted by an increase of the proportion of $\mathrm{C}_{20: 5} n-3$ from 11.5 to $27.1 \%$ and $22.6 \%$ in the phenolic mono- and diacylglycerols, respectively, as compared to that of the unmodified fish liver oil. Table 6 also indicates that the acidolysis-reaction resulted by a slight increase in the proportions of $\mathrm{C}_{22: 6} n-3$ from 20.2 to $23.1 \%$ and $22.8 \%$ in the phenolic mono- and diacylglycerols, respectively. However, the relative proportions of the $\mathrm{C}_{16: 0}$ decreased from 20.1 to 12.1 and $5.6 \%$ in the phenolic mono- and diacylglycerols, respectively. The acidolysis of fish liver oil with DHPA resulted by an increase in the proportions of the longer chain FA, $\mathrm{C}_{20: 5} n-3$ and $\mathrm{C}_{22: 6}$ n-3 in the phenolic lipids, while there was a decrease in the shorter FA chain, $\mathrm{C}_{16: 0 \text {. }}$ These results suggest that Novozym 435 has a lower specificity and stereoselectivity towards the exchange of the $\mathrm{C}_{20: 5} n-3$ and $\mathrm{C}_{22: 6} n-3$ acyl groups with that of the phenolic acid as compared to those of $\mathrm{C}_{16: 0}$ and $\mathrm{C}_{18: 2}$ n-6 (Ramirez et al., 2003). In contrast, Sabally et al. (2007) reported a decrease in the proportions of longer chained FAs and an increase in the shorter ones in the phenolic mono- and diacylglcyerols, upon the incorporation of dihydrocaffeic acid in fish liver oil. These findings could have revealed that the presence of an excess amount of the more non-polar fish liver oil (8:1 ratio) to the reaction mixture manifested a higher specificity towards the synthesis of the more non-polar shorter chained fatty acids. Similarly, Hill et al. (1990) reported a decrease in the proportions of shorter chain FA, $\mathrm{C}_{18: 2}$ and a two fold increase in the longer chain FA, $\mathrm{C}_{22: 5}$ and $\mathrm{C}_{20: 6}$, upon the esterification of cod liver oil and primrose oil. 
Table 6. Relative fatty acid composition of fish liver oil before and after its acidolysis with dihydroxyphenylacetic acid at 4:1 molar substrate ratio in hexane:2-butanone mixture $(75: 25, \mathrm{v} / \mathrm{v})$.

\begin{tabular}{|c|c|c|c|}
\hline \multirow[b]{2}{*}{ Fatty Acid } & \multicolumn{3}{|c|}{ Relative Fatty Acid (\%) } \\
\hline & Fish Liver Oil & Phenolic Monoacylglycerols & Phenolic Diacylglycerols \\
\hline $\mathrm{C} 14: 0$ & $6.7(2.4)^{b}$ & $11.2(2.8)^{b}$ & $4.5(1.7)^{b}$ \\
\hline $\mathrm{C} 16: 0$ & $20.1(3.7)^{b}$ & $12.1(2.5)^{b}$ & $5.6(1.2)^{b}$ \\
\hline C18:0 & $9.6(3.8)^{b}$ & $5.8(4.2)^{b}$ & $13.5(8.4)^{b}$ \\
\hline C18:1 n-9 & $3.4(7.0)^{b}$ & $3.4(0.4)^{\mathrm{b}}$ & $3.7(2.6)^{b}$ \\
\hline C18:2 n-6 & $16.8(3.5)^{b}$ & $3.5(4.0)^{b}$ & $11.8(5.3)^{\mathrm{b}}$ \\
\hline $\mathrm{C} 18: 3 n-3$ & $4.5(2.7)^{\mathrm{b}}$ & $8.9(3.2)^{b}$ & $6.7(6.3)^{b}$ \\
\hline C20:4 n-6 & $7.2(7.8)^{b}$ & $4.9(3.4)^{b}$ & $8.8(2.6)^{b}$ \\
\hline $\mathrm{C} 20: 5 n-3$ & $11.5(3.5)^{b}$ & $27.1(1.2)^{b}$ & $22.6(5.2)^{b}$ \\
\hline $\mathrm{C} 22: 6 n-3$ & $20.2(6.8)^{\mathrm{b}}$ & $23.1(1.4)^{\mathrm{b}}$ & $22.8(6.2)^{\mathrm{b}}$ \\
\hline
\end{tabular}

\footnotetext{
${ }^{a}$ Relative fatty acid composition was calculated by the percentage composition of each fatty acid divided by the fatty acid of the fish liver oil multiplied by 100

${ }^{\mathrm{b}}$ Relative standard deviation (RSTD) was calculated from the standard deviation of duplicate samples divided by their mean multiplied by 100 .
} 


\subsection{Determination of the Radical Scavenging Activity of Phenolic Lipids}

Among naturally occurring phenolic compounds, phenolic acids and their derivatives are recognized as natural potent antioxidants, exhibiting radical scavenging activity (Silva et al., 2000). It has been noted that the radical scavenging activity of phenolic acids and their derivatives is dependent on the number of hydroxyl and methoxyl groups on the benzene ring (Graf, 1992; Cuppett et al., 1997).

The radical scavenging activity of DHPA and its phenolic lipid ester toward a stable free radical $\mathrm{DPPH}^{*}$ was evaluated and compared with that of $\alpha$-tocopherol. Figure 16 shows that the steady state of the radical scavenging reaction of $\mathrm{DPPH}^{*}$ with 3,4dihydroxyphenylacetoylated lipids, DPHA and $\alpha$-tocopherol, was reached within 10 mins. The DPHA demonstrated the highest radical scavenging activity (86.0\%) compared to that of its ester with fish liver oil (18.5\%) and $\alpha$-tocopherol $(34.0 \%)$. The experiment findings (Fig. 16) suggest that the esterification of DHPA reduced its scavenging activity. DHPA has a side chain connected to the aromatic ring by single bond which allows the phenyl group to have a certain flexibility to rotate. Therefore, the attachment of a monoor diacyglycerol moiety to the side chain of the phenolic acid may have reduced or restricted the rotation degree of the phenyl moiety along the side chain, leading hence to a reduction in its ability to scavenge the free radicals (Silva et al., 2000; Sabally et al., 2006a). Similarly, Sabally et al. (2006b) reported that the phenolic acid, dihydrocaffeic acid, showed higher radical scavenging ability (62\%), whereas the phenolic lipids and $\alpha-$ -tocopherol scavenged 19.0 and $40.1 \%$ of the radical DPPH', respectively. Overall, the 3,4- dihydroxyphenylacetoylated lipids demonstrated a certain radical scavenging ability, indicating their potential as antioxidants. 


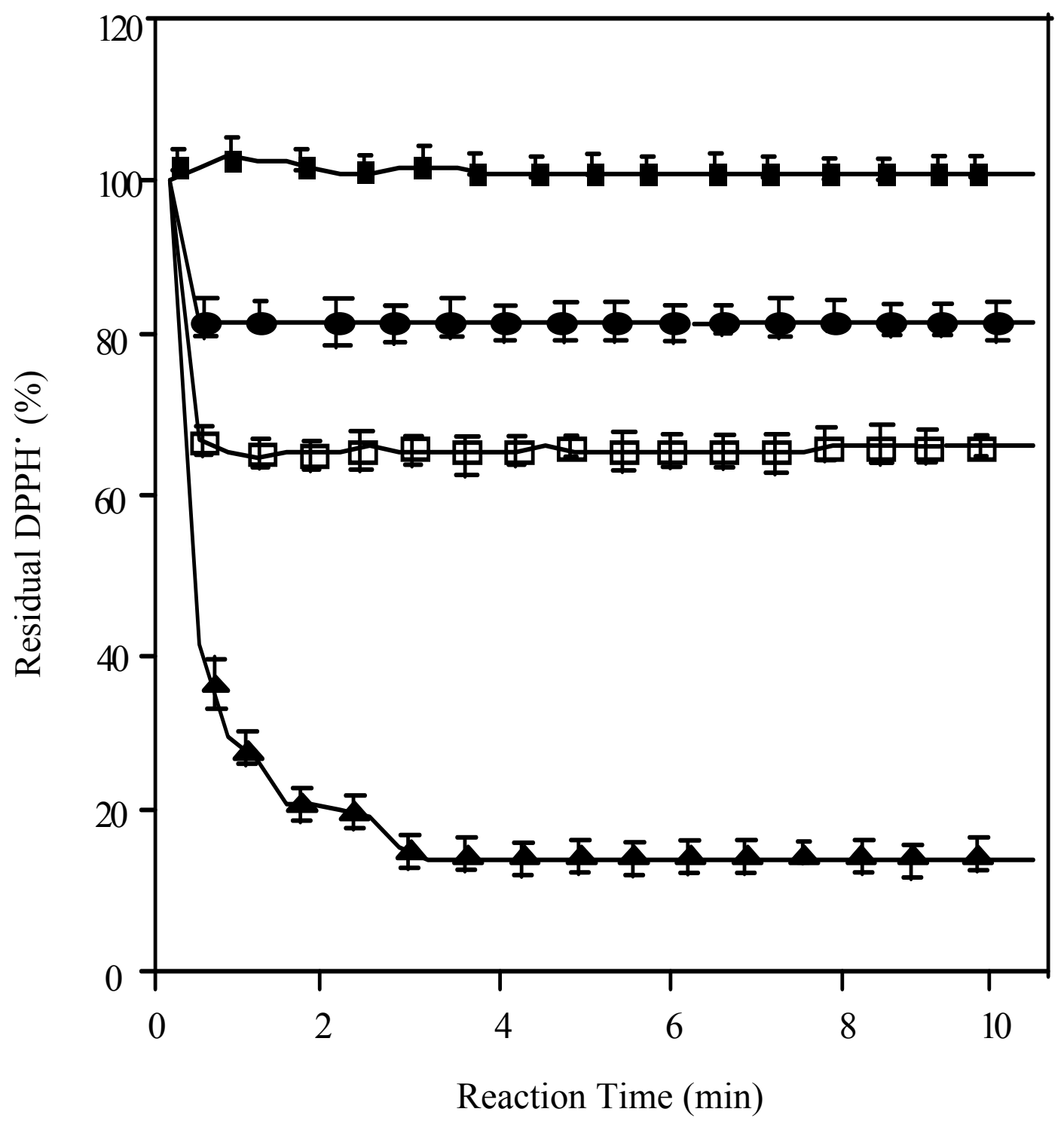

Figure 16. Time course for the remaining percentage of diphenylpicrylhydrazl $(\mathrm{DPPH} \cdot)$ radical after reaction with dihydroxyphenylacetic acid $(\mathbf{\Lambda})$, alpha-tocopherol (口), ester of dihydroxyphenylacetic acid with fish liver oil $(\bullet)$, and with $\mathrm{DPPH} \bullet(-\boldsymbol{\bullet})$ as a control trial. 


\section{CONCLUSION}

The experimental results showed that the lipase Novozym 435 was a more efficient biocatalyst than Lipozyme IM 20 for the acidolysis of fish liver oil (FLO) with dihydroxyphenylacetic acid (DHPA). The results also revealed that the amount of cosolvents had an effect on the biosynthesis of both the phenolic mono- and diacylglycerols; hence, increasing the proportion of the more polar solvent, 2-butanone, favored the synthesis of the phenolic monoacylglycerols, while increasing that of the non-polar solvent, hexane, resulted in a constant production of the phenolic diacylglycerols. Similarly, an increase in the concentration of FLO resulted in maintaining the level of synthesis of phenolic monoacylglycerols and total phenolic lipids; however, an excess of FLO led to an inhibitory affect on the maximum bioconversion yield. However, the presence of molecular sieve and Silica gel showed a decrease in bioconversion yield and enzymatic activity.

The modification of FLO with DHPA resulted in an increase in the content of the $\mathrm{C}_{20: 5} n$ 3 and $\mathrm{C}_{22: 5} n-3$ in the fatty acid profiles of the phenolic mono- and diacylglycerols in concomitant with a relative decrease in $\mathrm{C}_{16: 0}$ and $\mathrm{C}_{18: 2} n-6$, as compared to that of the unmodified FLO. The preliminary structural analysis confirmed the synthesis of phenolic monoacylglycerols, including monolinolenyl dihydroxyphenyl acetate, monolinoleyl dihydroxyphenyl acetate, and monooleyl dihydroxyphenyl acetate as well as phenolic diacylglycerols, including dilinolenyl dihydroxyphenyl acetate and linoleyl linolenyl dihydroxyphenyl acetate. On the other hand, the phenolic lipids products demonstrated a radical scavenging capacity of approximately half of that of $\alpha$-tocopherol.

In conclusion, the overall experimental findings could be considered as prelude step in contributing to the development of a bioprocess for the synthesis of phenolic lipids, using fish liver oil and selected phenolic compounds. 


\section{REFERENCES}

Adlercreutz, P. (1992). On the importance of the support material for enzymatic synthesis in organic media. Support effects at controlled water activity. In Biocatalysis in NonConventional Media, J., Tramper, M.H., Vermue, H.H., Beeftink, and U. von Stockar, (eds.), Elsevier Science Publishers B.V., New York, N.Y., pp. 55-61.

Adlercreutz, P. (2000). Biocatalysis in non-conventional media. In Applied Bicatalysis, $2^{\text {nd }}$ Edition, A.J., Straathof and P. Adlercreutz, (eds.), Harwood Academic Publishers, Amsterdam, Netherlands, pp. 295-316.

Adlercreutz, P., Vitro, C., Persson, M., Vaz, S., Adlercreutz, D., Svensson, I. and Wehtje, E. (2001). Enzymatic conversions of polar lipids. Principles, problems and solutions. J. Mol. Catal. B: Enz. 11, 173-178.

Almeida, M.C., Ruivo, R., Maia, C., Freire, L., de Sampaio, T.C. and Barreiros, S. (1998). Novozym 435 activity in compressed gases. Water activity and temperature effects. Enzyme Microb. Technol. 22, 494-499.

Andlauer, W., Stumpf, C. and Fürst, P. (2000). Influence of the acetification process on phenolic compounds. J. Agric. Food Chem. 48, 3533-3536.

Andrikopoulos, N.K., Brueschweiler, H., Felber, H. and Taeschler, C. (1991). HPLC analysis of phenolic antioxidants, tocopherols and triglycerides. J. Am. Oil Chem. Soc. 68, 359-364.

Andrikopoulos, N.K. (2002). Chromatographic and spectroscopic methods in the analysis of triacylglycerol species and regiospecific isomers of oils and fats. Crit. Rev. Food Sci. Nutr. 42, 473-505.

Arcos, J.A., Otero., C. and Hill G.H. (1998). Rapid enzymatic production of acylglycerols from conjugated linoleic acid and glycerol in a solvent-free system. Biotechnol. Lett. 20, 617-621. 
Awang, R., Basri, M., Ahmad S. and Sallah, A.B. (2005). Lipase-catalyzed esterification of palm-based 9,10- dihydroxysteric acid and 1-octanol in hexane- A kinetic study. Biotechnol. Lett. 26, 11-14.

Basri, M., Heng, A.C., Razak, C.N., Wan Yunus, W.M., Ahmad, M., Rahman, R.N., Ampon, K. and Salleh, A.B. (1997). Alcoholysis of palm oil mid-fraction by lipase from Rhizopus Rhizopodiformis. J. Am. Oil Chem. Soc. 74, 113-116.

Benatti, P., Peluso, G., Nicolai, R. and Calvani, M. (2004). Polyunsaturated fatty acids: Biochemical, nutritional and epigenetic properties. J. Am. Col. Nutr. 23, 281-302.

Biselli, M., Kragl, U. and Wandrey, C. (2002). Reaction engineering for enzyme-catalyzed biotransformations. In Enzyme Catalysis in Organic Synthesis: A Comprehensive Handbook, Volume I, K. Drauz and H. Waldmann, (eds.), Wiley-VCH Verlag GmbH, Weinheim, Germany, pp. 185-258.

Buisman, G.J.H., Van Helteren, C.T.W., Kramer, G.F.H., Veldsink, J.W., Derksen, J.T.P. and Cuperus, F.P. (1998). Enzymatic esterifications of functionalized phenols for the synthesis of lipophilic antioxidants. Biotechnol. Lett. 20, 131-136.

Burdge, G. (2004). $\alpha$-Linolenic acid metabolism in men and women: Nutritional and biological implications. Curr. Opin. Clin. Nutr. Metab. Care 7, 137-144.

Calder, P.C. (2001). More good news about fish oil. Nutrition 17, 158-160.

Castillo, E., Dossat, A., Marty, J.S., Condoret, A. and Combes., D. (1997). The role of silica gel in lipase-catalyzed esterification reactions of high-polar substrates. J. Am. Oil Chem. Soc. $\mathbf{7 4 ,}$ 77-85.

Carrea, G. and Riva, S. (2000). Properties and synthetic of enzymes in organic solvents. Angew Chem. Int. Ed. Engl. 13, 2226-2254. 
Cerdan, E., Medina, R., Gimenez, G., Gonzalez, I. and Grima, M. (1998). Synthesis of polyunsaturated fatty acid-enriched triglycerides by lipase-catalyzed esterification. J. Am. Oil Chem. Soc. 75, 1329-1337.

Chamouleau, F., Coulon, D., Girardin, M. and Ghoul, M. (2001). Influence of water activity and water content on sugar esters lipase-catalyzed synthesis in organic media. J. Mol. Catal. B: Enz. 11, 949-954.

Christie, W.W. (1982). The structure, chemistry and occurrence of lipids. In Lipid Analysis: Isolation Separation, Identification and Structural Analysis of Lipids. $2^{\text {nd }}$ Edition, W.W. Christie (ed.), Pergamon press, N.Y., pp. 1-16.

Christophoridou, S., Dais, P., Tseng, L.H. and Spraul, M. (2005). Separation and identification of phenolic liquid chromatography with postcolumn solid-phase extraction to nuclear magnetic resonance spectroscopy (LC-SPE-NMR). J. Agric. Food Chem. 53, 4667-79.

Compton, D.L., Laszlo, J.A. and Berhow, M.A. (2000). Lipase-catalyzed synthesis of ferulate esters. J. Am. Oil Chem. Soc. 77, 513-519.

Colombie, S., Tweddell, R.J., Condoret, J.S. and Marty, A. (1998). Water activity control: A way to improve the efficiency of continuous lipase esterification. Biotechnol. Bioengineer. 60, 362-368.

Cuppett, S., Schnepf, M. and Hall, C. (1997). Natural antioxidants - Are they a reality? In Natural Antioxidants: Chemistry, Health Effects \& Applications, F. Shahidi (ed.), AOCS Press, Champaign, IL, pp. 12-24.

Damiani, E., Belaid, C., Caloni, P. and Greci, L. (2003). Comparison of antioxidant activity between aromatic indolinonic nitroxides and natural and synthetic antioxidants. Radical Res. 37, 731-41. 
Deckere, E.A.M., Korver, O., Verschuren, P.M. and Katan, M.B. (1998). Health aspects of fish and n-3 polyunsaturated fatty acids from plant and marine origin. Eur. J. Clin. Nutr. 52, 749-753.

$D_{\mathrm{E}}$ Long, E.F. and Yayanos, A.A. (1986). Biochemical function and ecological significant of novel bacterial lipids in deep sea prokaryotes. Appl. Environ. Microbiol. 51, 730-737.

Diks, R.M.M. (2003). Production and modification of acylglycerides. Food Sci. Technol. 122, $237-253$.

Dobson, G. (2002). Analysis of fatty acids in functional foods with emphasis on $\omega-3$ fatty acids and conjugated linolenic acid. In Methods of Analysis for Functional Foods and Nutraceuticals. W.J. Hurst (ed.), CRC Press, New York, N.Y., pp. 65-99.

Dordick, J.S. (1989). Enzymatic catalysis in monophasic organic solvents. Enzyme Microb. Nutr. 52, 749-753.

Dossat, V., Combes, D. and Marty, A. (2002). Efficient lipase catalyzed production of a lubricant and surfactant formulation using a continuous solvent-free process. $J$. Biotechnol. 97, 117-124.

Dyerberg J., Bang HO., Stoffersen E., Moncada S. and Vane JR. (1978). Eicosapentaenoic acid and prevention of thrombosis and atherosclerosis? Lancet 2, 117-119.

Francisco, R. (2000). Phenolic Acids and Derivatives: Studies on the relationship among structure, radical scavenging activity, and physicochemical parameters. J. Agric. Food Chem. 48, 2122-2126.

Friedman, M. and Jürgens, H.S. (2000). Effect of $\mathrm{pH}$ on the stability of plant phenolic compounds. J. Agric. Food Chem. 48, 2101-2110.

Gan, L. and Seib, P.A. (1998). Preparation and antioxidant activities of phenolic esters and esters of L-Ascorbic acid. J. Chromatogr. Chem. 17, 397-404 
Gandhi, N.N. (1997). Applications of lipase. J. Am. Oil Chem. Soc. 74, 621-635.

Gandhi, S.R. and Weete, J.D. (1991). Production of the polyunsaturated fatty acids arachidonic acid and eicosapentaenoic acid by the fungus Pythium ultimum. J. Gen. Microbiol. 137, 1825-1830.

Gandhi, N.N., Patil, N.S., Sawant, S.B. and Joshi, J.B. (2000). Lipase-catalyzed esterification. Catal. Rev. Sci. Eng. 42, 439-480.

Gupta, M.N. and Roy I. (2004). Enzymes in organic media: Forms, functions, and applications. Eur. J. Biochem. 13, $2575-2583$.

Guptam, R., Rathi, P. and Bradoo, S. (2003). Lipase mediated upgradation of dietary fats and oils. Crit. Rev. Food Sci. Nutr. 43, 635-644.

Gunstone, F.D. (1999). Enzymes as biocatalysts in the modification of natural lipids. J. Sci. Food Agric. 79, 1535-1549.

Gurr, M.I. and Harwood, J.L. (1991). Dietary lipids: Implications for health and disease. In Lipid Biochemistry. $5^{\text {th }}$ Edition, M.I. Gurr, and L.M. Harwood (eds.), Chapman and Hall, N.Y., pp. 162-243.

Gurr, M.I. and Harwood, J.L. (2002). Fatty acid structure and metabolism. In Lipid Biochemistry. $5^{\text {th }}$ Edition, M.I. Gurr, and L.M. Harwood (eds.), Chapman and Hall, N.Y., pp. 23-118.

Guyot, B., Bosquette, B., Pina, M., Pina, J. and Graille, J. (2001). Esterification of phenolic acids from green coffee with an immobilized lipase from Candida Antarctica in solventfree medium. Biotechnol. Lett. 19, 259-285.

Graf, E. (1992). Antioxidant potential of ferulic acid. Free Radic. Biol. Med. 13, 435-448. 
Hadzir, N.M., Basri, M., Rahman, M.B.A., Razak, C.N.A., Rahman, R.N.Z.A. and Salleh, A.B. (2001). Enzymatic alcoholysis of triolein to produce wax ester. J. Chem. Technol. Biotechnol. 76, 511-515.

Halling, P.J. (1994). Thermodynamic predictions for biocatalysis in non-conventional media: Theory, tests, and recommendations for experimental design and analysis. Enzyme Microb. Technol. 16, 271-276.

Halling, P.J. (2000). Biocatalysis in low-water media: Understanding effects of reaction conditions. Curr. Op. Chem. Biol. 4, 74-80.

Halling, P.J. (2002). Enzymatic conversion in organic and other low-water media. In Enzyme Catalysis in Organic Synthesis: A Comprehensive Handbook, Volume I, $2^{\text {nd }}$ edition, K. Drauz and H. Waldmann (eds.), Wiley-VCH Verlag GmbH, Weinheim, Germany, pp. 259-286.

Halsted, C.H. (2003). Dietary supplements and functional foods: 2 sides of a coin? Am. J. Clin. Nutr. 4, 1001-1007.

Handelman, G.J. and Pryor, W.A. (1999). Evaluation of antioxidant status in humans. In Antioxidant Status, Diet, Nutrition and Health, A.M. Papas (ed.), CRC Press, LLC, pp. $36-62$.

Haraldsson, G.G. and Hjaltason, B. (2001). Fish oils as sources of important polyunsaturated fatty acids. In Structured and Modified Lipids, F.D. Gunstone (ed.), Marcel Dekker, Inc., New York, N.Y., pp. 313-350.

Hari, K.S. (2002). Developments and trends in enzyme catalysis in nonconventional media. Biotechnol. Adv. 20, 239-267.

Hills, J.M., Kiewitt, I. and Mukheje, K.D. (1990). Enymatic fractionation of polyunsaturated fatty acids: Enrichment of $\gamma$-linolenic acid $\&$ docosahexaenoic acid by selective esterification catalyzed by lipases. J. Am. Oil Chem. Soc. 67, 561-564. 
Ho, C.T. (1992). Phenolic compounds in food, an overview. In Phenolic Compounds in Food and Their Effects on Health, Analysis, Occurrence \& Chemistry, C.-T. Ho, C.Y. Lee, and M.-T. Huang (eds.), American Chemical Society Symposium 506, Washington, D.C., pp. 2-7.

Hollman, P.C.H. (2001). Evidence for health benefits of plant phenols: Local or systemic effects? J. Sci. Food Agric. 81, 842-852.

Hoq, M.M., Tagami, H., Yamane,T. and Shimizu, S. (1985). Agric. Biol. Chem. 49, 335342.

Høy, C.-E. and Xu, X. (2001). Structured triacylglycerols. In Structured and Modified Lipids, F.D. Gunstone, (ed.), Marcel Dekker, Inc., New York, N.Y., pp. 209-240.

Humeau, C., Girardin, M., Rovel, B. and Miclo, A. (1998). Enzymatic synthesis of fatty acid ascorbyl esters. J. Mol. Catal. B: Enz. 5, 19-23.

Jennings, B.H. and Akoh, C.C. (1999). Enzymatic modification of triacylglycerols of high eicosapentaenoic and docosahexaenoic acids content to produce structured lipids. J. Am. Oil Chem. Soc. 76, 1133-1137.

Jensen, R.G., Dejong, F.A. and Clark, R.M. (1983). Determination of lipase specificity. Lipids 18, 239-252.

Indlekofer, M., Funke, M., Claassen, W. and Reus, M. (1995). Continuous enantioselective transesterification in organic solvents. Use of suspended lipase preparations in a microfiltration membrane reactor. Biotechnol. Prog. 11, 436-442.

Karboune, S., Safari, M., Lue, B-M., Yeboah, F. K. and Kermasha. S. (2005). Lipasecatalyzed biosynthesis of cinnamoylated lipids in a selected organic solvent medium. $J$. Biotechnol. 3, 281-290.

Kim, I-H., Yoon., C.S. and Lee, K.W. (2001). Transesterification of conjugated linoleic acid and tricaprylin by lipases in organic solvents. Food Res. International 34, 301-306. 
Kim, I-H. and Heill G. (2006). Lipase-catalyzed acidolysis of menhaden oil with pinolenic acid. J. Am. Oil Chem. Soc. 83, 109-115.

Kikuzaki, H., Hisamoto, M., Hirose, K., Akiyama, K. and Taniguchi, H. (2002). Antioxidant properties of ferulic acid and is related compounds. J. Agric. Food Chem. 7, 2161-2168.

Klibanov, A.M. (1997). Why are enzymes less active in organic solvents than in water? Trends Biotechnol. 15, 97-101.

Kontogianni, A., Skouridou, V., Sereti, V., Stamatis, H. and Kolisis, N. (2001). Regioselective acylation of flavonoids catalyzed by lipase in low toxicity media. Eur. J. Lipid Sci. Technol. 103, 655-660.

Köse, O., Tuter, M. and Aksoy H.A. (2001). Immobilized Candida Antartica lipasecatalyzed alcoholysis of cotton seed oil in a solvent-free medium. J. Biotechnol. 83, 125129.

Krauses, R.S., Mahan, L.K. and Escott-Strump, S. (2004). In Food, Nutrition and Diet Therapy, $11^{\text {th }}$ Ed. Prentice-Hall/Ellis Horwood, Hertfordshire, Great Britain, pp. 25-29.

Kris-Etherton, P.M., Harris, W.S. and Appel, L.J. (2002). Fish consumption, fish oil, omega3 fatty acids, and cardiovascular disease. Circulation 106, 2747-2757.

Kris-Etherton, P.M., Taylor, D.S., Yu-Poth., S., Huth. P., Moriarty, K., Fishell, V., Hargrove, R.L., Guixiary, Z. and Etherton T.D. (2000). Polyunsaturated fatty acids in the food chain in the United States. Am. J. Clinical Nutr. 71, 1795-1885.

Krishna, S.H. (2002). Developments and trends in enzyme catalysis in non-conventional media. Biotechnol. Adv. 20, 239-67.

Krog, N.J. (1997). Food emulsifiers and their chemical and physical properties. In Food Emulsions, $3^{\text {rd }}$ Edition, S.E. Friberg, and K. Larsson, (eds.), Marcel Dekker, Inc., New York, N.Y., pp. 141-160. 
Laane, C., Boeren, S., Vos, K. and Veeger, C. (1987). Rules for optimization of biocatalysis in organic solvents. Biotechnol. Bioengineer. 30, 81-87.

Lee, M.Y. and Dordick, J.S. (2002). Enzyme Activation for non-aqueous media. Curr. Opin. Biotechnol. 13, 37-384.

Lee, G.-C., Wang, D.-L., Ho, Y.-F. and Shaw, J.-F. (2004). Lipase-catalyzed alcoholysis of triglycerides for short-chain monogylceride production. J. Am. Oil Chem. Soc. 81, 533536.

Lee, K.W. and Lip, G.H. (2003). The role of omega-3 fatty acids in the secondary prevention of cardiovascular disease. Q. J. Med. 96, 465-480.

Lehninger, A.L., Nelson, D.L. and Cox, M.M. (1993). Water: Its effect on dissolved biomolecules. In Principles of Biochemistry, $2^{\text {nd }}$ Edition, Worth Publishers, Inc., New York, N.Y., pp. 81-105.

Lue, B.M., Karboune, S., Yebaoh, F.K. and Kermasha, S. (2005). Lipase-catalyzed esterification of cinnamic acid and oleyl alcohol in organic solvent media. J. Chem. Technol. Biotechnol. 80, 462-468.

Ma, L., Persson, M. and Adlercreutz, P. (2002). Water activity dependence of lipase catalysis in organic media explains successful transesterification reactions. Enzyme Microb. Technol. 31, 1024-1029.

Martinez, C.E., Vinay, J.C., Brieva, R., Hill Jr, C.G. and Garcia, H.S. (2004). Preparation of mono- and diacylglycerols by enzymatic esterification of glycerol with conjugated linoleic acid in hexane. Appl. Biochem. Biotechnol. 125, 63-75.

Medina, A.R., Cerdan L.E., Gimenez, A.G., Paez, B.C., Gonzaliz, M.J.I. and Grima, E.M. (1999). Lipase-catalyzed Esterification of glycerol and polyunsaturated fatty acids from fish and microalgae oil. J. Biotechnol. 70, 379-391. 
Medina, I., Tomno, I., Satue-Gracia, M.T., German, J.B. and Frankel, E.N. (2002). Effects of natural phenolic compounds on the antioxidant activity of lactoferrin in liposomes and oil-in-water emulsions. J. Agric. Food Chem. 8, 2392-2393

McCann, J.C. and Ames, B.N. (2005). Is docosahexaenoic acid, an n-3 long-chain polyunsaturated fatty acid, required for development of normal brain function? An overview of evidence from cognitive and behavioral tests in humans and animals. American J. Clin. Nutr. 82, 281-295

Moreno, J.J. and Mitjavila, M.T. (2003). The degree of unsaturation of dietary fatty acids and the development of arthrosclerosis (Review). J. Nutr. Biochem. 14, 182-195.

Negishi, S., Shirasawa, S., Arai, Y., Suzuki, J. and Mukataka, S. (2003). Activation of powdered lipase by cluster water and the use of lipase powders for commercial esterification of food oils. Enyme Microb. Technol. 32, 66-70.

Opstvedt, J., Urdahl, N. and Pettersen, J. (1990). Fish oils - An old fat with new possibilities. In Edible Fats and Oils Processing: Basic Principles and Modern Practices, M.E. Stansby, (ed.), Von Nostrand Reinhold, New York, N.Y., pp. 250-258.

Osório, N.M., Ferreira-Dias, S., Gusmão, J.H. and da Fonseca, M.R. (2001). Response surface modelling of the production of $\omega-3$ polyunsaturated fatty acids-enriched fats by a commercial immobilized lipase. J. Mol. Catal. B: Enz. 11, 677-686.

Palmer, T. (1995). Kinetics of multi-substrate enzyme-catalysed reactions. In Understanding Enzymes, $4^{\text {th }}$ Ed. Prentice-Hall/Ellis Horwood, Hertfordshire, Great Britain, pp. 155-174.

Petel, T. (2003). In Biogeneration of Lipophenols by Lipases Using Selected Substrate Models. M.Sc. Thesis, McGill University, Montreal.

Pérez-Magariño, S., Revilla, I., González-SanJosé, M.L. and Beltrán, S. (1999). Various applications of liquid chromatography-mass spectrometry to the analysis of phenolic compounds. J. Chromatogr. A 847, 75-81. 
Perona, J.S. and Gutierrez-Ruiz, V. (1999). Characterization of the triacylglycerol molecular species of fish oil by reversed-phase high performance liquid chromatography. J. Liq. Chromatogr. Related Technol. 22, 1699-1714.

Persson, M., Costes, D., Wehtje, E. and Adlercreutz, P. (2002). Effects of solvent, water activity, and temperature on lipase and hydroxynitrile lyase enantioselectivity. Enzyme Microb. Technol. 7, 916-923.

Pomeranz, Y. and Meloan, C.E. (1994). Lipids. In Food Analysis: Theory and Practice, $3^{\text {rd }}$ Ed., Chapman \& Hall, New York, N.Y., pp. 678-724.

Proestos, C., Sereli, D. and Komaitis, M. (2006). Determination of phenolic compounds in aromatic plants by RP-HPLC and GC-MS. Food Chem. 95, 44-52.

Quinlan, P. and Moore, S. (1993). Modification of triglycerides by lipases: Process technology and its application to the production of nutritionally improved fats. Inform $\mathbf{4}$, 580-585.

Ramirez, F.A., Akoh, C.C. and Lai, O.M. (2003). Lipase-catalyzed incorporation of $n-3$ PUFA into palm oil. J. Am. Oil Chem. Soc. 80, 1197-1200.

Rice-Evans, C., Miller, N. and Paganga, G. (2003). Anti-oxidant properties of phenolic compounds. Trends Plant Sci. 52, 152-159.

Rice-Evans, C., Miller, N. and Paganga, G. (1996). Structure-antioxidant activity relationships of flavonoids and phenolic acids. Free Radical Biol. Med. 29, 933-956.

Roche, H.M. (1999). Unsaturated fatty acids. Proceed. Nutr. Soc. 58, 397-401.

Rodríguez-Delgado, M.A., Malovaná, S., Pérez, J.P., Borges, T. and Montelongo, F.J.G. (2001). Separation of phenolic compounds by high-performance liquid chromatography with absorbance and fluorimetric detection. J. Chromatogr. A 912, 249-257. 
Sabally, K., Karboune, S., Yebaoh, F.K. and Kermasha, S. (2005a). Enzymatic esterification of dihydrocaffeic acid with linoleyl alcohol in organic solvent media. Biocatal. Biotransform. 23, 37-44.

Sabally, K., Karboune, S., Yebaoh, F.K. and Kermasha, S. (2005b). Lipase-catalyzed esterification of linolenyl alcohol with selected phenolic acids in organic solvent media. Appl. Biochem. Biotechnol. 127, 17-28.

Sabally, K., Karboune, S., St-Louis., R. and Kermasha, S. (2006a). Lipase-catalyzed transesterification of trilinolein or trilinolenin with selected phenolic acids. J. Am. Oil Chem. Soc. 83, 101-107.

Sabally, K., Karboune, S., St-Louis., R. and Kermasha, S. (2006b). Lipase-catalyzed transesterification of dihydrocaffeic acid with flaxseed oil for the synthesis of phenolic lipids. J. Biotechnol. 127, 167-176.

Sabally, K., Karboune, S., St-Louis., R. and Kermasha, S. (2007). Lipase-catalyzed synthesis of phenolic lipids from fish liver oil and dihydrocaffeic acid. Biocatal. Biotransform. (In Press).

Senanayake, N. and Shahidi, F. (2002). Lipase-catalyzed incorporation of docosahexaenoic acid (DHA) into borage oil: Optimization using response surface methodology. Food Chem. 77, 115-123.

Shahidi, F. and Naczk, M. (1995a). Phenolic compounds in fruits and vegetable. In Food Phenolics: Sources, Chemistry, Effects, Applications, Technomic Publishing Co., Inc., Lancaster, PA, pp. 75-107.

Shahidi, F. and Naczk, M. (1995b). Contribution of phenolic compounds to sensory characteristics of food. In Food Phenolics: Sources, Chemistry, Effects, Applications, Technomic Publishing Co., Inc., Lancaster, PA, pp. 199-233. 
Shahidi, F. and Naczk, M. (1995c). Food phenolics: An overview. In Food Phenolics: Sources, Chemistry, Effects, Applications, Technomic Publishing Co., Inc., Lancaster, PA, pp. 1-5.

Shahidi, F. and Wanasundara, U.N. (1998). Omega-3 fatty acid concentrates: Nutritional aspects and production technologies. Trends Food Sci. Technol. 9, 230-240.

Silva, F.A.M, Borges, F., Guimarã, Lima, F.C., Matus, C. and Reis, S. (2000). Phenolic antioxidants and derivatives: Studies on the relationship among structure, radical scavenging activity and physicochemical parameters. J. Agric. Food Chem. 48, 21222126.

Stamatis, H. V., Sereti, F.N. and Kolisis. (1999). Studies on the enzymatic synthesis of lipophilic derivatives of natural anti-oxidants. J. Am. Oil Chem. Soc. 76, 1505-1510.

Stamatis, H. V., Sereti, F.N. and Kolisis. (2001). Enzymatic synthesis of hydrophilic and hydrophobic derivatives of natural phenolic acids in organic media. J. Mol. Catal. B: Enz. 11, 323-328.

Stansby, M.E., Schlenk, H. and Gruger Jr., E.H. (1990). Fatty acid composition of fish. In Edible Fats and Oils Processing: Basic Principles and Modern Practices, M.E. Stansby (ed.), Von Nostrand Reinhold, New York., N.Y. pp. 6-9.

Stevenson, D.E., Stanley, R.A. and Furneaux, R.H. (1994). Near-quantitative production of fatty acid alkyl esters by lipase-catalyzed alcoholysis of fats and oils with adsorption of glycerol by silica gel. Enzyme Microb. Technol. 16, 478-484.

Torre-Carbot, K., Jauregui, O., Gimeno, E., Castellote, I., Lamuela-Raventos, M. and Lopez-Sabater, C. (2005). Characterization and quantification of phenolic compounds in olive oils by solid-phase extraction, HPLC-DAD, and HPLC-MS/MS. J. Agric. Food Chem. 53, 4331-40. 
Torres de Pinedo, A., Penalver, P., Rondon, D. and Morales, J.C. (2005). Efficient lipasecatalyzed synthesis of new lipid antioxidants based on a catechol structure. Tetrahedron 61, 7654-7660.

Uauy, R., Peirano, P., Hoffman, D., Mena, P., Birch, D. and Birch, E. (1996). Role of essential fatty acids in the function of the developing nervous system. Lipids 31, S167S176.

Valivety, R.H., Halling, P.J. and Macrae, A.R. (1992). Solvent effects on biocatalysis in organic systems: Equilibrium position and rates of lipase catalyzed esterification. Biotechnol. Bioengineer. 38, 1137-1143.

Verger, R. Rivière, C., Moreau, H., Gargouri, Y., Rogalska, E., Nury, S., Moulin, A., Ferrato, F., Ransac, S., Carrière, F. and Trètout, N. (1990). Enzymes kinetics of lypolysis lipase inhibition by proteins. In Lipases: Structure, Mechanism and Genetic engineering, L. Alberghina, R.D. Schmid and R. Verger (ed.), VCH Publishers, Inc., New York, N.Y., pp. 105-115.

Wei, D., Gu, C., Song, Q. and Su, W. (2003). Enzymatic esterification for glycoside lactate synthesis in organic solvent. Enzyme Microb. Technol. 33, 508-512.

Wehtje, E. and Adlercreutz, P. (1997). Water activity and substrate concentration effects on lipase activity. Biotechnol. Bioengineer. 55, 798-806.

Whitaker, J.R. (1996). Enzymes. In Food Chemistry, $3^{\text {rd }}$ Ed., Fennema, O.R. (ed.), Marcel Dekker, Inc., New York, N.Y., pp. 431-526.

Willis, W.M., Lencki, R.W. and Marangoni, A.G. (1998). Lipid modification strategies in the production of nutritionally functional fats and oils. Crit. Rev. Food Sci. Nutr. 38, 639674.

Yadav, G.D. and Lathi, P.S. (2003). Kinetics and mechanism of synthesis of butyl isobutyrate over immobilized lipases. Biochem. Engineer. J. 16, 245 -252. 
Yan, Y., Bornscheuer, U.T. and Schmid, R.D. (2002). Efficient water removal in lipasecatalyzed esterifications using a low-boiling-point azeotrope. Biotechnol. Bioengineer. 78, 31-34.

Yang, Y.C., Vali, S.R. and Ju, Y.-H. (2003). A process for synthesizing high purity monoglyceride. J. Chin. Inst. Chem. Engineer. 34, 617-623.

Zaks, A. and Klibanov, M. (1988). The effect of water on enzyme action in organic media. J. Biol. Chem. 263, 8017-8021.

Zu-Yi, L. and Ward, P. (1993). Lipase-catalyzed esterification of glycerol and n-3 polyunsaturated fatty acid concentrate in organic solvent. J. Am. Oil Chem. Soc. 70, 745748. 